Florida International University FIU Digital Commons

\title{
On the Role of the Pore Water Chemistry of Deficient Post-Tension Grout to Promote Steel Corrosion
}

Samanbar Permeh

sperm005@fiu.edu

DOI: $10.25148 /$ etd.FIDC000280

Follow this and additional works at: https://digitalcommons.fiu.edu/etd

Part of the Civil Engineering Commons, Environmental Engineering Commons, and the Structural Engineering Commons

\section{Recommended Citation}

Permeh, Samanbar, "On the Role of the Pore Water Chemistry of Deficient Post-Tension Grout to Promote Steel Corrosion" (2016). FIU Electronic Theses and Dissertations. 2445.

https://digitalcommons.fiu.edu/etd/2445 


\title{
FLORIDA INTERNATIONAL UNIVERSITY
}

Miami, Florida

\section{ON THE ROLE OF THE PORE WATER CHEMISTRY OF DEFICIENT POST-TENSION GROUT TO PROMOTE STEEL CORROSION}

\author{
A thesis submitted in partial fulfillment of the \\ requirements for the degree of \\ MASTER OF SCIENCE \\ in \\ ENVIRONMENTAL ENGINEERING \\ by \\ Samanbar Permeh
}

2016 
To: Interim Dean Ranu Jung

College of Engineering and Computing

This thesis, written by Samanbar Permeh, and entitled, On the Role of the Pore Water Chemistry Deficient Post-Tension Grout to Promote Steel Corrosion, having been approved in respect to style and intellectual content, is referred to you for judgment.

We have read this thesis and recommend that it be approved.

Berrin Tansel

Shonali Laha

Kingsley Lau, Major Professor

Date of Defense: March 30, 2016

The thesis of Samanbar Permeh is approved.

\author{
Interim Dean Ranu Jung \\ College of Engineering and Computing \\ Andrés G.Gil \\ Vice President for Research and Economic Development \\ and Dean of the University Graduate School
}

Florida International University, 2016 
(C) Copyright 2016 by Samanbar Permeh

All rights reserved. 


\section{DEDICATION}

I dedicate this thesis to my dear Mom, whose patience, sacrifice, support, and understanding made the completion of this work possible, and to my beloved Sisters and beautiful Niece, For their endless love, support and prayers.

And at Last but not the least to the memory of my loving father who could not see this accomplishment and who had given me dreams to look forward to $\ldots$ 


\section{ACKNOWLEDGMENTS}

I would like to give my sincere appreciation and gratitude to my major Advisor Dr.Kingsley Lau for his support, presence, insightful guidance, for having confidence in my abilities and expert contribution though the period of research and thesis development, which without, it would not have been possible to accomplish. I sincerely appreciate Dr Shonali Laha and Dr Berrin Tansel 's suggestions, advice, efforts and corrections during the development of this thesis. I also want to acknowledge the help of K.K. Krishna Vigneshwaran during this research and also Support from the FDOT State Materials Office.

This investigation was support by the Florida Department of Transportation. The opinions, findings and conclusions expressed here are those of the authors and not necessarily those of the Florida Department of Transportation or the U.S Department of Transportation.

Last but not the least; I would like to thank my Dear Cousin, Yazdan for having faith in me and motivating me in pursuing my goal. 
ABSTRACT OF THE THESIS

ON THE ROLE OF THE PORE WATER CHEMISTRY OF DEFICIENT POSTTENSION GROUT TO PROMOTE STEEL CORROSION

by

Samanbar Permeh

Florida International University, 2016

Miami, Florida

Professor Kingsley Lau, Major Professor

Corrosion failure of post-tension tendons with pre-packaged thixotropic grout was documented in Florida Bridges in less than 10 years of service. Analysis of deficient grout in Florida post-tensioned (PT) bridges where severe corrosion developed indicated enhanced sulfate ion concentration, high pore water $\mathrm{pH}$, enhanced moisture and low chloride content. The corrosion wasn't consistent with the conventional causes of steel corrosion such as bleed water accumulation in grout void spaces, chloride contamination and pore water carbonation. Corrosion development was associated with deficient grout with enhanced sulfate levels. However, limited information is available on the corrosion behavior of PT strand in grout materials with enhanced sulfate content. Review of the technical literature has not shown consistent evidence of the role of sulfate ions in the corrosion of steel in solution and in hydrated cementitious material. In this research, the role of 
sulfates in cementitous materials was examined including identifying practical limits for sulfates in grout materials.

Laboratory samples were created with $15 \%$ and $20 \%$ excess water to enhance deficient grout materials and included enhanced sodium and chloride content. Enhanced sulfate and chloride ion presence was thought to provide aggressive corrosion condition of steel in segregated grout. Testing was intended to differentiate the corrosion of steel in pore water condition of deficient grout.

TABLE OF CONTENTS 


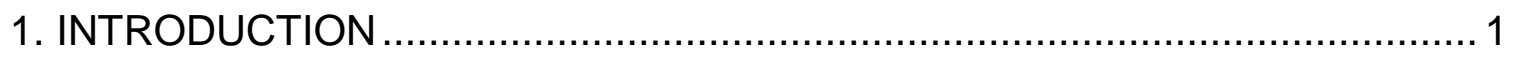

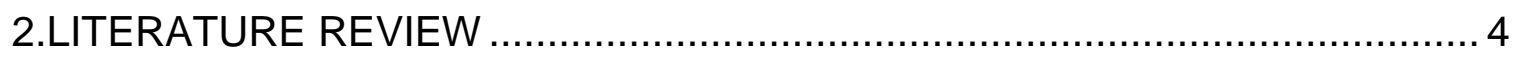

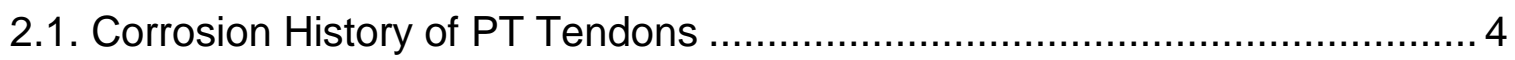

2.2. Recent Corrosion Failure in Florida Utilizing Thixotropic Grouts ................. 8

2.3. Cement Characteristics ...................................................................... 10

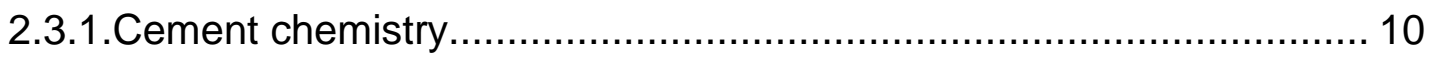

2.3.2.Different degradation mechanism of concrete ............................... 12

2.3.2.1. Alkali-silica and Alkali-carbonate reaction (ASR), (ACR) ............ 13

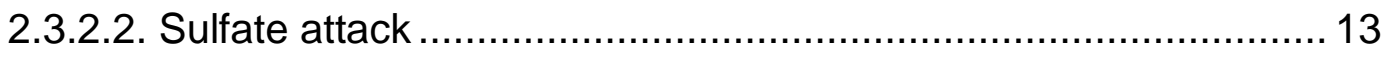

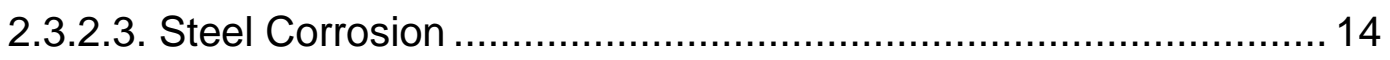

2.3.2.3.1 Corrosion due to Chloride ............................................. 14

2.3.2.3.1 Corrosion due to Carbonation ............................................ 14

2.4.Corrosion of Steel in Cementitious Material.............................................. 15

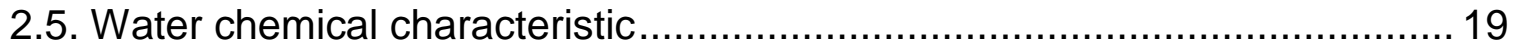

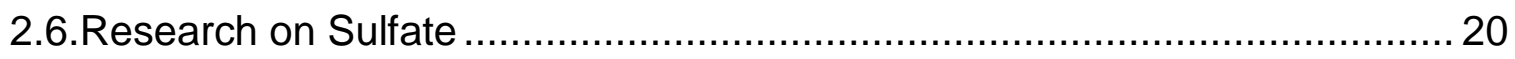

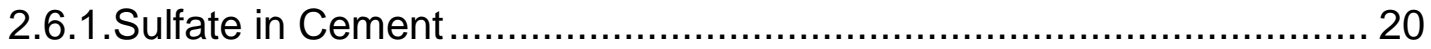

2.6.1.Sulfate, Moisture Content and Corrosion........................................ 22

2.6.2.Corrosion Initiation by Sulfate Ion................................................ 23

3. RESEARCH OBJECTIVES, APPROACH, AND METHODOLOGY ................ 30

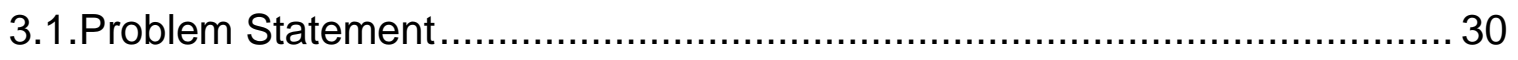

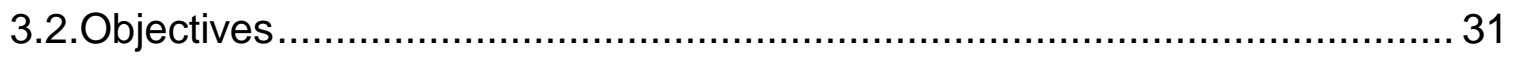

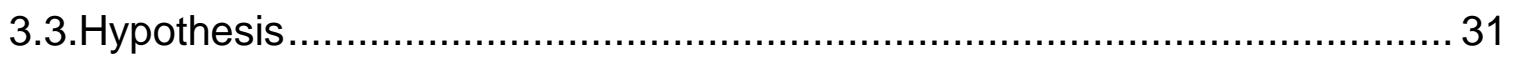

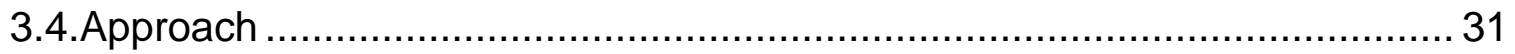

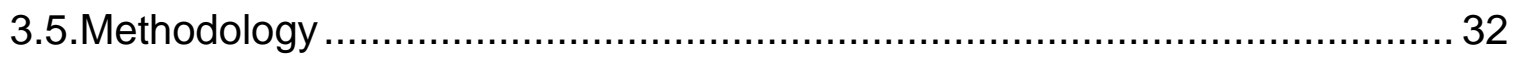




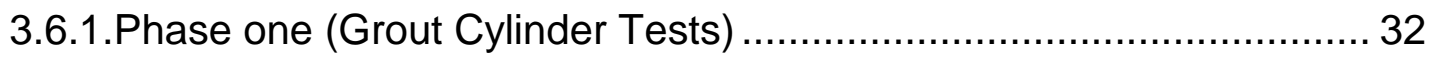

3.6.2.Phase two (Modified incline tube test (MIT)) ................................... 35

3.6.3.Phase three (Inverted Tee test (INT)) …....................................... 38

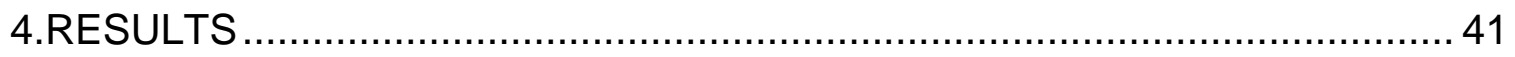

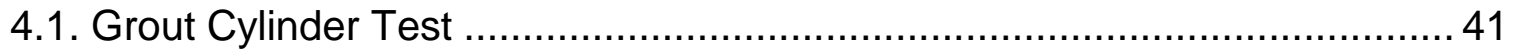

4.2. Modified Incline Tube Test (MIT) ….................................................... 48

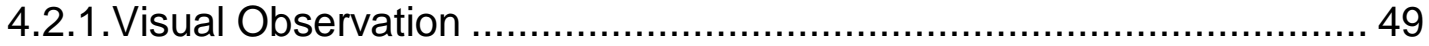

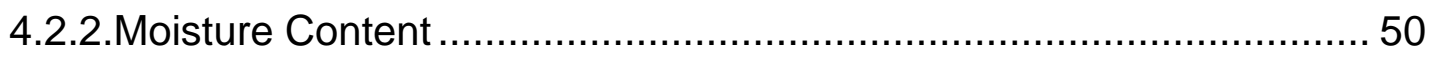

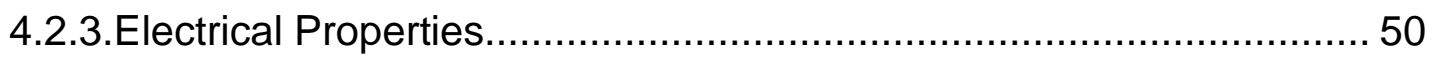

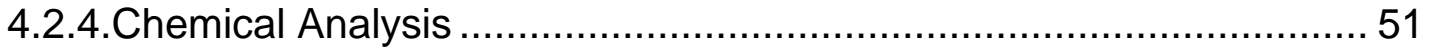

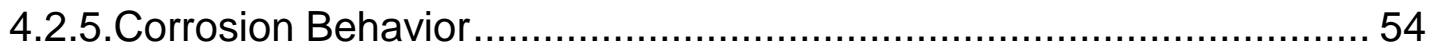

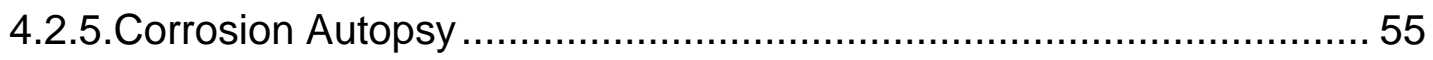

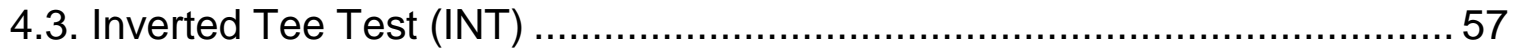

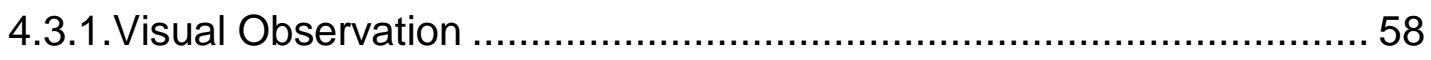

4.3.1.1.Combine Sulfate and Chloride Concentration............................ 62

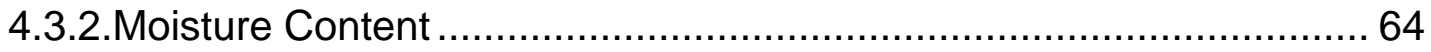

4.3.2.1.Combine Sulfate and Chloride Concentration.............................65

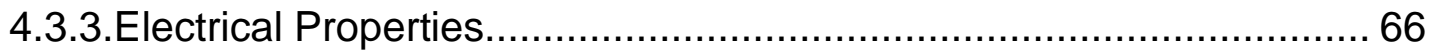

4.3.4.1.Combine Sulfate and Chloride Concentration ............................ 71

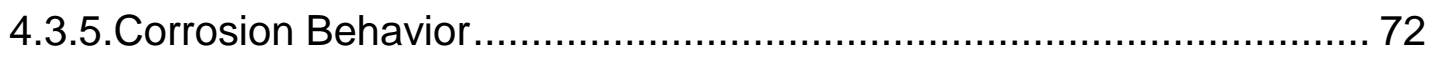

4.3.5.1. Combine Sulfate and Chloride Concentration)......................... 74

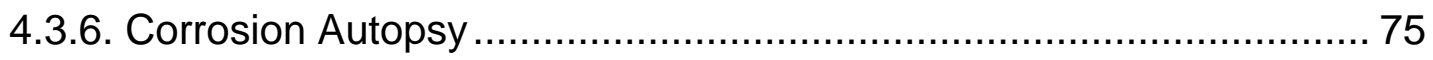

4.3.6.1. Combine Sulfate and Chloride Concentration ............................ 76

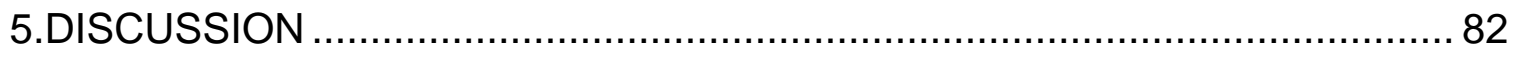

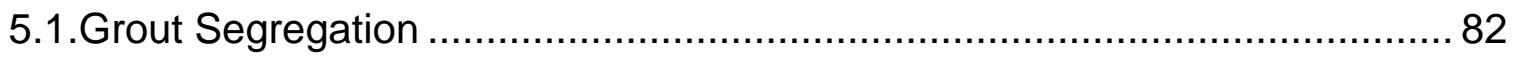

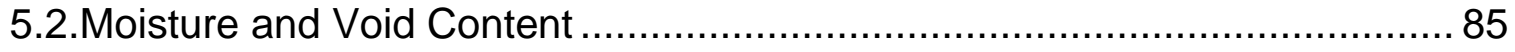




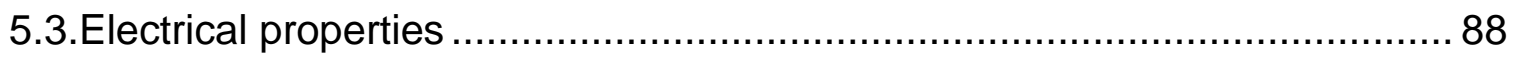

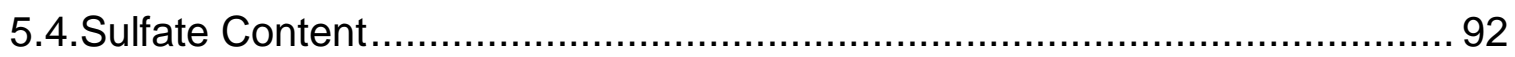

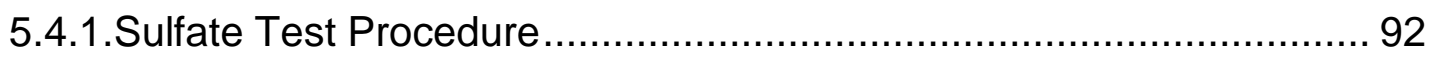

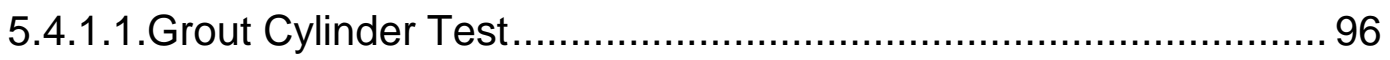

5.4.1.2 Modified incline tube test (MIT) ............................................ 97

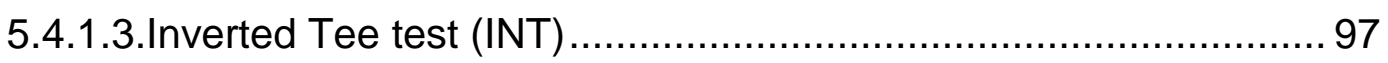

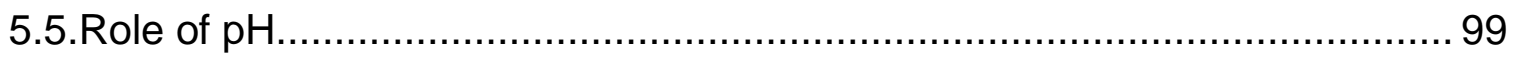

5.5.1.Role of $\mathrm{pH}$ in aqueous sulfate environment.................................. 100

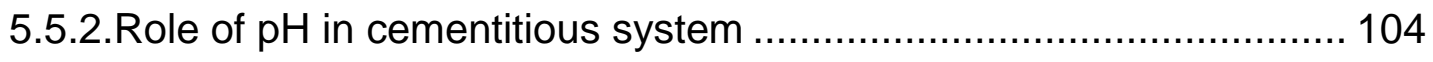

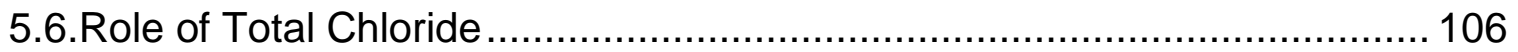

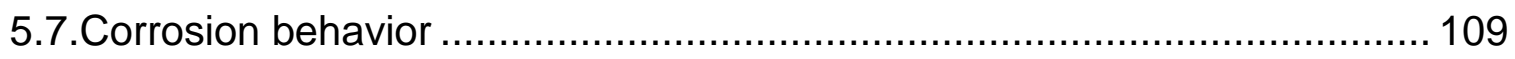

5.7.1 Modified incline tube test (MIT) …............................................ 109

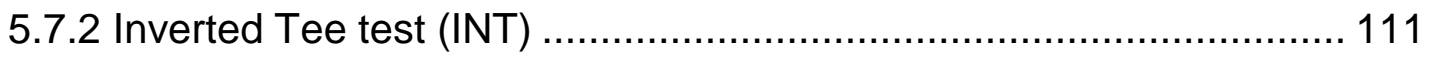

5.7.2.1 Combined Sulfate and Chloride .......................................... 114

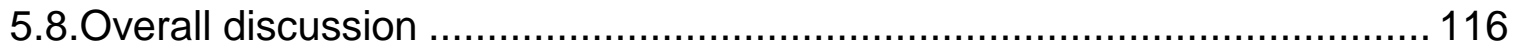

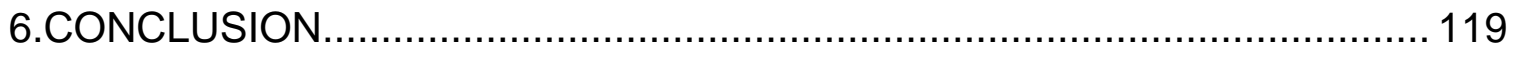

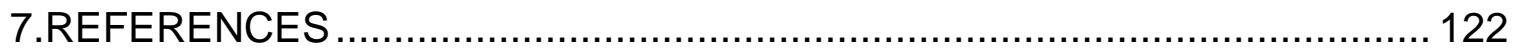

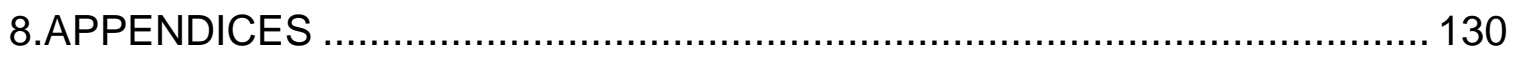


Figure 1.1: Illustration of Post Tensioning Process............................................ 3

Figure1.2: Illustration of Three Levels of Protection to Internal /External

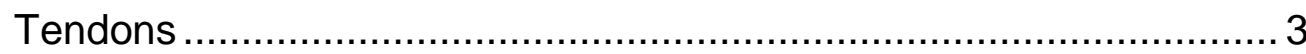

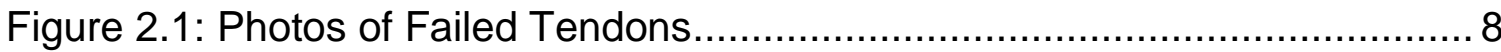

Figure 2.2: Corrosion of Strand Embedded in Deficient Grout. ......................... 9

Figure 2.3: Visual and Chemical Makeup of Stratified Deficient Grout at an

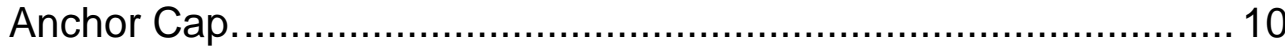

Figure 2.4: Schematic of Steel Corrosion Acting as an Anode and Cathode...... 16

Figure 2.5: Schematic Illustration of Chloride Induced Pitting Corrosion and

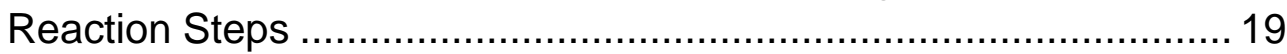

Figure 2.6: Two-dimensional PZD of Fe (II) Species ......................................... 25

Figure 2.7: Corrosion Rate of ,Mild steel as a Function of $\mathrm{Na}_{2} \mathrm{SO}_{4}$

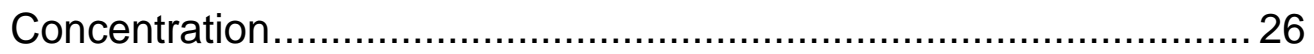

Figure 3.1: pH Range by Color for German Instruments pH Indicator ................ 35

Figure 3.2. Grout Batching, Mixing, and Pumping Sequence........................... 36

Figure 3.3: Photos of $15 \mathrm{ft}$. Lab Casted Mock up Tendons (MIT) ...................... 37

Figure 3.4: Schematic of INT Test Samples ................................................... 39

Figure 4.1: Moisture Content of the Powder After Exposure …......................... 42

Figure 4.2: Pre-Exposed Grout Products A and B Cylinder Samples ................ 42

Figure 4.3: Percent Volume of Segregated Grout.......................................... 43

Figure 4.4: Moisture and Void Content for Grout Cylinder Test........................ 44

Figure 4.5:Moisture Uptake and Grout Wet Resistivity for Grout Cylinder Test . 44

Figure 4.6: Photos of Stratified Layer in Expired Grout Samples Collected from

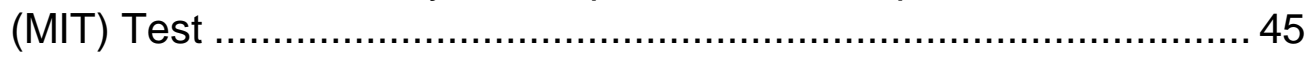

Figure 4.7: Sulfate Concentration for Expired Grout and Field Samples ........... 46

Figure 4.8: Sulfate Concentration for Bridge I by Three Methods...................... 46

Figure 4.9: Sulfate Concentration for Grout Cylinder Test............................... 47 
Figure 4.10: Sulfate Concentration for Grout Cylinder Test with Pre-Exposed Grout B (Top, Bottom, Mix)

Figure 4.11: pH Results by Ex-Situ Leaching For Grout Cylinder Test.............. 47

Figure 4.12: Photos of Deficient Grout from MIT test. ..................................... 49

Figure 4.13: Photos of Deficient Grout in the Elevated Portion of MIT Test ....... 49

Figure 4.14: Moisture Content of the Grout from MIT Test Samples ................. 50

Figure 4.15: Solution Resistance of Grout from MIT Test Samples................... 51

Figure 4.16: Sulfate and free Chloride Concentration of Grout from MIT Test

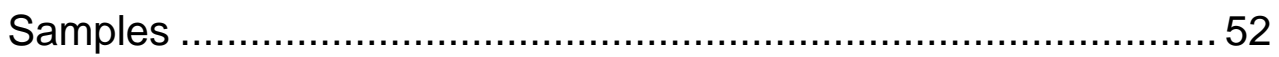

Figure 4.17: Total Chloride Content of Grout from MIT Test Samples............... 52

Figure 4.18: Chemical Characteristic Profiles along $15 \mathrm{ft}$. of MIT Tests ............. 53

Figure 4.19: pH Measurements of Grout from MIT Test Samples by Ex-situ

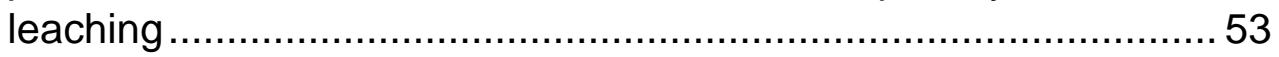

Figure 4.20: Photos of $\mathrm{pH}$ Results for the First Corrosion Probe Located at $0.5 \mathrm{ft}$. from the Top of MIT Test (Case A) ..................................... 54

Figure 4.21: Corrosion Potential and Current Density for MIT Test................... 55

Figure 4.22: Photos of Embedded Strands in MIT Samples............................. 55

Figure 4.23: Micrograph of Segregated Top and Bottom Section in MIT Test

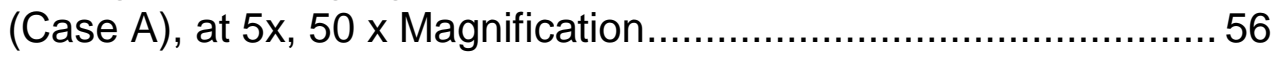

Figure 4.24: Micrograph of Top Segregated Section of Field Samples at 5 and 30 Magnification and Micrograph of Bottom Section at 5x, 50x,

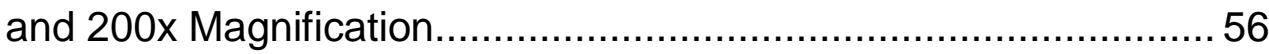

Figure 4.25: Micrograph of Segregated Top and Bottom Section in MIT Test,

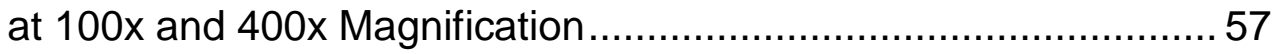

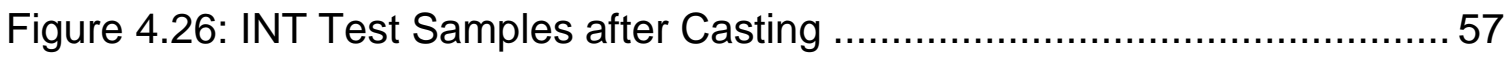

Figure 4.27: Photos of Deficient Grout Surface in INT Test in the Tee Header (Cases A.P.1-4) after 1 day from casting...................................... 58

Figure 4.28: Photos of Deficient Grout Surface in INT Test in the Tee Header (Cases A.P.1-6) After 300 Days from Casting ............................... 59

Figure 4.29: Photo of the Prototype for INT Sample Cast with Pre-exposed Grout B 
Figure 4.30: Photos of Segregated Grout in Tee Header from INT Test Samples (Cases B.P.1-4)..... 59

Figure 4.31: Photos of Grout in Tee Body from INT Test (Cases B.P.1-4) ......... 60

Figure 4.32: Photos of INT Samples (Cases A.P.1 and A.P.10)...................... 60

Figure 4.33: Photos of Segregated Grout in Tee Header from INT Test (Cases A.P.1-6) 61

Figure 4.34: Photos of Grout in Tee Body from INT Test (Cases A.P.1-6) ......... 61

Figure 4.35: Photos of Deficient Grout Surface in INT Test in the Tee Header (Cases A.P.7-12) After 300 Days from Casting . 62

Figure 4.36: Photos of Segregated Grout in Tee Header from INT Test Cast (Cases A.P.7-12) 63

Figure 4.37: Layer Differentiation in Soft Grout from INT Test Cases A.P.8) .... 63

Figure 4.38: Photos of Grout in Tee Body from INT Test (Cases A.P.7-12) ....... 64

Figure 4.39: Moisture Content of Grout from INT Test Samples (Cases B.A.1-3, B.P.1-4) 64

Figure 4.40: Moisture Content of Grout from INT Test Samples

(Cases A.A.1-3 and A.P.1-6) 65

Figure 4.41: Moisture Content of Grout from INT Test Samples

(Cases A.P.7-12) 65

Figure 4.42: Bulk Resistivity for INT Test Samples

(Cases B.A.1-3, B.P.1-4, A.A.1-3 and A.P.1-4) 66

Figure 4.43: Solution Resistance for INT Test Samples

(Cases B.A.1-3, B.P.1-4, A.A.1-3 and A.P.1-4) 66

Figure 4.44: Sulfate Concentration of Grout from INT Test Samples

(Cases B.A.1-3, B.P.1-4

Figure 4.45: Total Chloride Content of Grout from INT Test Samples

(Cases B.A.1-3, B.P.1-4)

Figure 4.46: Sulfate concentration of grout from INT test samples

(Cases A.A.1-3 and A.P.1-6) 68

Figure 4.47: Total Chloride Content of Grout from INT Test Samples (Cases A.A.1-3 and A.P.1-6) 68 
Figure 4.48:pH Measurements of Grout from INT Test Samples

(Cases B.A.1-3, B.P.1-4), by Ex-situ Leaching 69

Figure 4.49:pH Measurements of Grout from INT test Samples

(Cases A.A.1-3 and A.P.1-6), by Ex-situ Leaching 69

Figure 4.50: Chemical Characteristic Profiles of INT Tests (Case B.P.1) .......... 70

Figure 4.51: Chemical Characteristic Profiles of INT Tests (Case A.P.1) ........... 70

Figure 4.52: Sulfate Concentration of Grout from INT Test Samples (Cases A.P.7-12) 71

Figure 4.53: Total Chloride Content of Grout from INT Test (Cases A.P.7-12) .. 71

Figure 4.54:pH Measurements of Grout From INT Test Samples

(Cases A.P.7-12), by Ex-situ Leaching. 72

Figure 4.55: Corrosion Potential and Current Density for INT test, Cases: B.A.1-3, B.P.1-4 73

Figure 4.56: Corrosion Potential and Current Density for INT test, cases: A.P.5-6

Figure 4.57: Corrosion Potential and Current Density for INT test, cases: A.A.1-3 and A.P.1-14

Figure 4.58: Corrosion Potential and Current Density for INT test cases: A.P.7-12.

Figure 4.59: Photos of Corroded Wire in Segregated Part of INT Test Samples (Case A.P.3) 76

Figure 4.60: SEM Micrograph for Case A.P.3 76

Figure 4.61: Photos of Corroded Wire in Segregated Part of INT Test Samples (Case A.P.7-8). 78

Figure 4.62: Photos of Corroded Wire in Segregated Part of INT Test Samples (Case A.P.9-10). 79

Figure 4.63: SEM Micrograph and EDS Elemental Maps of Corrosion Product (Case A.P.11.1) 80

Figure 4.64: SEM Micrograph and EDS Elemental Maps on Pitting Corrosion for Corroded Wire (Case A.P.11.1).......................................... 81

Figure 5.1: Pourbaix Diagram for Iron (Jones, 1993)................................... 100 
Figure 5.2: Corrosion Potential and Corrosion Current Density for Steel in Alkaline Sulfate Solution

Figure 5.3: Anodic Polarization Graphs. - Right: 1-Day Cathodic Polarization ............................................ 102

Figure 5.4: Corrosion of Steel in Concrete as a Function of pH .................... 106

Figure 5.5 :Sulfate /Hydroxyl Threshold Value Based on Corrosion Potential and Current Density.)......................................................... 117

Figure 5.6: Corrosion Potential and Current Density versus Total Chloride Content

Figure A.1: Photos of pH Results for MIT Test(Case A,B,C, D,E,F) ................ 131

Figure A.2: Photos of pH Results for INT Test (Case B.A.1-3) ........................ 131

Figure A.3: Photos of pH Results for INT Test (Case B.P.1-4) ....................... 132

Figure A.4: Photos of pH Results for INT Test (Case A.A.1-3) ....................... 132

Figure A.5: Photos of pH Results for INT Test (Case A.P.1-6) ........................ 133

Figure A.6: Photos of pH Results for INT Test (Case A.P.7-12) ...................... 133

Figure B.1: Photos of Steel Wire in Tee Header in INT Test (Case A.P.1-6).... 134

Figure B.1: Photos of Steel Wire in Tee Header in INT Test (Case A.P.7-12).. 134 


\section{INTRODUCTION}

Prestressed concrete bridge construction in the United Stated became widely used in twentieth century. It allows the construction of large bridges with longer span and opens up the range of design possibilities. The term prestressing is used to describe the process of introducing internal forces in a concrete structural element during the construction process in order to resist the external loads that will be applied when the structure is put into use (Hurst and Keith, 2002). These internal forces are applied by tensioning high strength steel, which can be done either before or after the concrete in the structural element is cast. Tension is applied to prestressing steel by using a hydraulic stressing jack (Figure 1.1).

When a concrete element is prestressed, it means that the steel is being tensioned and the concrete is being compressed. As a building material, concrete is strong in compression, but it is relatively weak in tension. Steel, on the other hand, is strong in tension. The result is a stiffer structural element that is being actively compressed and has more capacity to resist tensile forces (Hurst and Keith, 2002).

When the steel is tensioned before concrete placement the process is called pre-tensioning. When the steel is tensioned after concrete placement the process is called post- tensioning. The prestressing strand, duct, and filler material are collectively referred to as a -ttemsioned Reonstons are differentiated as being bonded or un-bonded where un-bonded post-tensioned tendons typically rely on fillers such as grease and wax to provide encapsulation of the steel and 
providing a barrier to environmental exposure and in bonded, the pre-stress steel is set in an injected cementitious grout.

The systems used for bonded post-tension concrete typically consist of the concrete structural element, pre-stressing steel (in the form strand, wire, or bar), duct that houses the pre-stressing steel, cementitious grout and the anchorage system. Concrete is cast in for the structural element and allowed to reach a predetermined strength before the pre-stressing steel is tensioned.

The concrete for the pre-stressed structural elements provide some level of protection for the pre-stressing steel from external environmental exposure (Figure1.2). For pre-tensioned wire the concrete does not let aggressive chemicals such as chloride ions and atmospheric carbon dioxide to diffuse in the system. High performance concretes with low permeability provide good corrosion durability of the embedded steel elements.

The alkaline cementitious environment in the grout of bonded PT systems allows for stable steel passivation that prevents any significant corrosion; however, some cases of steel corrosion had been documented. Corrosion-related failures of post-tensioning, PT, tendon have been documented in several Florida bridges from the late 1990's to mid 2000's (Powers, 1999; Corven, 2001; FDOT, 2002; Sagues, 2005; Trejo et al.2009; Hansen, 2007). Research had been conducted and improved design and construction guidelines were employed by the transportation department to prevent and control corrosion damages. 

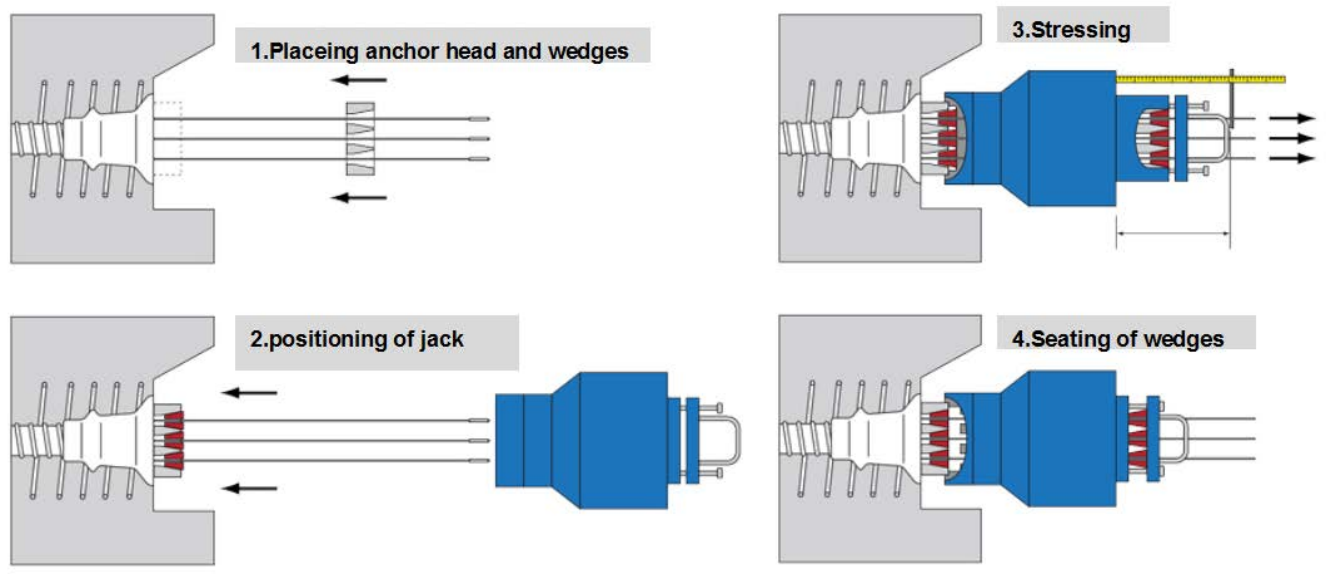

Figure 1.1: Illustration of Post Tensioning Process (Post-Tensioning Institute, 2000)
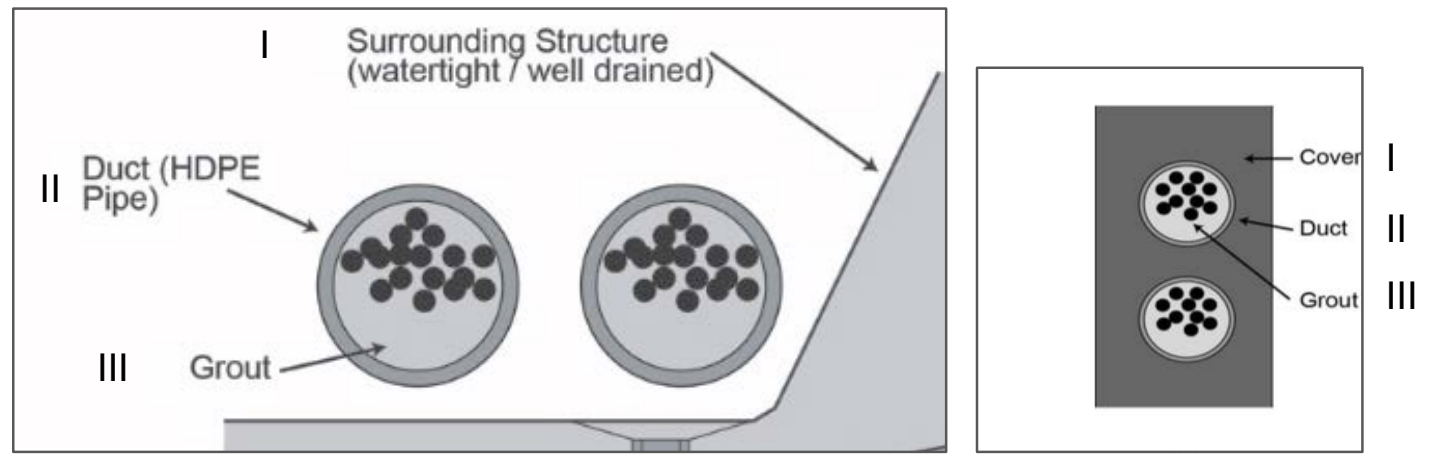

Figure1.2: Illustration of Three Levels of Protection to Internal /External Tendons (Coven, 2013) 


\section{LITERATURE REVIEW}

\subsection{Corrosion History of PT Tendons}

Corrosion damage to the pre-stressing steel of post-tensioned concrete components can occur by different mechanisms depending on pre-stressing environmental exposure. There has always been concern about the inspection of tendons in post tensioned concrete bridges mainly because of the difficultly of detection and quantifying any deterioration. The brief history is described here.

The idea of prestressing concrete was first applied by Eugene Freyssinet, often referred to as the "father of pre-stressed concrete," at the beginning of the last century (Das Parag et al., 2001). The first internal post-tensioned bridge was built in 1927 in Alsleben, Germany which was followed by the construction of first external post tensioned bridges in Aue, Germany and Algiers designed by Dischinger in 1936.

In the United Kingdom, the first post-tensioned bridge was the Nunns Bridge that was completed in 1947. Over the next five decades post-tensioned concrete became the preferred method of construction for bridges with long spans. During the 1950 s and early 1960 s post-tensioned concrete bridges gave satisfactory performance; however, the collapse of two footbridges during the 1960s gave an indication of the problems that could arise. The tendons were severely corroded and the corrosion was attributed to difficulties during grouting. The first problems with a major structure were found in early 1970s when longitudinal cracks were observed on some of the beams which was built in 1961. The cracks were 
attributed to the expansion of water due to freezing; there was only slight corrosion on the tendons. Subsequent investigations were taken on twelve bridges built between 1958 and 1977 . Voids were found in over $50 \%$ of the ducts examined and were present in all but one of the structures. During the 1980s, problems were found in an increasing number of bridges. The most serious event occurred in December 1985 when a single span segmental post-tensioned bridge collapsed without warning. It happened due to the ineffective corrosion protection of the prestressing steel at concrete segment joints filled with mortar. Moisture and chloride penetrated the joints and corroded the tendons. In 1992,transportation officials announced that it would not be commissioning any new post-tensioned concrete bridges with internal grouted tendons until design and construction standards could be reviewed. The reason for moratorium was concern over the vulnerability of prestressing system to corrosion resulting from penetration of water and de-icing salts (Fib, 2001).

During the last 20 years in France, use of fluid grouts facilitated the injection of the prestressed ducts. From 1980, the search for greater fluidity was accompanied with a generalized use of super plasticizers. In 1994, an investigation was carried out on the external prestressing tendons of a box girder bridge under construction. Anomalies were detected at the upper point of the sheaths, which had been grouted with cement mixed with admixture. After opening of some sheath, incomplete grout filling and the presence of a product having consistency of a wet and soft paste (which hardened after exposing to the air) was observed. In the investigation carried out in 1995 on other bridges under construction, 
mineralogical analysis showed that this soft product had 40\% ettringite, $20 \%$ portlandite and $20 \%$ calcite. Also the remainder of the paste presents enrichment in admixture and sulfates. A yellowish liquid had the $\mathrm{pH}$ of 13.8. After these phenomena, the injections by soft products cover the injection with grease and oil wax. The first injections of external tendons with grease did not give satisfactory results, mainly because of the instability of the grease in short term. This is why the soft injections are currently carried out with oil wax, which is more stable product in the time (Fib, 2001).

In the United States, the first post-tensioned construction is usually associated with the construction of the walnut lane bridge in Philadelphia in 19491950. This bridge was replace in the mid 1980 due to the detailing and grouting problems which led to significant corrosion damage to the post tensioning tendons. The first specification for prestressed concrete in 1958 stated that the steel for bonded tendons should be kept clean and dry and the foreign matter, grease, oil, paint and loose rust should be removed before steel is placed in the ducts.

Prior to the early 2000 s, post-tension grouts were neat grouts and were documented to have challenges due to the excess formation of bleed water and resulting in grout void formation and severe corrosion of tendons in a number of bridges. The presence of voids in the grout of tendon ducts could provide conditions whereby corrosion development may occur. The early failures of several PT systems in Florida and Virginia (including the Niles Channel Bridge, Midbay Bridge, Sunshine Skyway Bridge, and Varina-Enon Bridge, after only 18, 7, 15, and 
17 years service; respectively) were cases of severe corrosion associated in part with grout voids (Powers, 1999; Corven, 2001; FDOT, 2002; Sagues, 2005; Trejo et al.2009; Hansen, 2007). The causes of the voids have been attributed to development of bleed water during grouting and following re- absorption or evaporation from the grout.

Afterwards, in 2001 specification included requirements of thixotropic (antibleed) grouts to be used in aggressive environments, to reduce the corrosion issue associated with grout bleeding. However after adoption of the new grout material specification, corrosion occurred in post-tensioning bridges in Florida. Unfortunately, recent developments since 2011 have shown that challenges in corrosion mitigation persists for these pre-packaged thixotropic grouts. These cases of severe corrosion of steel strand were not directly associated with voids; bleed water, carbonation, and chlorides. However, the corrosion was associated with deficient grout (Lau et al, 2013) (Figure2.1). Similar corrosion of steel in deficient grout was reported in Europe (Bertolini and Carsana, 2011; Bertolini and Carsana, 2015). In all of these accounts, the grout was described as having poor cohesive bulk properties, high moisture content, high alkali content, and high sulfate ion concentrations. In the European case, failure of a bridge pre-stressing cable occurred in less than 2 years of service. In Florida, two post-tensioned bridges with less than 8 years in service had severe steel corrosion in grouts with these characteristics but unexpectedly occurred in the newer low-bleed prepackaged thixotropic grouts. The lack of supporting evidence of significant chloride presence and carbonation and inconsistent association of severe 
corrosion to void spaces would indicate different corrosion mechanisms than those conventionally associated with corrosion of pre-stressed steel were involved.

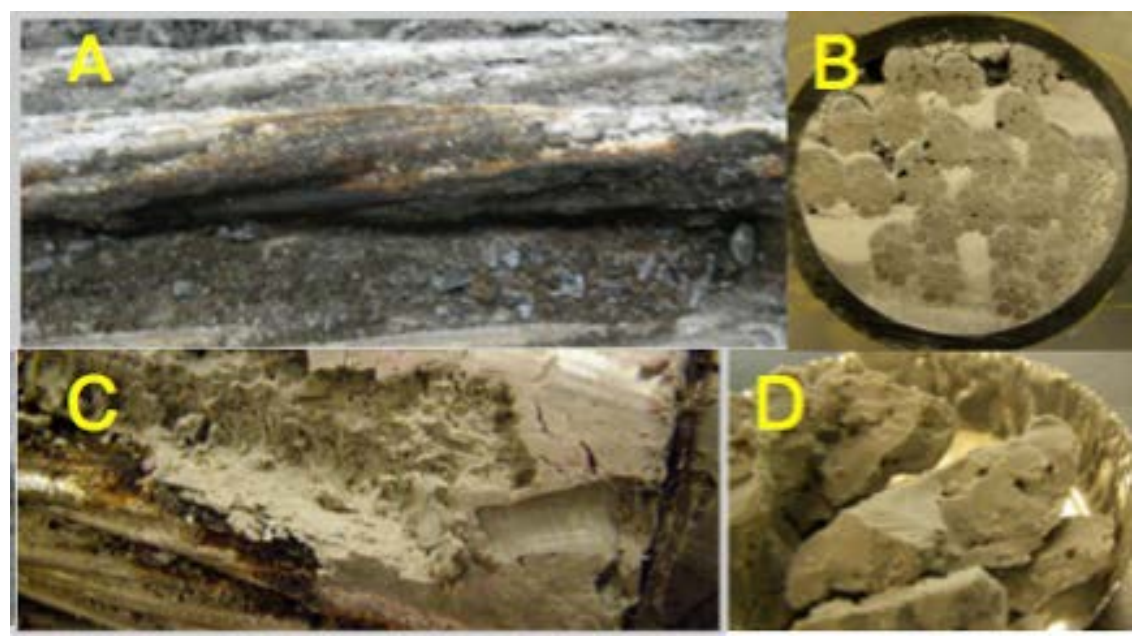

Figure 2.1: Photos of Failed Tendons; A-Corroded strand, B -Different layers of deficiency in tendon, C- Corroded stands in deficient grout, D-, Deficient grout, Courtesy by FDOT

Bertolini and Carsana, 2011 reported that segregation of injection cement grout for prestressing cables may lead to the formation of a whitish phase with plastic consistency, characterized by high content of alkalis and sulfate ions. Low oxidizing conditions due to limited oxygen supply in crevice regions and highly alkaline pore water conditions with $\mathrm{pH}$ greater than 14 would allow for active corrosion conditions. Also a slight increase in the anodic current density was observed in the presence of sulfate ions.

\subsection{Recent Corrosion Failure in Florida Utilizing Thixotropic Grouts}

John Ringling Causeway, post-tensioned bridge in Florida was finished in 2003. After only eight years of service, it was confirmed that 17 external post- 
tensioned tendon failed due to corrosion (Lau et al., 2013). These corrosion problems were alarming because it happened in tendons containing pre-packaged thixotropic grout prescribing to the recent grout specification.

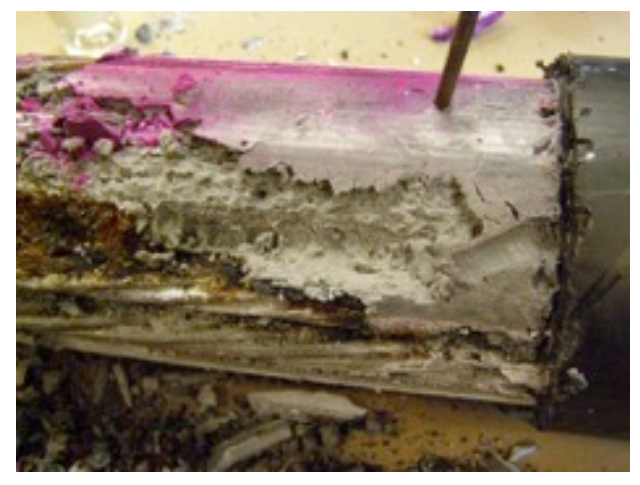

Figure 2.2: Corrosion of Strand Embedded in Deficient Grout. Pink color shows phenolphthalein indicator sprayed on grout surface. Courtesy by FDOT

The severe corrosion of the steel occurred at locations with deficient grout. The deficient grout was not consistently associated with void, bleed water and enhance chloride content. In the most severe manifestation of the deficient grout, the grout remained unhardened (Figure 2.1 and 2.2) with a putty-like consistency and becomes friable upon drying. In nearby regions, the deficient grout had a white color and had a chalky consistency. The deficient grout material had as much as $80 \%$ moisture content. Pore-water $\mathrm{pH}$, was generally greater than 12 and the $\mathrm{pH}$ in the soft grout with nearby corrosion was sometimes greater than 13 . No consistent indication of carbonation being the primary corrosion mechanism was observed. The total chloride content was low to moderate but may be enhanced in the deficient grout due to capillary transport during the grout segregation process. Severe corrosion and deficient grout was associated with high free sulfate 
concentrations (as high as $\sim 10,000 \mathrm{ppm}$ ). As seen in Figure 2.3, variation of grout consistency and chemical makeup was observed in stratified grout layers at a low point anchor cap. Corrosion of the strand and wedge plate was predominant in regions of severe grout deficiency that had enhanced moisture and sulfate ion presence.

As of 2014, five other bridges in Florida built with low-bleed water formation grouts had been identified to have analogous deficient grout, but the amount and severity varied significantly between bridges (Lau et al. 2014).

Similar to the deficient grout found in the Ringling Causeway, the extracted deficient grout there had high sulfate ion concentrations (ranging from 1,000 to $12,000 \mathrm{ppm}$ ) relative to extracted hardened grout (10 to $200 \mathrm{ppm}$ ).
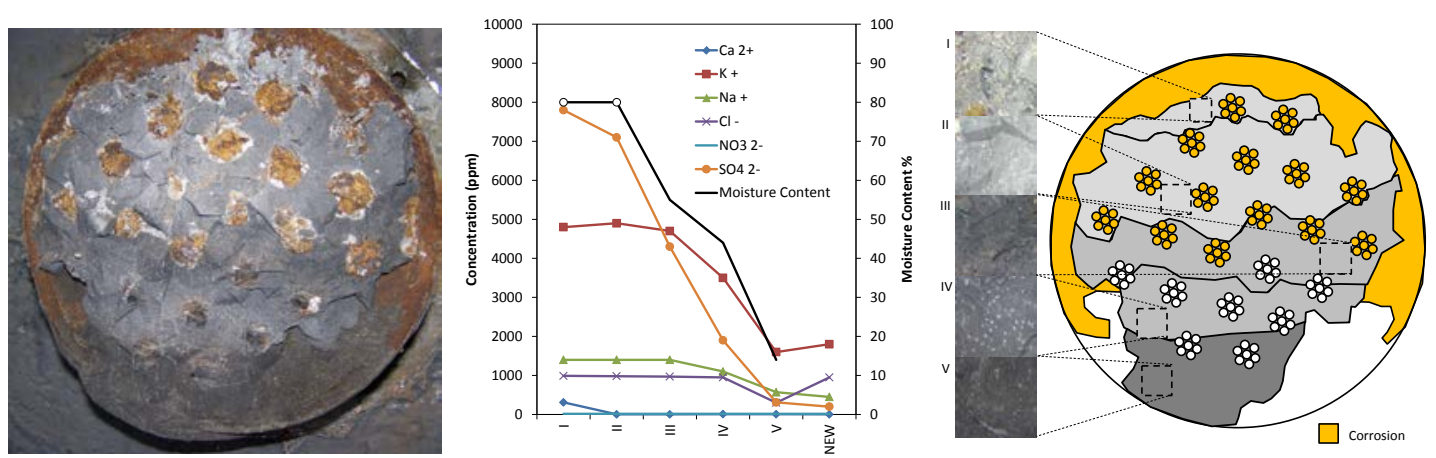

Figure 2.3: Visual and Chemical Makeup of Stratified Deficient Grout at an Anchor Cap. (Lau et al., 2013)

\subsection{Cement Characteristics}

\subsubsection{Cement chemistry}


Cement plays a significant role in the recent corrosion development of PT tendons. Portland cement is made by heating a mixture of limestone and clay (or other materials of similar bulk composition and sufficient reactivity) ultimately to a temperature of about $1450^{\circ} \mathrm{C}$. Partial fusion occurs, and clinker is produced. The clinker is mixed with a few percent of calcium sulfate to make the cement. The calcium sulfate controls the rate of set and influences the rate of strength development. It is commonly described as gypsum, but this may partly or wholly replace by other forms of calcium sulfate. The clinker typically has a composition in the region of $67 \% \mathrm{CaO}, 22 \% \mathrm{SiO}_{2}, 5 \% \mathrm{Al}_{2} \mathrm{O}_{3}, 3 \% \mathrm{Fe}_{2} \mathrm{O}_{3}$ and $3 \%$ other components, and normally contains four major phases, called alite, belite, aluminate and ferrite. Several other phases, such as alkali sulfates and calcium oxide are normally present in minor amounts (Taylor, 1997). The cement paste is in equilibrium with a pore solution with a pH of between 13 and 14 (Lagerblad, 2001).

In cement chemistry, the term hydration means the changes that occur when anhydrous cement is mixed with water. The chemical reactions taking place are generally more complex than simple conversions of anhydrous compounds into the corresponding hydrates. When Portland cement is brought into contact with water, its constituents start to react and various hydration products such as C-S-H (calcium silicate hydrate) gel, calcium hydroxide (portlandite), ettringite, monosulfate or monocarbonate form. The composition of the cement, the interacting solution and the reaction time determine which solids (hydrates) will 
form, as the solid hydrates can precipitate only if the solutions are saturated or oversaturated with respect to the respective solid. (Taylor, 1997)

Tricalcium aluminate $\left(\mathrm{C}_{3} \mathrm{~A}\right)$, an important mineral phase in Portland cement, formed when the appropriate proportions of fine calcium oxide and aluminum oxide are heated together above $1300^{\circ} \mathrm{C}$. It liberates a large amount of heat and contributes somewhat to early strength. Gypsum is added to Portland cement to retard $\mathrm{C}_{3} \mathrm{~A}$ hydration. Without gypsum, $\mathrm{C}_{3} \mathrm{~A}$ hydration would cause Portland cement to set almost immediately after adding water (flash set). At the same time, calcium chloride $\left(\mathrm{CaCl}_{2}\right)$ added to Portland cement and accelerates the reaction between $\mathrm{C}_{3} \mathrm{~A}$ and gypsum (Kishar et al.2013).

Therefore, the dissolution of sulfate and alkali constituents, together with reactive $\mathrm{C}_{3} \mathrm{~A}$ (tricalcium aluminate) is the first step of reaction in cement hydration process. This will form trisulfoaluminate hydrate (ettringite), which can be stabilizing by adding calcium chloride. Later, when the sulfates are consumed, the ettringites will transform into monosulfates that contain relatively less sulfate. This is due to the fact that the cement is unbalanced in sulfate (Lagerblad, 2001).

\subsubsection{Different degradation mechanism of concrete}

Concrete structures are vulnerable to a number of factors that can cause deterioration. Deterioration can result in loss of strength, degradation and corrosion of embedded steel reinforcement. Corrosion of reinforcing steel may be accelerated under conditions where other mechanisms of damage are in action 
simultaneously. For examples, simultaneous freeze-thaw conditions or chemical deterioration of concrete by access of sulfates ions may be aided by conditions leading to reinforcement corrosion (Marchand et al, 2003). Therefore it is important to have an understanding different kind of deteriorations in concrete:

\subsubsection{Alkali-silica and Alkali-carbonate reaction (ASR), (ACR)}

ASR occurs if the reactive aggregates are used in the mix. Some siliceous minerals $\left(\mathrm{SiO}_{2}\right)$ react with water in a high alkaline environment to form silica gel, as silica gel swells when it absorbs moisture, the material can cause concrete to crack. ACR is observed with certain dolomitic rocks $\left(\mathrm{CaMg}\left(\mathrm{CO}_{3}\right)\right)$. This phenomenon is less common and can cause concrete degradation. (Thomas, M.D.A, et al., 2011).

\subsubsection{Sulfate attack}

Sulfate attack sometimes called sulfate corrosion is a severe type of deterioration resulting from chemical reaction occurring when concrete components react with sulfate ions present in solution in contact with concrete or under certain conditions within the concrete mixture itself. It will cause the expansion, crack and loss of cohesion and strength in the cement paste, the cracks may remain empty or later be partly or even completely filled with ettringite.

Internal sulfate corrosion should be then categorized as either a) composition induced internal sulfate attack, caused by an excess of sulfate ions in the concrete itself (from clinker, aggregate, admixture, and rare excessive addition of calcium sulfate) or b) heat-induced internal sulfate attack (also referred to as 
delayed ettringite formation DEF), caused by thermal decomposition and subsequent reformation of ettringite due thermal conditions during concrete processing, this type of mechanism involves only monosulfate and ettringite ( trisulfate)( Lamond,2006).

\subsubsection{Steel Corrosion}

\subsection{Corrosion due to Chloride}

The mobile chloride ions disperse through concrete pores in solution and where they come into contact with the reinforcing steel they attack the passive layer (Jones, 1992). Steel passivity is elaborated in Section 2.4.

\subsection{Corrosion due to Carbonation}

High concrete porosity, high concrete diffusivity, low moisture content, and deep cracks reaching the depth of reinforcement increase the rate of carbon dioxide ingress. Carbonation of the calcium hydroxide, $\mathrm{Ca}(\mathrm{OH})_{2}$, present in the cement paste by atmospheric carbon dioxide $\left(\mathrm{CO}_{2}\right)$ results in the formation calcium carbonate, $\mathrm{CaCO}_{3}$ :

$\mathrm{Ca}(\mathrm{OH})_{2}+\mathrm{CO}_{2} \Rightarrow \mathrm{CaCO}_{3}+\mathrm{H}_{2} \mathrm{O}(1)$

Carbonation results in a drop of $\mathrm{pH}$ in the cement pore water. Severe carbonation at levels up to the depth of the reinforcing steel promotes corrosion of steel to take place (Marchand et al, 2003). 


\subsection{Corrosion of Steel in Cementitious Material}

Corrosion is the deterioration of materials by chemical interaction with their environment (Jones, 1992). Corrosion of reinforcing steel is the leading cause of deterioration in concrete. When steel corrodes, the resulting rust occupies a greater volume than the steel. This expansion creates tensile stresses in the concrete, which can eventually cause cracking, delamination, and spalling (PCA, Portland Cement Association).

The five components of a corrosion cell include the anode, cathode, electrolyte, conductor and ionic path. In reinforced concrete, the rebar may have many separate areas at different energy levels and acts as the anode and cathode and the concrete acts as the electrolyte and the ionic path (PCA).

This electrochemical process involves the flow of charges (electrons and ions). At active sites on the bar, called anodes, iron atoms lose electrons and move into the surrounding concrete as ferrous ions. This process is called a half-cell oxidation reaction, or the anodic reaction, and is represented as (Equation 2). The electrons remain in the bar and flow to sites called cathodes, where they combine with water and oxygen in the concrete. The reaction at the cathode is called a reduction reaction. A common reduction reaction is (Equation3). The rates of the anodic and cathodic reactions must be equivalent, being determined by the total flow of electrons from anodes to cathodes which is called the corrosion current, Icor (Mandhyan, 2007).

$\mathrm{Fe} \rightarrow \mathrm{Fe}^{2+}+2 \mathrm{e} \quad$ Anodic reaction (corrosion) (2) 
$2 \mathrm{H}^{+}+2 \mathrm{e} \rightarrow \mathrm{H}_{2} \quad$ Cathodic reactions (simplified) (3) or

$\mathrm{H}_{2} \mathrm{O}+1 / 2 \mathrm{O}_{2}+2 \mathrm{e} \rightarrow 2 \mathrm{OH}^{-}(4)$

Reaction (Equation 3 ) is most common in acids and in the $\mathrm{pH}$ range $6.5-8.5$; the most important reaction is oxygen reduction (Equation 4). In this latter case corrosion is usually accompanied by the formation of solid corrosion product from the reaction between the anodic and cathodic products (Mandhyan, 2007)(Equation 5,6):

$\mathrm{Fe}^{2+}+2 \mathrm{OH}^{-} \rightarrow \mathrm{Fe}(\mathrm{OH})_{2}$ iron (II) hydroxide (5)

$2 \mathrm{Fe}(\mathrm{OH})_{2}+\mathrm{H}_{2} \mathrm{O}+{ }^{1 /}{ }_{2} \mathrm{O}_{2} \rightarrow 2 \mathrm{Fe}(\mathrm{OH})_{3}$ hydrated iron (III) oxide (6)

Pure iron (II) hydroxide is white but the material initially produced by corrosion is normally a greenish color due to partial oxidation in air.

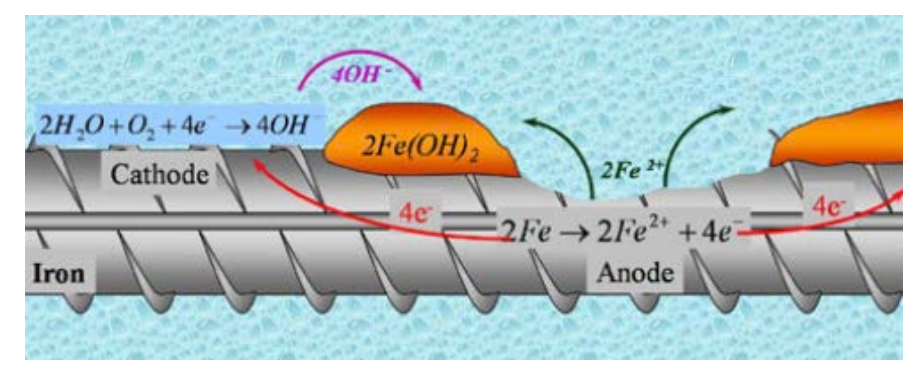

Figure 2.4: Schematic of Steel Corrosion Acting as an Anode and Cathode (PCA)

Further hydration and oxidation reactions can occur and the reddish rust that eventually forms is a complex mixture encourages further corrosion. At the 
high $\mathrm{pH}$, if solid corrosion products are produced directly on the surface as the first result of anodic oxidation these may provide a highly protective surface film, which retards further corrosion, the surface is then said to be passive. It reduces the corrosion rate to an insignificant level. Because of concrete's inherent protection, reinforcing steel does not corrode in the majority of concrete elements and structures. However, corrosion can occur when the passive layer is destroyed. The destruction of the passive layer occurs when the alkalinity of the concrete is reduced or when the chloride/sulfate concentration in concrete is increased to a certain level.

Halides, especially chloride are well known in destroying passive layer formation, they can cause local breakdown of the protective oxide film, which cause pitting corrosion. In spite of general corrosion that occurs uniformly on the whole surface of the metal, pitting corrosion will lead to local damage. Once this small hole or cavity has formed, its geometry enacts some limitation to mass transport. If oxygen diffusion into the pit is slower than its depletion through the cathodic reaction, deoxygenation occurs. Hence, oxygen reduction will occur predominantly surfaces around the pit, while anodic iron dissolution take place inside the pit (Equation1). In order to prevent re-passivation, the solution inside the pit is required to maintain in chemically aggressive state (Turnbull, 1984; Shreir et al., 1994; Strehblow, 2002; Burstein et al., 1993). The dissolve iron in the pit hydrolyze and cause acidification in the solution, e.g. by the following chemical reaction (Shreir et al., 1994): 
$\mathrm{Fe}^{2+}+2 \mathrm{H}_{2} \mathrm{O} \Rightarrow \mathrm{Fe}(\mathrm{OH})_{2}+2 \mathrm{H}^{+}(7)$

Figure 2.5 schematically summaries the localized character of pitting corrosion with the involved charge transfer reactions, mass transport processes and the macro-cell. It shows a pit where anodic reaction of iron dissolution and hydrolysis of the iron ions take place. In order to balance the produced positive charge in the pit, anions move into the pit and cations migrate to the exterior bulk solution. These anions can be the hydroxide, chloride or sulfate ions. In pure neutral or alkaline water, hydroxide will migrate into the pit and prevent a fall in $\mathrm{pH}$, while the acidification of the solution can happen in presence of chloride or sulfate ion (Turnbull, 1984). Hydrolysis reactions involving sulfate ions such as $\mathrm{Fe}^{2+}+$ $2 \mathrm{H}_{2} \mathrm{O}+2 \mathrm{SO}_{4}{ }^{2-} \rightarrow \mathrm{Fe}(\mathrm{OH})_{2}+2 \mathrm{H}_{2} \mathrm{SO}_{4}$ in crevice environments may allow for localized corrosion (Jones, 1996).

As a result of the deoxygenation-acidification mechanism, and having the large cathodic and small anodic area. a macro-cell is established. When the anodic and cathodic half-cell reactions are spatially separated. Anodic iron dissolution preferentially takes place in the acidic deaerated pit environment, while cathodic oxygen reduction proceeds on the alkaline, aerated external metal surfaces. 


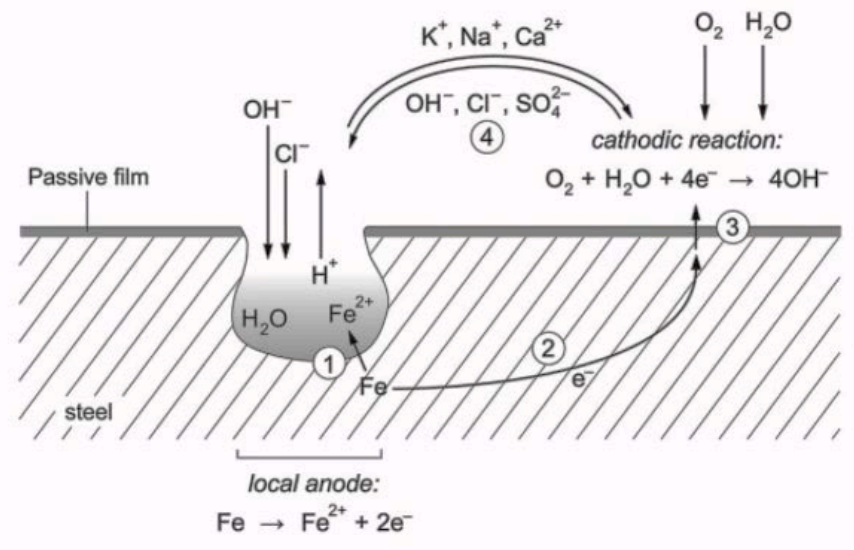

Figure 2.5: Schematic Illustration of Chloride Induced Pitting Corrosion and Reaction, Steps: 1. Anodic iron dissolution; 2. Flow of electrons through metal;

3. Cathodic reduction reaction; 4 . Ionic current flow through the electrolyte.

\subsection{Water chemical characteristic}

The chemical characteristic of the aqueous environment will affect the extent of steel corrosion. As discussed in Section 2.3.2.3, $\mathrm{pH}$ and chloride contamination are important factors for steel corrosion in concrete. In other systems, other factors such as alkalinity, hardness, carbon dioxide and dissolve solids can also influence corrosion (Fazle Elahi et al, 2014). Alkalinity, hardness and $\mathrm{pH}$ interact to determine whether water will produce scale or corrosion or will be stable for steel in soil and runoff water exposure. The table (1) summarizes whether water will produce scale or corrosion or will be stable (Soil Science Australia, 2004).

Scaling tends to be the result of water with high hardness. Hard water typically contains a lot of calcium compounds, which can precipitate out as calcium carbonate (Fazle Elahi et al, 2014). However if the hardness in the water is 
primarily noncarbonated, the chloride and sulfate ions will tend to keep the calcium in the solution and it increase the amount of $\mathrm{CaCO}_{3}$ in solution and decrease the $\mathrm{pH}$ level and finally cause corrosion.

Table 2.1:Characteristics of Corrosive Water and Scale-forming Water

\begin{tabular}{|c|c|}
\hline Corrosive water & Scale-forming water \\
\hline Low $\mathrm{pH}$ & High $\mathrm{pH}$ \\
\hline $\begin{array}{c}\text { Soft or with primarily noncarbonated } \\
\text { hardness }\end{array}$ & Hard with primarily carbonate \\
\hline Low alkalinity & High alkalinity \\
\hline
\end{tabular}

\subsection{Research on Sulfate}

As was concluded from the recent field observations of corrosion from Florida PT bridges (section 2.1), corrosion occurred in deficient grout containing high sulfate concentrations. Therefore sulfates are important in investigating the corrosion condition of PT tendons with deficient grout. Review of information regarding the role of sulfates with respect to cement chemistry, cement degradation and steel corrosion, is discussed in this section.

\subsubsection{Sulfate in Cement}

As discussed in (section 2.3.1) sulfate ion supplied by clinker, especially as alkali sulfates or calcium langbeinite and free lime. The alkali sulfates provide a source of $\mathrm{SO}^{2-}$. The hydration process of these low solubility compounds causes 
a release of $\mathrm{OH} \sim$ ion, which will affect the early strength of the cement (Taylor, 1997).

Calcium hydroxide and alumina-bearing phase of hydrated cement react with sulfate ions (Prasad, 2006). Ettringite and gypsum are the primary products of the chemical reaction. Failure by expansion of concrete in the presence of sulfate is due to the formation of ettringite (DEF). These crystals occupy empty space, and as they continue to form, they cause the paste to crack and further damaging the concrete. Two principal reactions in concrete followed by the reaction of Sodium Sulfate $\left[\mathrm{Na}_{2} \mathrm{SO}_{4}\right]$ or magnesium sulfate $\left[\mathrm{MgSO}_{4}\right]$ and calcium hydroxide $\left[\mathrm{Ca}(\mathrm{OH})_{2}\right]$ to form gypsum (Equations 8 and 9 and the reaction of the formed gypsum with calcium aluminate hydrates to form ettringite (Equation 10) (Ramezanianpour, 2010). In addition to above, the magnesium sulfate reacts with all cement compounds, including calcium silicate hydrates $[\mathrm{C}-\mathrm{S}-\mathrm{H}]$ and subsequently forming gypsum and ettringite (Equation 11) (Hekal \& Kishar, 2002).

The magnesium hydroxide reacts with silica gel to form magnesium silicate hydrate $[\mathrm{M}-\mathrm{S}-\mathrm{H}]$, being a soft material and affects the strength and durability of concrete. The form of ettringite developed in the cement paste is depending on phase of calcium aluminate hydrates, which reacts with sulfate.

In the fresh concrete, the gypsum, which is blended to prevent flash set, reacts with calcium aluminate hydrates to form primary ettringite $\left[\mathrm{C}_{3} \mathrm{~A} \overline{\mathrm{S}}_{3} \mathrm{H}_{32}\right]$. This primary ettringite is converted to monosulfate $\left[\mathrm{C}_{3} A \bar{s} \mathrm{H}_{32}\right]$ with time. The chemical 
reactions associated with sulfate are as follows (Prasad, 2006):

$$
\begin{aligned}
& \mathrm{Na}_{2} \mathrm{SO}_{4}+\mathrm{Ca}(\mathrm{OH})_{2}+2 \mathrm{H}_{2} \mathrm{O} \Rightarrow \mathrm{CaSO}_{4} \cdot 2 \mathrm{H}_{2} \mathrm{O}+2 \mathrm{NaOH}(8) \\
& \mathrm{MgSO}_{4}+\mathrm{Ca}(\mathrm{OH})_{2}+2 \mathrm{H}_{2} \mathrm{O} \Rightarrow \mathrm{CaSO}_{4} \cdot 2 \mathrm{H}_{2} \mathrm{O}+\mathrm{Mg}(\mathrm{OH})_{2}(9) \\
& 3 \mathrm{CaO} \cdot \mathrm{Al}_{2} \mathrm{O}_{3} \cdot 12 \mathrm{H}_{2} \mathrm{O}+3\left(\mathrm{CaSO}_{4} \cdot 2 \mathrm{H}_{2} \mathrm{O}\right)+13 \mathrm{H}_{2} \mathrm{O} \Rightarrow 3 \mathrm{CaO} \cdot \mathrm{Al}_{2} \mathrm{O}_{3} \cdot 3 \mathrm{CaSO}_{4} . \\
& 31 \mathrm{H}_{2} \mathrm{O}(10) \\
& \mathrm{Mg} \mathrm{SO}_{4}+\mathrm{C}-\mathrm{S}-\mathrm{H} \Rightarrow \mathrm{CaSO}_{4} \cdot 2 \mathrm{H}_{2} \mathrm{O}+\mathrm{M}-\mathrm{S}-\mathrm{H}(11)
\end{aligned}
$$

Also stated that the most adverse condition of sulfate ions within the cement matrix is when sulfate source interact chemically with the $\mathrm{C}-\mathrm{S}-\mathrm{H}$ and calcium hydroxide in the presence of carbonate ions. The resulting product is termed as thaumasite $\left(\mathrm{CaSiO}_{3} \cdot \mathrm{CaCO}_{3} \cdot \mathrm{CaSO}_{4} \cdot 15 \mathrm{H}_{2} \mathrm{O}\right)$. This is a rare condition to occur which is accompanied by the loss of strength and loss of adhesion to a greater extent (Bashir, et al, 2012).

\subsubsection{Sulfate, Moisture Content and Corrosion}

The moisture content in the concrete is one of the critical factors to form gypsum and ettringite in sulfate attack, which in turn affect the durability of the concrete structure. In the absence of sufficient moisture in the concrete, the destructive reactions will not occur. The risk of the concrete damage caused by such a chemical reactions with the presence of low or medium amount of moisture in the concrete is insignificant, whereas concrete with high moisture content has high risk of corrosion initiation.

There may be an excess of sulfate ions in the concrete itself (from clinker, 
aggregate, admixture, and rare excessive addition of calcium sulfate). Diffusion of ions like sulfate may happens when there is sufficient moisture in the pore structure of the concrete. These ions may penetrate faster when there is moisture content available in the grout (Kwan, 2005).

The sulfate concentration in the grout is of interest because sulfate, like chloride, reduces the passive protection provided by the alkaline environment provided by cementations materials (Turnbull 1984; Lau et al., 2013,2014; O'Reilly, 2013). The combination of high sulfate content and low $\mathrm{pH}$ for grout pore solution may lead to reduced corrosion protection.

\subsubsection{Corrosion Initiation by Sulfate Ion}

Information from the technical literature indicated that there could be conditions where enhanced sulfate ion concentrations may lead to corrosion development but a uniform description of corrosion activation processes of steel in relevant grout environments is lacking.

Literatures mostly focused on the effect of chloride ion in pitting corrosion of the steel; By contrast, the literature for pitting by sulfate ions is scarce. Although it has been considered that chloride ions are more aggressive than other anions, the effect of $\mathrm{SO}_{4}{ }^{2-}$ ions is probably seen most frequently because of their stability in water over a wide range of $\mathrm{pH}>2$. The role of sulfate ion in corrosion of the iron has not been uniformly described. Inhibitory effect of sulfate ion has been observed in a few experiments in different condition at low to Neutral pH (Frankel 1998; Man and Gabe 1981a;Pistoriusand Burstein 1992; Leckie and Uhlig.1966; Rosenfeild 
and Danliov 1967; Man and Gabe 1981b). However it has been reported that pitting induced by sulfate ions on iron occurs within the active/passive region and sulfate ions may also enhance the effect of chloride ions. (Vatankhah, Gh, et al. 1998)

Many parameters can affect the corrosion behavior including, pore water chemistry, soluble ions (chloride and sulfate) temperature and the $\mathrm{pH}$ of the environment. Arzola et al., 2003 showed that enhanced corrosion rate can occur in the presence of sulfats due to the oxidation of iron to form $\mathrm{FeSO}_{4}$. as shown in Figure 2.6 , the predominance-zone diagrams for $\mathrm{Fe}(\mathrm{II})-\mathrm{SO}_{4}{ }^{2-}-\mathrm{H}_{2} \mathrm{O}$ as presented by Arzola et al., 2003 showed stability of $\mathrm{Fe}^{2+}$ (below pH 10) when $\log \left[\mathrm{SO}_{4}{ }^{2-}\right]<$ -2.25. In this regime, the oxidation-reduction will be followed by:

$\mathrm{Fe}(\mathrm{s}) \rightarrow \mathrm{Fe}\left(\mathrm{aq}^{2+}+2 \mathrm{e}^{-}(12)\right.$

Whereas if $\log \left[\mathrm{SO}_{4}{ }^{2-}\right]>-2.25(1000 \mathrm{ppm})$ steel corrosion in sulfate solution will proceed according to (Arzola et al.2003):

$\mathrm{SO}_{4}{ }^{2-}+\mathrm{Fe}(\mathrm{s}) \rightarrow \mathrm{FeSO}_{4(\text { aq })}+2 \mathrm{e}^{-}(13)$ 


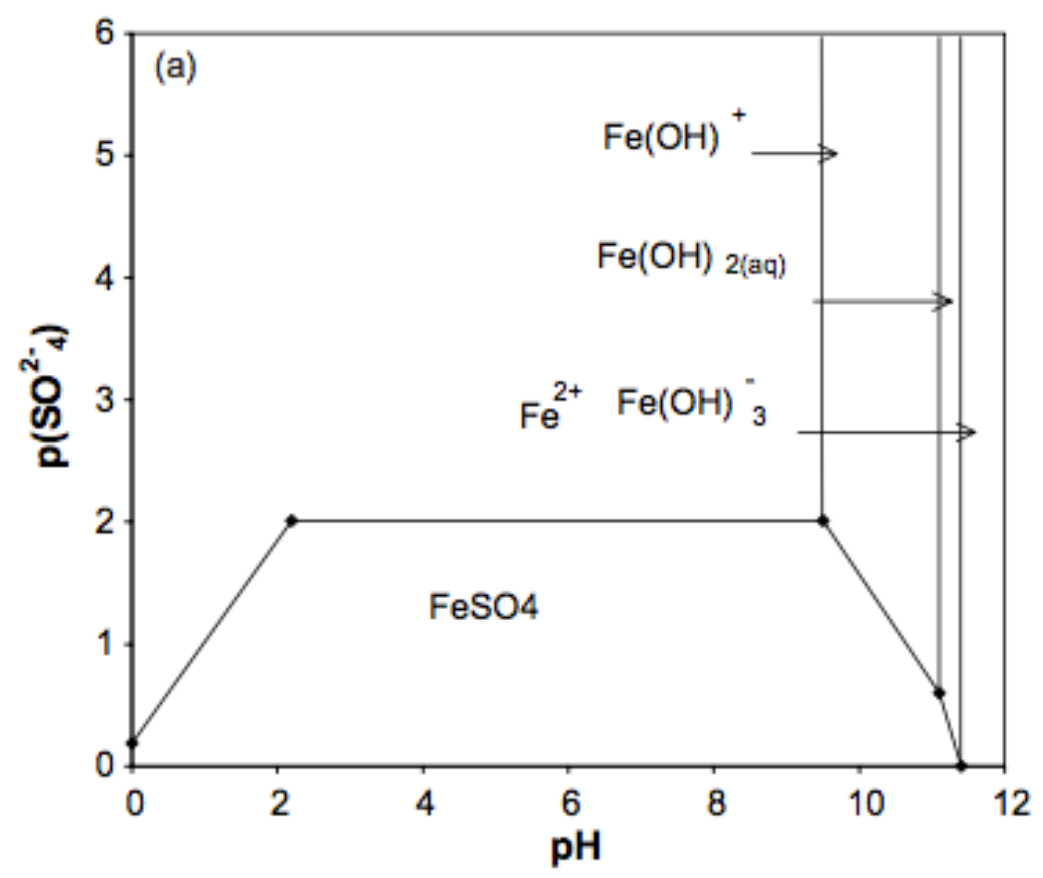

Figure 2.6:Two-dimensional PZD of Fe (II) Species (Arzola et al., 2003)

As shown in Figure 2.7, It is clear that when the predominant species is $\mathrm{FeSO}_{4}$, the corrosion rate increases significantly. As pointed out by Arzola the effect of sulfate ion on the rate of oxidation of iron in mildly alkaline solutions results from its ability to form soluble complexes with either $\mathrm{Fe}^{2+}$ or $\mathrm{Fe}^{3+}$. Sulfate ions accelerate the active dissolution of iron. Iron dissolves in sulfate solutions at a high rate when sulfate concentration exceeds $550 \mathrm{ppm}$ in certain $\mathrm{pH}$ of the water. This implies that a supersaturated solution allowing precipitation of a non-protective film occurs. 


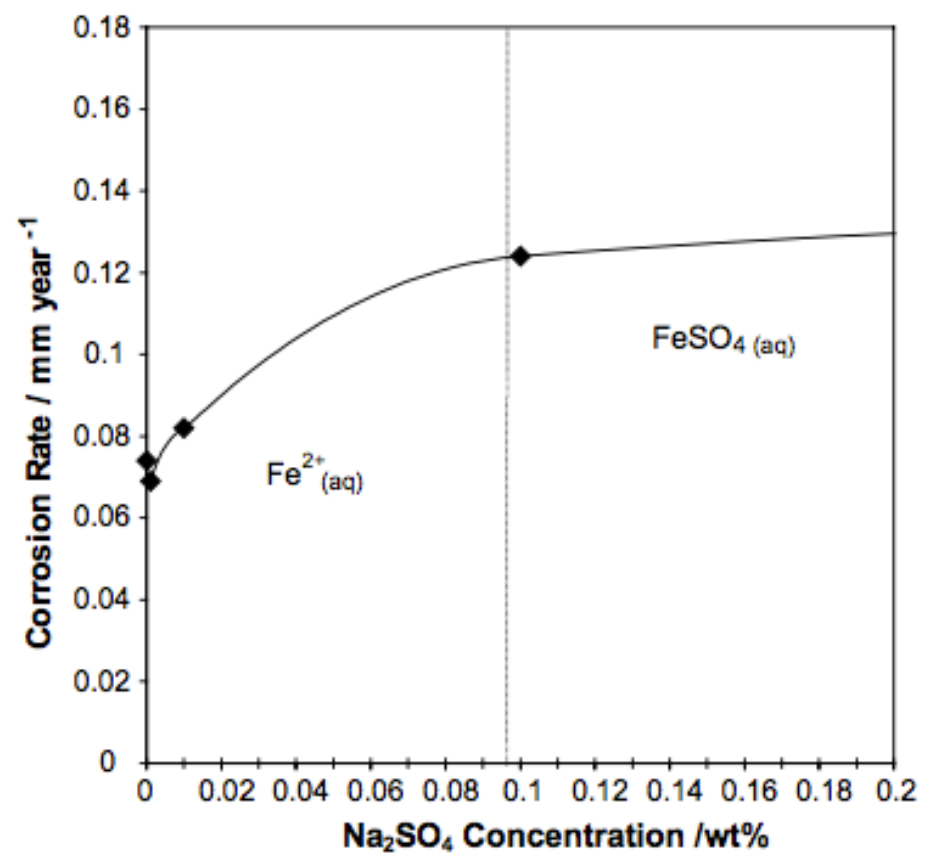

Figure 2.7: Corrosion Rate of Mild steel as a Function of $\mathrm{Na}_{2} \mathrm{SO}_{4}$ Concentration (Arzola et al., 2003)

MacDougall And Bardwell, 1988 have shown that the passivation of iron is a highly inefficient process in $\mathrm{SO}_{4}{ }^{2-}$ solutions in $\mathrm{pH}=3$, or 8.4. A very large anodic charge prior to a substantial decrease in current was observed. They concluded the passivation might be assisted by the formation of an inhibiting surface film, which is made by changes in the $\mathrm{pH}$ and precipitation of iron sulfate. Alkire et al., 1988 also reported dissolution of iron in sulfuric acid. This led to the conclusion that passivation is established following by precipitation of ferrous salt film (iron sulfate) on the surface.

Gui and Devine, 1994 observed that anions such as sulfate appear to absorb on to surface of passive film in mildly alkaline solution ( $\mathrm{pH} 5-10)$; the 
passive film itself consist of a mixture of iron oxide and hydroxide and the exact identity of the film is dependent on the identities of the anions present in the solution. In mildly acidic sulfate, the effect of $\mathrm{SO}_{4}{ }^{2-}$ on the rate of oxidation of iron in mildly alkaline solutions results from its ability to form soluble complexes with either $\mathrm{Fe}^{2+}$ or $\mathrm{Fe}^{3+}$. Sulfate ion not only absorbs on the surface of the passive film but is also covalently bonded to iron and is incorporated in the film.

Traubenberg and Foley, 1971 reported at pH 3 in sulfuric acid solution, sulfate ions accelerate corrosion when the reaction is under cathodic control. Chloride has virtually no effect, whereas sulfate increases corrosion (in low pH 38 Sulfate will accelerate corrosion,)

Mrowczynski and Szklarska-Smialowska, 1979 have shown the corrosion process is controlled by passivation in neutral and alkaline solutions of sodium sulfate . The active dissolution of iron occurs within the $6-11.5 \mathrm{pH}$ range.in $0.05 \mathrm{M}$ sodium sulfate or $4800 \mathrm{ppm}$ sodium sulfate solution. Therefore if the sulfate concentration exceeds this amount, depassivation may occur.

Szklarska-Smialowska, 1978 indicated, localized corrosion can occur in sulfate solution with $0.5 \mathrm{M}$ sodium sulfate concentration under certain condition, but can change into general corrosion after a certain time (at potential near passive state). Formation of the pits can occur, when the dissolution of the metal surface compete with the production of oxide film. 
Gouda, 1970 reported that when steel was embedded in concrete containing up to $8 \%$ of sodium sulfate, the passivity was not affected. On the other hand, when the sulfates were added to the cement extract, the passivity was destroyed readily even when as little as $0.2 \%$ of sulfate was used. The same effect has been obtained when sulfates were added to calcium hydroxide solution (Gouda and Halaka 1970). Acha, Alonso, and Andrade, 1990 also indicated the role of potassium sulfate in inhibiting of passive layer formation of steel in saturated calcium hydroxide solution. Al-Tayyib, Somuah, Boah, Leblanc, and Al-Mana, 1988; S.M. Abd El Haleem, 2010 also indicated increased corrosion current of steel in calcium hydroxide solution with sodium sulfate presence.

It is well known that the alumina-containing phase of cement reacts with sulfate to form sulphoaluminate double salts, which are highly insoluble in calcium hydroxide solution. Thus it seems that the sulfate that remains after such a reaction is not sufficient to cause the destruction of the passivity. These reactions do not take place in cement extract or in calcium hydroxide solution. Ambiguous conclusions would therefore have been drawn if the effect of sulfate had been studied in simple alkaline solution. Al-Tayyib and Khan, 1991 reported only modest increase in corrosion rate of steel in concrete with up to $1.8 \mathrm{~kg} / \mathrm{m}^{3}$ sulfate by weight of concrete. Research on the role of sulfates in the corrosion of steel

Several issues of corrosion in cementitious material have yet to be elucidated. Consensus on the cause of the grout degradation (as well as definition 
of grout deficiency) and mechanism for sulfate ion accumulation has not been made. Earlier work based on field observations provided loose qualifications such as soft and chalky grout. Early reports have attributed enhanced water content and grout expiration contributing to grout degradation (Hamilton, 2014). Uniform description of corrosion activation processes of steel in relevant grout environments, (especially that conforming to the documented conditions in Florida bridges) is lacking. Relevant issues include the importance of the pore water chemistry (including $\mathrm{pH}$, alkali concentrations, and presence sulfur-bearing chemical species and how steel passivity may be impaired), chemical interactions with cement phases (including cement hydration, binding parameters, and cement degradation)(Lau et al., 2013; Lau et al., 2014).

As field evidence has shown that steel corrosion in thixotropic grouts occur where both deficient grout with high bulk moisture content and enhanced sulfate ion concentrations were observed, it is of importance to differentiate and characterize that grout deficiency, to consider the role of moisture in the formation of deficient grout and accumulation of sulfate ions, to differentiate physical and chemical grout properties by grout deficiency, and to differentiate corrosion behavior of steel by degree of grout deficiency and sulfate presence and finally identify where corrosion can occur. 


\section{RESEARCH OBJECTIVES, APPROACH, AND METHODOLOGY}

\subsection{Problem Statement}

There are several important issues that need to be addressed to resolve the failure mechanism. The first issue is not only to identify the cause of grout segregation but also possible resulting adverse changes to the grout solid matrix and pore water chemistry. It is important to consider that the physical manifestation of segregated grout alone may not necessarily cause corrosion development if the grout chemistry allows steel passivation to occur in the absence of bleed water and grout/air interfaces in void spaces. The grout chemistry in conjunction with grout consistency must be considered jointly to elucidate cause of corrosion. At this time, the role of enhanced concentrations of free sulfates is among important material parameters to be addressed. Additionally the cause of localized enhanced free sulfate concentrations has not been identified. Other important grout parameters in terms of corrosion development include adverse variation in grout porosity and electrical properties such as solution resistance.

To what extent prevention or loss of steel passivation occurs while embedded in the deficient grout needs to be addressed. Initiation of corrosion in the presences of high levels of sulfate ions if the steel had already attained stable passivity has not been found. The combined role of pore water $\mathrm{pH}$, free sulfate concentration, oxygen presence and crevice condition should be considered when identifying the level of sulfate that may contribute to corrosion initiation. 


\subsection{Objectives}

Characterization of deficient grout properties that may cause active corrosion of strand in post-tensioned tendons is needed. Important material and corrosion parameters that may need to be more comprehensively studied as well as refinement in the proposed set of criteria is to be identified. The following initiatives are proposed:

- Identify material conditions of deficient grout including determining extent of sulfate ion concentration enhancement that can cause active corrosion.

- Differentiate physical and chemical grout characteristic by grout deficiency.

- Differentiate corrosion behavior of steel by degree of grout deficiency and sulfate presence.

- Identify combined effect of enhanced chloride content and free sulfate content in deficient grout on corrosion initiation and identify practical threshold limits.

\subsection{Hypothesis}

The aggressive pore water and cement chemistry of deficient grout cause corrosion initiation of steel. Enhanced sulfate content can cause steel depassivation. Other Physical and chemical condition in deficient grout can promote corrosion development.

\subsection{Approach}

Corrosion testing was made from components of large-scale mockup 
tendons and field-extracted tendons. Smaller laboratory samples made up of grout were made as well to elucidate the role of pore water chemistry on corrosion development. Testing in laboratory-simulated conditions of deficient grout was done in duplicate. The role of moisture content, pore water $\mathrm{pH}$, sulfate ions, combine effect of sulfate and chloride ions, and cement content were explored to identify the important conditions where corrosion initiation may occur and provide rational recommendations on limit values.

\subsection{Methodology}

\subsubsection{Phase one (Grout Cylinder Tests)}

Testing of grout materials utilized two commercial pre-packaged PT grout products that were labeled here as Product A and B. Except for the variance noted below, the mixing procedures for small grout quantities followed manufacturers recommendation. Initial testing (referred to here as 'Pre-Exposed Grout') was made to evaluate the severity of grout degradation due to pre-exposure in high humidity and excess moisture content. Grout was removed from its original packaging and was placed in containers within a 100\%RH chamber for 3 or 7 days. Some grout material was exposed for up to 28 days. A control set of grout was not exposed in high humidity. In addition to possible absorbed moisture, the grouts were mixed with additional 20\% excess water (by mass of grout after exposure for treated samples) above the manufacturer recommended mix water content to enhance material deficiency. Additional test samples (referred to here as 'Expired Grout') considered grout-mixing conditions that were reported to produce deficient 
grout with enhanced bulk moisture content. For those experiments, expired-grout of Product A was mixed with $15 \%$ additional water. Furthermore, subsets of those samples (used for corrosion evaluation) contained sodium chloride and sodium sulfate. The test subsets included grout mixed with $0.08 \% \mathrm{Cl}^{-}$and $0.2 \% \mathrm{Cl}^{-}$by mass cement; and 2,000,20,000, and 150,000 ppm sodium sulfate concentrations in the mix water.

Relevant grout material parameters (that were thought possibly higher in deficient grout) included bulk conductivity, void content, and moisture content. The inverse of electrical conductivity was calculated as wet resistivity using a four-point resistance test setup. The void content was determined per ASTM C642-13. The moisture content of the grout samples was determined by gravimetric methods. The pre-exposed Grout and expired Grout samples had different curing conditions. The pre-exposed grouts (de-molded 4 days after casting) were placed in $100 \% \mathrm{RH}$ for 40 days. The expired grout samples (as part of a the Modified Incline Tube Test describe later) were cured in ambient conditions for $\sim 200$ days and then de-molded and placed in 100\%RH for 60 days. Mass change and wet resistance measurements were made during the conditioning period in high humidity. After conditioning, the samples were subjected to drying as part of ASTM C642 and also to measure moisture content.

The free sulfate concentrations in leachate from the Expired Grouts with zero amended sodium sulfate and with 20,000 and $150,000 \mathrm{ppm}$ sodium sulfate were measured by ion chromatography. Representative samples of stratified layers were collected and crushed to pass a No. 100 sieve. Three leaching procedures 
were used to elucidate the availability of sulfate ions in the pore water of deficient grout. Method 1 followed from a modified Tex-620-J method for determination of sulfates in soils as well as methodology used in earlier phases of research on deficient grout. Important leaching conditions included sample drying, leaching volume, leaching time, and leaching temperature. Method 1 included procedures to dry the powder samples at $55^{\circ} \mathrm{C}$ for 24 hours, combine $1 \mathrm{~g}$ of the dried powder with 1:10 leaching volume at $66^{\circ} \mathrm{C}$ for $15-18$ hours, and filter and dilute the leachate into $100 \mathrm{~mL}$ solution. Method 2 included procedures to use $1 \mathrm{~g}$ as received powder with 1:10 leaching volume at room temperature for 1 week, and filter and dilute the leachate into $100 \mathrm{~mL}$. Method 3 included procedures to use $\sim 12 \mathrm{~g}$ of powder as received, use 1:1 leaching volume at room temperature for 7 days, filter, and collect leachate. The results were reported as gram of sulfate per gram of powder (dry powder mass used for calculation for all three method). Total chloride content was measured following the Florida Method (FM 5-516).

Grout pore water $\mathrm{pH}$ was measured in in two different ways, ex-situ Leaching and applying the $\mathrm{pH}$ indicator on the material. Ex-situ Leaching is based on using a given amount of powder suspension of a ground concrete sample with a solvent after their equilibration which is known as the ex-situ leaching method (Behnood et al., 2016). This is a frequently used method for measuring the $\mathrm{pH}$ of soil ASTM D4972. There is no standardize or common test procedure in ex-situ Leaching, ASTM C25 is only applicable for measuring the $\mathrm{pH}$ of limestone, quicklime and hydrated lime. Hence in this research ex-situ leaching followed 
leaching procedure from method 1.Simillar method were conducted by Behnood et al., 2016, Räsänen and Penttala, 2004 and Pu, Qi, et al.2012. Beside ex-situ leaching method, small fragment of all samples sprayed with rainbow Indicator (GERMANN INSTRUMENTS, Inc). In order to measure the $\mathrm{pH}$ of the cement paste, a freshly broken piece of concrete or a newly cut core is sprayed with the indicator, and allowed to dry. The approximate $\mathrm{pH}$ of the paste is indicated by colors as illustrated below.

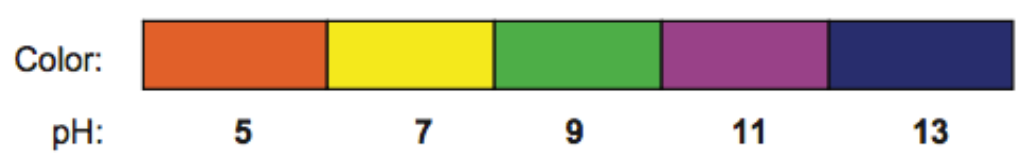

Figure 3.1: pH Range by Color for German Instruments $\mathrm{pH}$ Indicator

3.6.2.Phase two (Modified incline tube test (MIT))

Corrosion behavior of steel in expired Grout was measured in large mock up tendons followed by Modified incline tube test (MIT). All MIT samples were cast with expired grout materials in non-ideal conditions in order to promote grout deficiencies. Only one grout product was utilized in these experiments (Grout A) .All grout materials used were past marked expiration dates and at least excess $15 \%$ mix water over manufacturers recommended high end limit was added. Batching and mixing was conducted at the State Materials Office (SMO) using a high shear grout plant (Figure 3.2). 


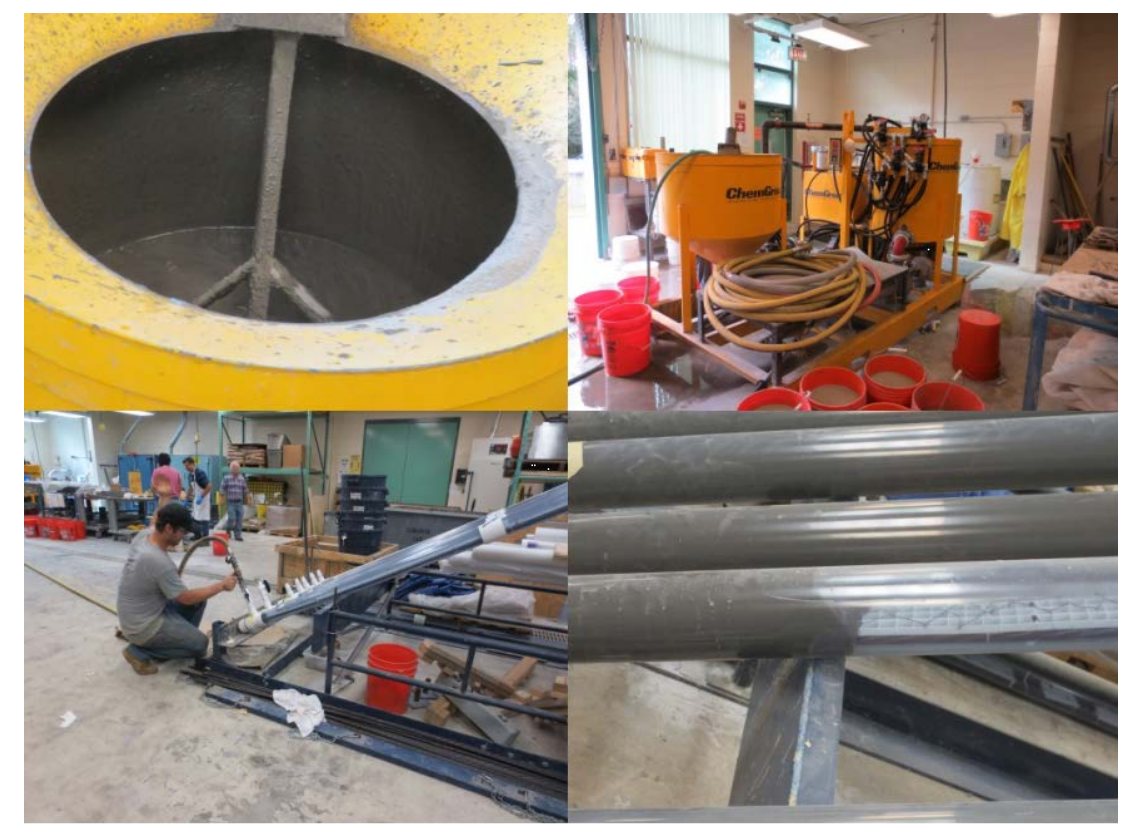

Figure 3.2. Grout Batching, Mixing, and Pumping Sequence

The MIT test provided the benefit to assess the extent of corrosion with varying degrees of grout deficiency due to pumping procedures and possible segregation due to vertical elevation deviation. Fifteen foot long tendon with 4 inch diameter PVC mockups were cast at a $30^{\circ}$ incline with expired grout and $15 \%$ excess mix water .One set of samples was considered a base case of deficient grout with no external additions of aggressive chemical ions. A second set of samples contained $\sim 0.09 \%, 0.9 \%$, and $\sim 5.5 \%$ sulfates by cement mass. The third set of samples contained $\sim 0.08 \%$ and $\sim 0.2 \%$ chlorides by cement mass (Test condition listed in Table 3.1). In these samples, two 7-wire strands were embedded. Clear PVC was used so that grout anomalies could be viewed. Figure 3.3 shows some of the samples after casting. The samples contained embedded corrosion probes (including embedded activated titanium reference and counter 
electrodes) along the length of the tendon. Duplicate tendons were made for each condition.

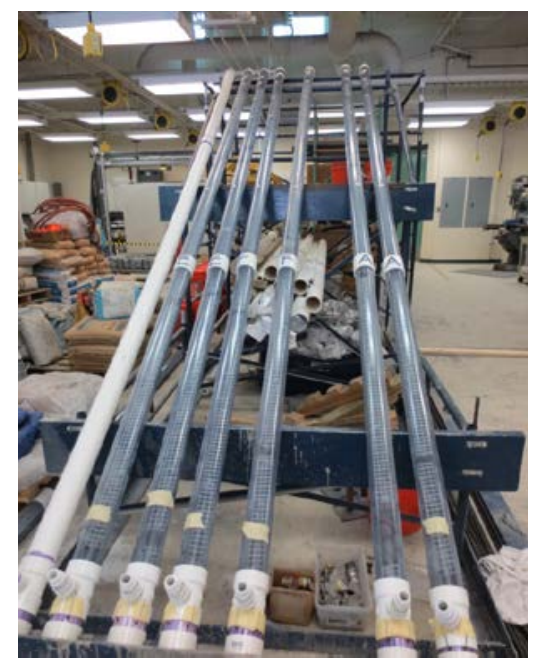

Figure 3.3: Photos of $15 \mathrm{ft}$. Lab Casted Mock up Tendons (Modified Incline Tube Test (MIT))

The corrosion potential (OCP) was measured with a copper/copper-sulfate reference electrode via access points along the length of the tendon. Corrosion currents of embedded steel probes were measured by linear polarization resistance method. Linear Polarization Resistance monitoring is an effective electrochemical method of measuring corrosion. Corroding system can be characterized by artificially changing its potential from its OCP by a small amount and measuring polarization resistant, which is the ratio of changes in the potential to a change in current density. Corrosion current density of embedded steel s was calculated from linear polarization resistance method following Equation 14:

$$
\text { icorr }_{\text {co }}=\frac{B}{\operatorname{Rp} \times A}
$$


Where the Stern-Geary Coefficient, B, was assumed to be $26 \mathrm{mV}$ for active corrosion conditions. Rp is the resolved measured polarization resistance, and A is the area of the probe exposed to the grout. Solution resistance was measured with a soil resistivity meter using a three-electrode configuration.

After these testing, the tendons were opened to conduct chemical analysis to quantify the levels of sulfates and other important ions along the length of the tendons. The samples were collected from top section ( $\sim 0.3 \mathrm{ft}$. from top) and bottom section ( $\sim 7 \mathrm{ft}$. from top).

Table 3.1: Grout Mix Condition for Modified Incline Tube Test (MIT) (Grout Condition: E=Expired)

\begin{tabular}{|c|c|c|c|c|}
\hline $\begin{array}{c}\text { Grout } \\
\text { Product }\end{array}$ & $\begin{array}{c}\text { Grout } \\
\text { Condition }\end{array}$ & $\begin{array}{c}\text { Test } \\
\text { Cases }\end{array}$ & $\begin{array}{c}\text { Sulfate amount } \\
\text { (ppm) }\end{array}$ & $\begin{array}{c}\text { Chloride amount } \\
\text { (\%by cement) }\end{array}$ \\
\hline \multirow{4}{*}{ A } & E & A & 0 & 0 \\
\cline { 3 - 5 } & & B & 0 & 0.08 \\
\cline { 3 - 5 } & & C & 0 & 0.2 \\
\cline { 3 - 5 } & & D & 2000 & 0 \\
\cline { 3 - 5 } & & E & 20,000 & 0 \\
\cline { 3 - 5 } & & F & 150,000 & 0 \\
\hline
\end{tabular}

3.6.3.Phase three (Inverted Tee test (INT))

Small laboratory sample were cast with 32 days pre-exposed Grout A and B. These samples were casted in $\left(2 \times 2 \times 1 \frac{1}{2}\right.$ " $\varnothing, 43 \frac{3}{4}$ "length) $P V C$ tee and mix with $20 \%$ excess water with varying sulfate and chloride addition for test condition as listed in Table 3.2. As the schematic shows (Figure 3.4), the samples contained embedded high strength carbon steel wire within the tee header as well as within the tee body. Activated titanium rod that was routinely calibrated with a copper/copper-sulfate reference electrode was used as the reference electrode and a stainless steel rod was used as the counter electrode. 
The PVC tee was expected to facilitate volume displacement of the deficient grout material to the tee header and allow discrete testing and sampling of the deficient grout materials. The test is called here as Inverted Tee test (INT). The control set of the samples casted with as received Grout A and B, using the manufacturer recommended mix water content containing different sulfate concentration (0 ppm, 2000 ppm, 20,000 ppm).After 1-2 days from casting ,the samples were sealed either with Sikadur epoxy or permanent PVC cap.
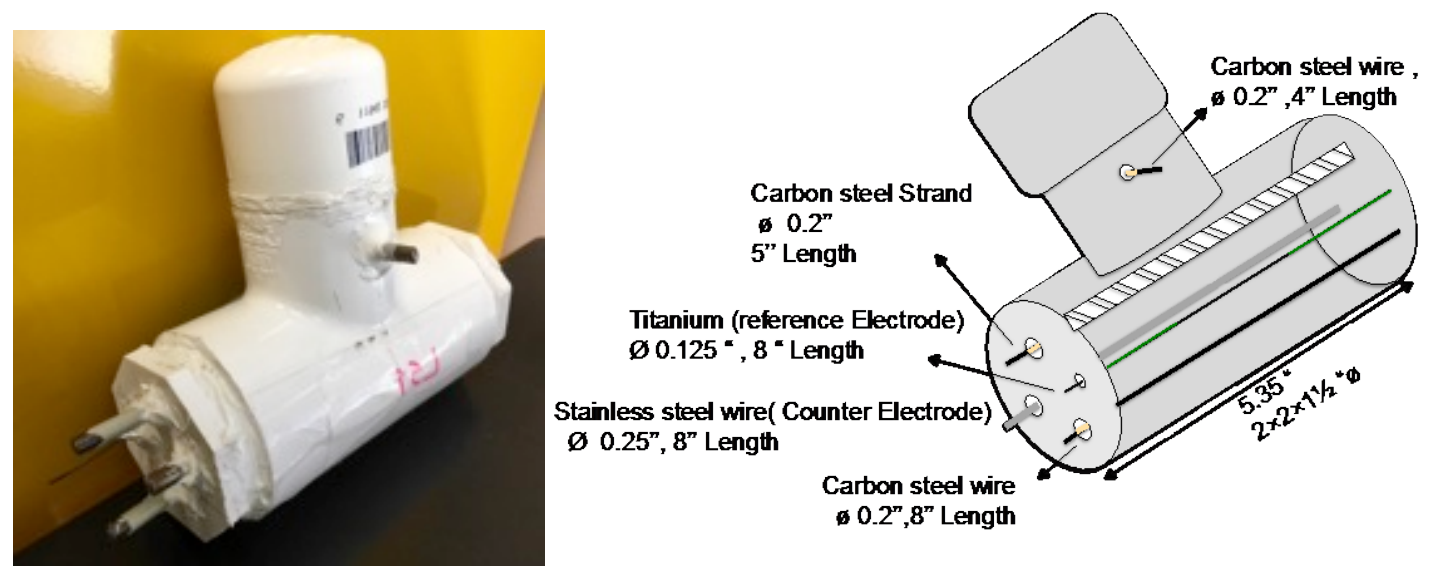

Figure 3.4: Schematic of INT Test Samples

The corrosion potential (OCP) was measured with a copper/copper-sulfate reference electrode. The polarization resistance of embedded steel probes was measured by linear polarization resistance method, and solution resistance was measured with a soil resistivity meter. After electrochemical testing, chemical analysis of the grout was made to quantify the levels of sulfates and chloride in the stratified grout layers. A modified test procedure adapted from TX-620-J, was followed for sulfate analysis and the total chloride content, was measured following 
FM 5-516. The samples were also subjected to drying as part of ASTM C566-13 to measure moisture content. Grout pore water $\mathrm{pH}$ was measured a $\mathrm{pH}$ spray indicator.

Table 3.2: Grout Mix Condition for Inverted Tee test (INT) (Grout Condition: $\mathrm{p}=$ Pre-exposed, A=As-received)

\begin{tabular}{|c|c|c|c|c|}
\hline $\begin{array}{c}\text { Grout } \\
\text { Product }\end{array}$ & $\begin{array}{c}\text { Grout } \\
\text { Condition }\end{array}$ & $\begin{array}{l}\text { Test } \\
\text { Cases }\end{array}$ & $\begin{array}{c}\text { Sulfate amount } \\
(\mathrm{ppm})\end{array}$ & $\begin{array}{c}\text { Chloride amount } \\
\text { (\%by cement) }\end{array}$ \\
\hline \multirow[t]{12}{*}{$\mathbf{A}$} & \multirow[t]{12}{*}{$\mathbf{P}$} & 1 & 0 & 0 \\
\hline & & 2 & 2000 & 0 \\
\hline & & 3 & 20,000 & $\mathbf{0}$ \\
\hline & & 4 & 100,000 & 0 \\
\hline & & 5 & 0 & 0.08 \\
\hline & & 6 & $\mathbf{0}$ & 0.2 \\
\hline & & 7 & 2000 & 0.08 \\
\hline & & 8 & 20,000 & 0.08 \\
\hline & & 9 & 100,000 & 0.08 \\
\hline & & 10 & 2000 & 0.2 \\
\hline & & 11 & 20,000 & 0.2 \\
\hline & & 12 & 100,000 & 0.2 \\
\hline \multirow[t]{4}{*}{ B } & \multirow[t]{4}{*}{$\mathbf{P}$} & 1 & 0 & $\mathbf{0}$ \\
\hline & & 2 & 2000 & $\mathbf{0}$ \\
\hline & & 3 & 20,000 & $\mathbf{0}$ \\
\hline & & 4 & 100,000 & 0 \\
\hline \multirow[t]{3}{*}{$\mathbf{A}$} & \multirow[t]{3}{*}{$\mathbf{A}$} & 1 & 0 & $\mathbf{0}$ \\
\hline & & 2 & 2000 & $\mathbf{0}$ \\
\hline & & 3 & 20,000 & 0 \\
\hline \multirow[t]{3}{*}{ B } & \multirow[t]{3}{*}{$\mathbf{A}$} & 1 & 0 & $\mathbf{0}$ \\
\hline & & 2 & 2000 & 0 \\
\hline & & 3 & 20,000 & $\mathbf{0}$ \\
\hline
\end{tabular}




\section{RESULTS}

\subsection{Grout Cylinder Test}

As indicated in the section 3.5, two grout sample preparation methodologies were followed. In the test setup, to consider the impact of early moisture availability to the grout as pre-exposure before casting (Pre-Exposed Grout), the grout powder was placed in high humidity conditions. As shown in Figure 4.1, Grout product A and $\mathrm{B}$ had less than $1 \%$ moisture in the as-received condition. Sampling of the powder after exposure showed increase in moisture content in the raw grout material. As much as 5\% moisture content was measured. The grout was stored in plastic bins that were kept in $100 \% \mathrm{RH}$ chambers. Although the moisture content of the exposed grout initially at the top portion of the containers could have had the most moisture uptake, the sampling of the raw grout was made after mixing of the material to determine the overall grout quality. The mixing of the grout powder was subjective and indeed, variability in the measurements was shown where the sampling of grout exposed for 3-days yielded higher moisture content than the 7 day and 28 day exposure. Nevertheless, all exposure conditions created physical changes such as clumping in the raw grout. The grout in the as-received condition and exposed to high humidity for 3 and 7 days were mixed with $20 \%$ excess mix water content and cast into 3 inch diameter cylinder molds. After initial curing, some portions of the Grout B separated due to segregation but Grout A samples form uniform hard material (Figure 4.2), As shown in Figure 4.3, the relative percent volume of the top segregated material in grout product B was $10-20 \%$. 
Each segment was treated as individual samples except for some samples that were made from non-pre-exposed Grout B (used for resistivity measurements) where the segregated grout was well adhered to hardened grout portion. Each segment was placed into 100\%RH chambers (Figure 4.2).

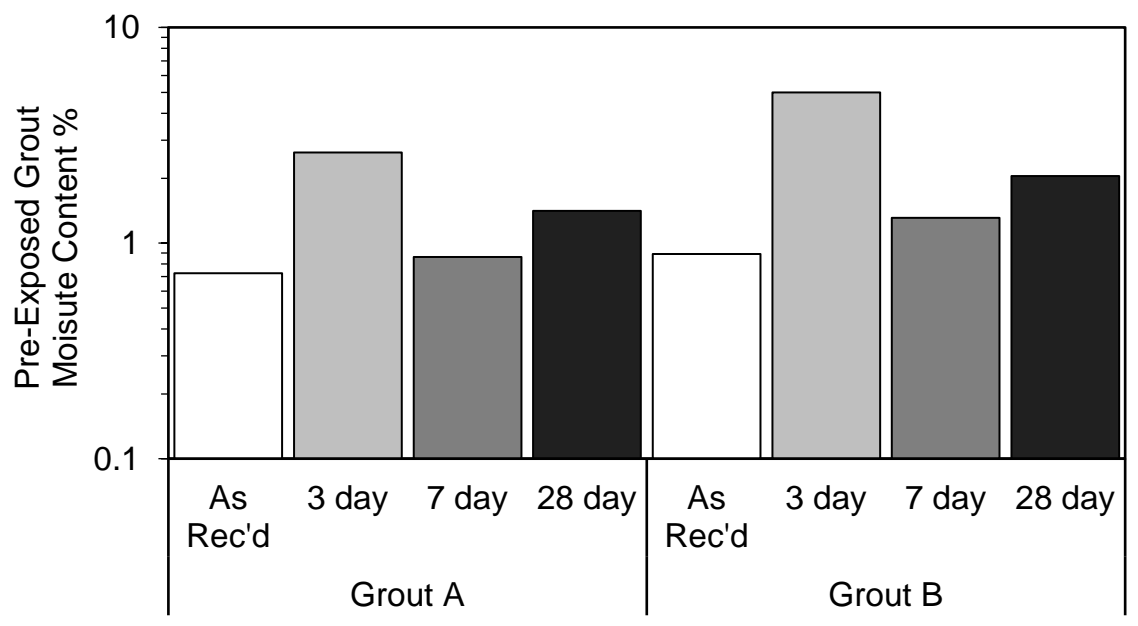

Figure 4.1: Moisture Content of the Powder After Exposure

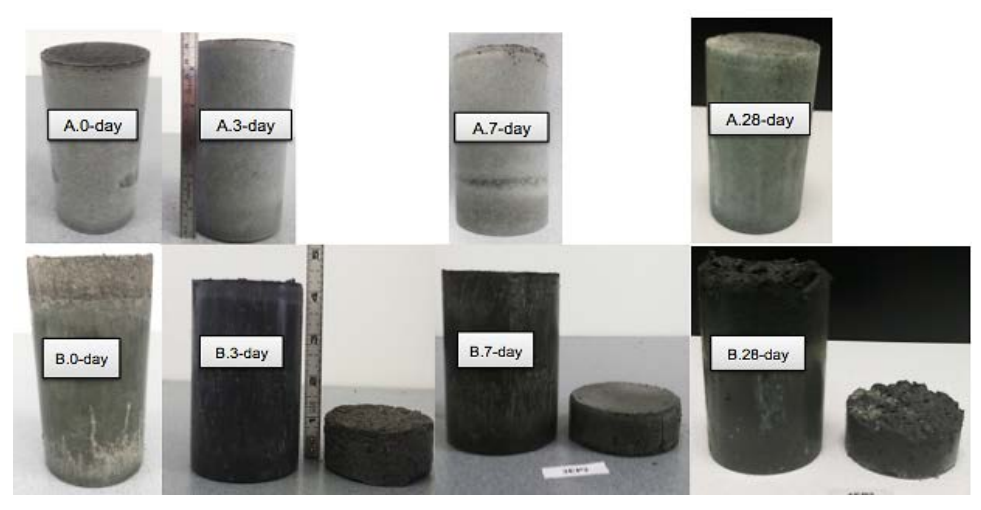

Figure 4.2: Pre-Exposed Grout Products A and B Cylinder Samples 


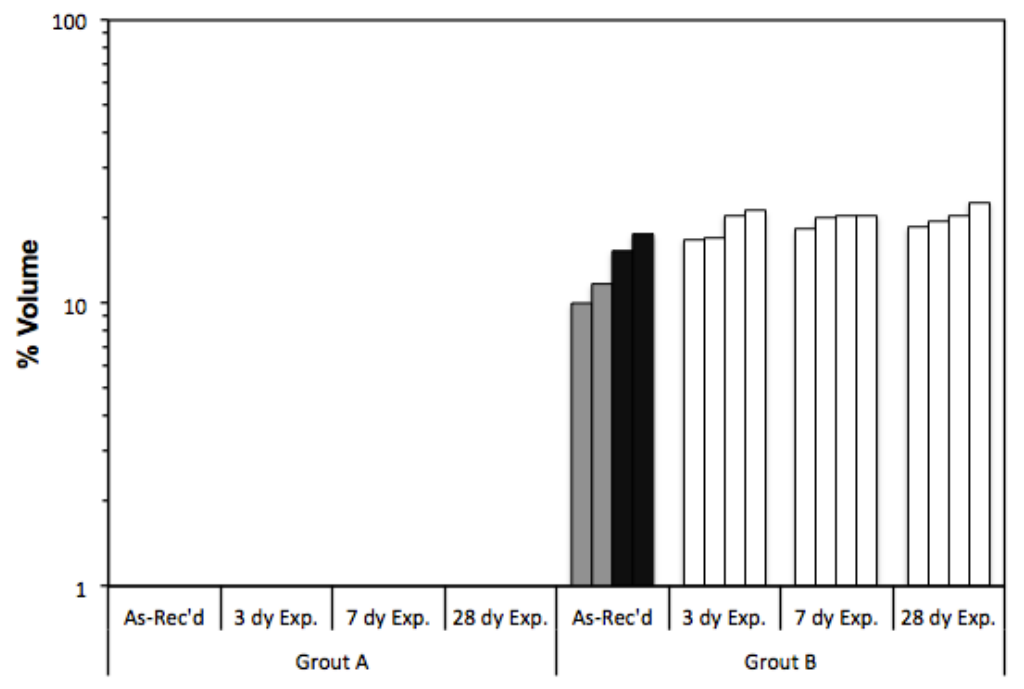

Figure 4.3: Percent Volume of Segregated Grout

(White bars: Segregated grout layer separated after de-molding. Gray bars: Segregated grout layer separated during testing. Black bars: Segregated grout layer adhered.)

Similar grout cylinder samples had been cast $\sim 200$ days earlier (Expired Grout) as part of the Modified incline tube (MIT) test containing expired grout with excess $15 \%$ mix water for corrosion testing that will be described later. Those mature grout samples were likewise placed in $100 \% \mathrm{RH}$ chambers.

Investigation of the level of deficiency, which was created in first step by incorporating the pre-exposed /expired grout and additional mixing water ratio, can be approached by examination of physical, chemical and electrical properties. Moisture and void content and wet resistivity of the samples were measured and plotted in Figures below (Figures 4.4-5). 

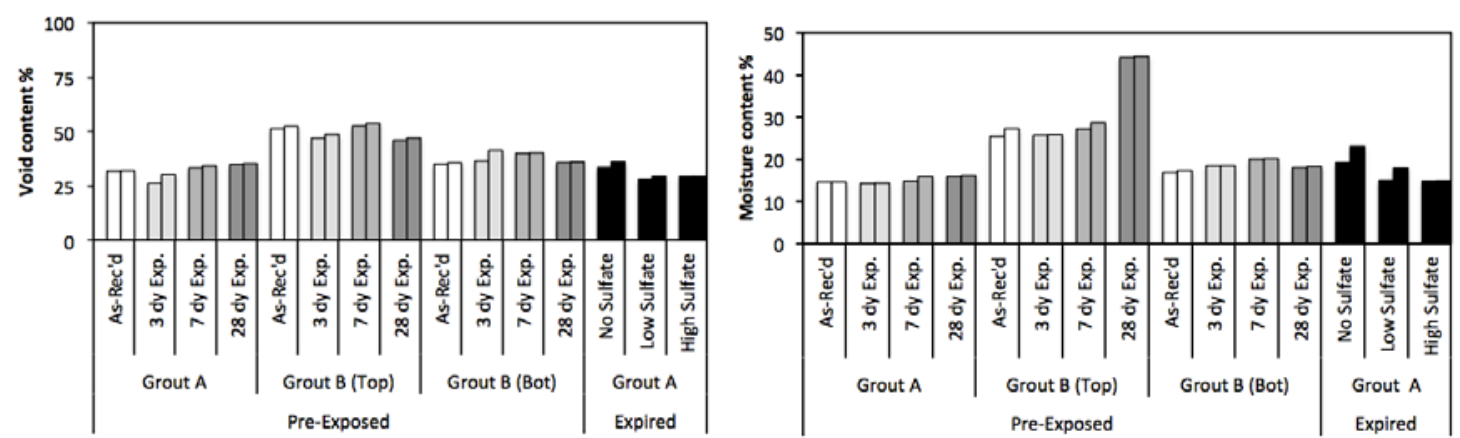

Figure 4.4: Moisture and Void Content for Grout Cylinder Test
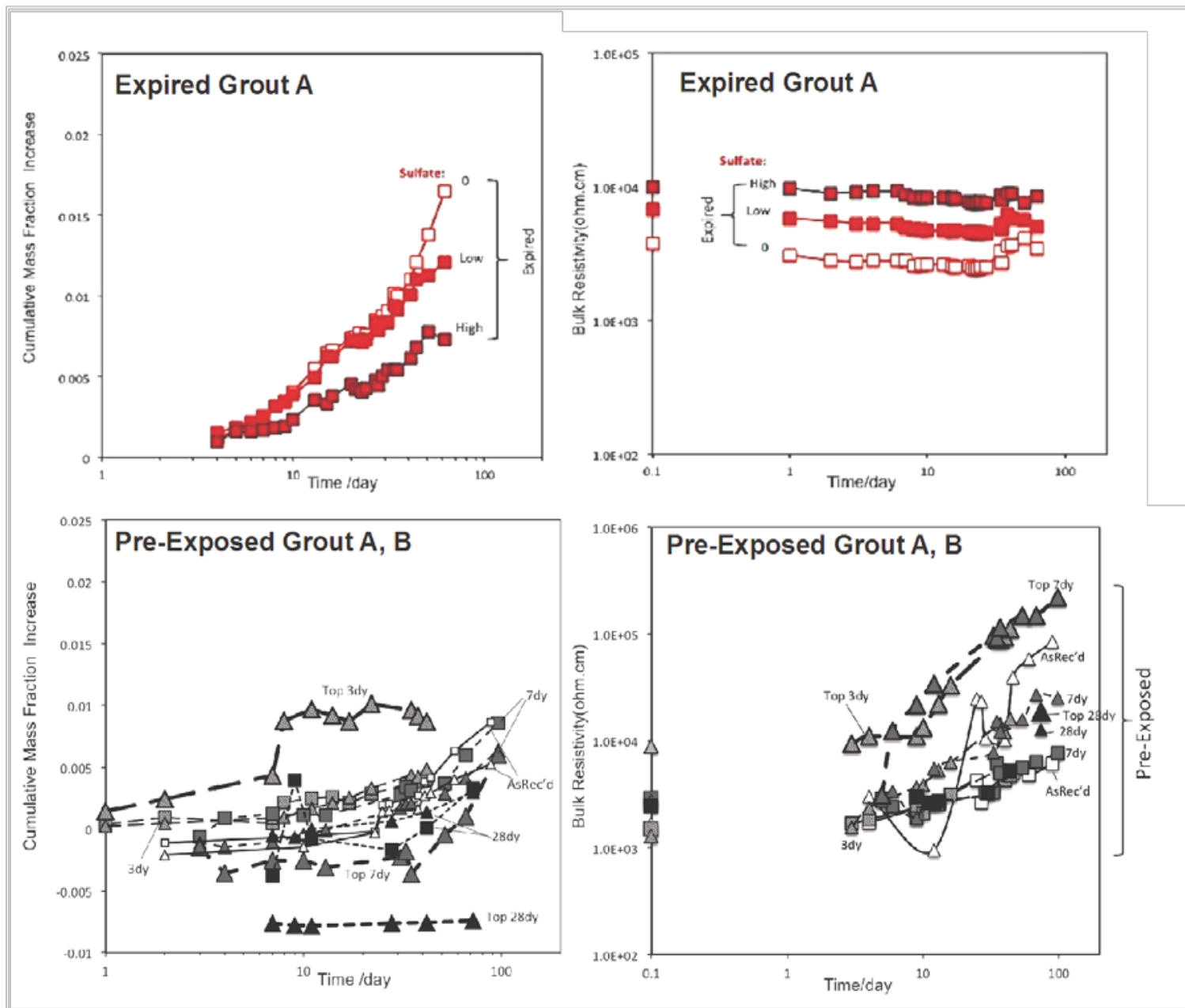

Figure 4.5:Moisture Uptake and Grout Wet Resistivity for Grout Cylinder Test (Square: Grout product A. Triangle: Grout product B)

(Med Sulf: 20,000ppm/High Sulf: 150,000 ppm) 
As part of the work, identification of sulfate ion accumulation in laboratory created (and defined) deficient grout was of importance. Grout samples collected from the outflow of pumped grout in MIT test and Pre-exposed Grout A and B (Mix samples from top and bottom) were collected and analyzed for sulfate ions.

The expired grout samples all showed varying layers along the 6-inch height (Figure 4.6). Although none of the layers had the degree of deficiency as observed in the field, the textures of the layers (especially at the top) were synonymous with grout segregation. Representative samples of those layers were collected for sulfate analysis (Figure 4.7). As a comparison, field samples were also collected for sulfate analysis with the three leaching method (Figure 4.8).

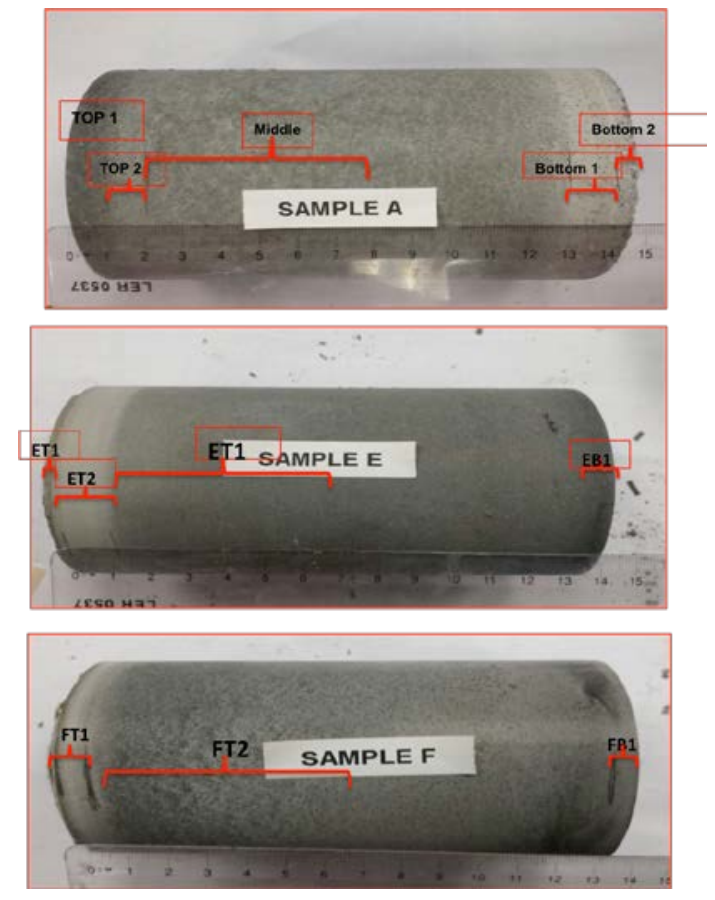

Figure 4.6: Photos of Stratified Layer in Expired Grout Samples Collected from the Outflow of Pumped Grout in Modified Incline tube test (MIT) 


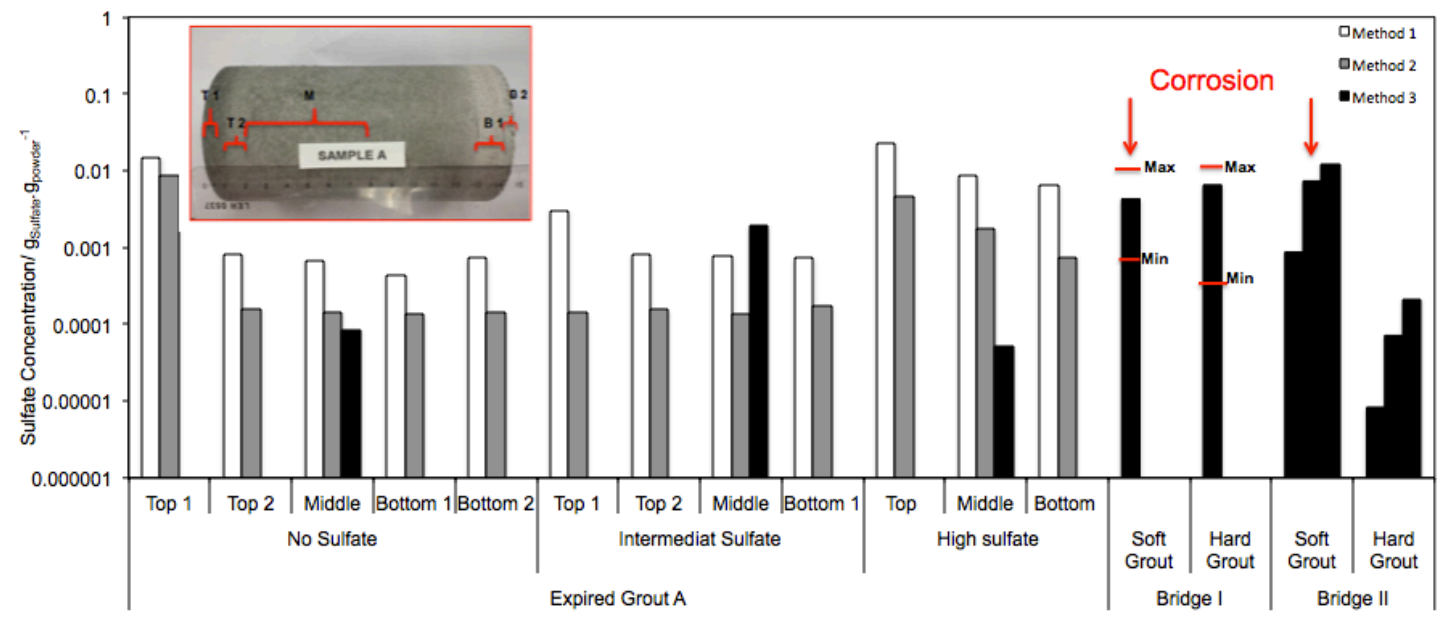

Figure 4.7: Sulfate Concentration for Expired Grout and Field Samples (Med Sulf: 20,000ppm/High Sulf: 150,000 ppm)

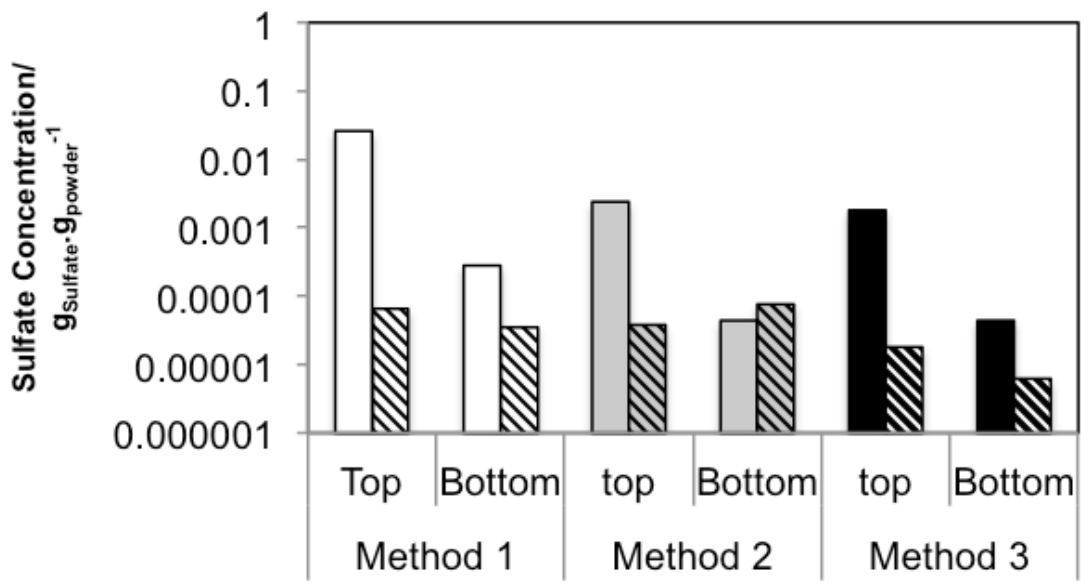

Figure 4.8: Sulfate Concentration for Bridge I by Three Methods

As shown in Figure 4.2, pre-exposed Grout B after exposure formed two segments, which became completely detached after initial set. Chemical analysis was made for sample collected from both segments (Figures 4.9-4.11). 


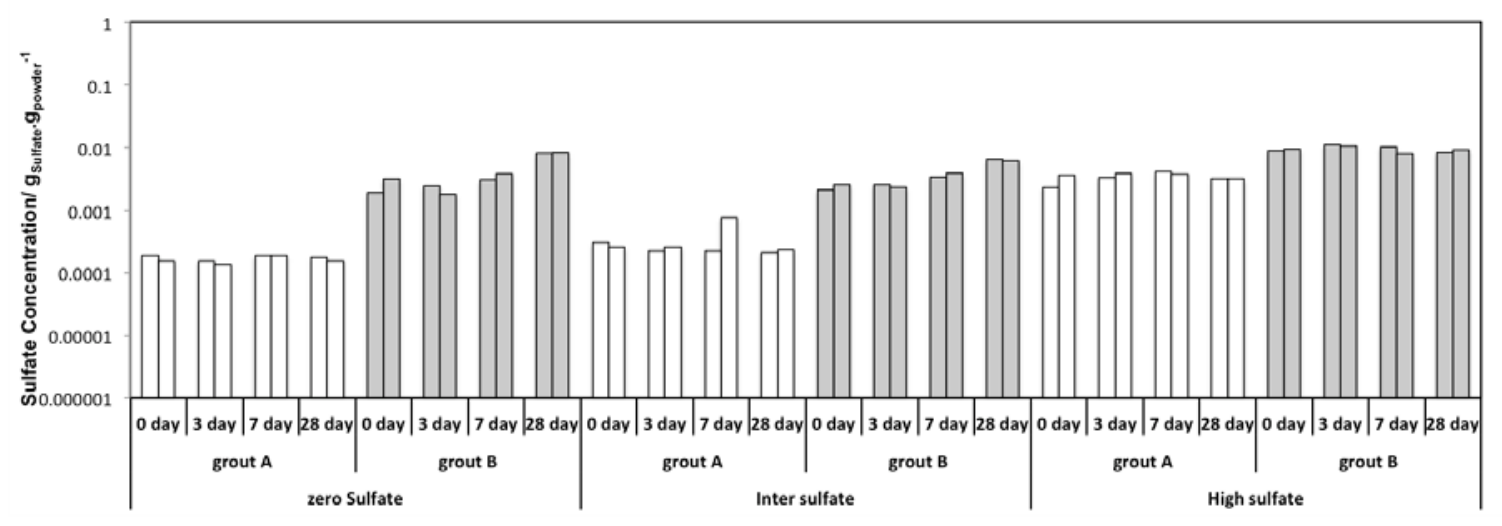

Figure 4.9: Sulfate Concentration for Grout Cylinder Test

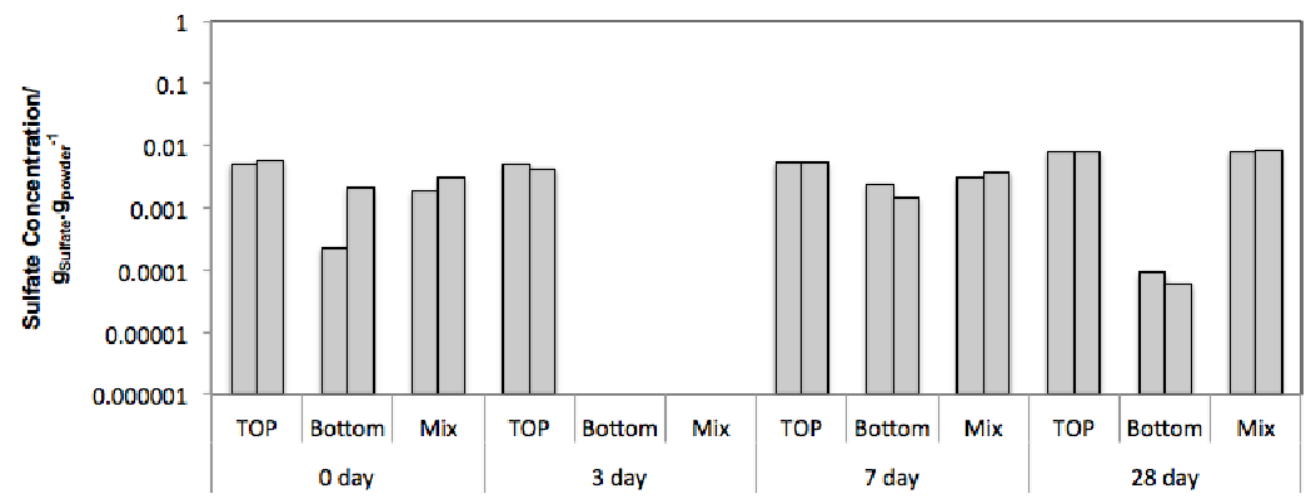

Figure 4.10: Sulfate Concentration for Grout Cylinder Test with Pre-Exposed Grout B (Top, Bottom, Mix)

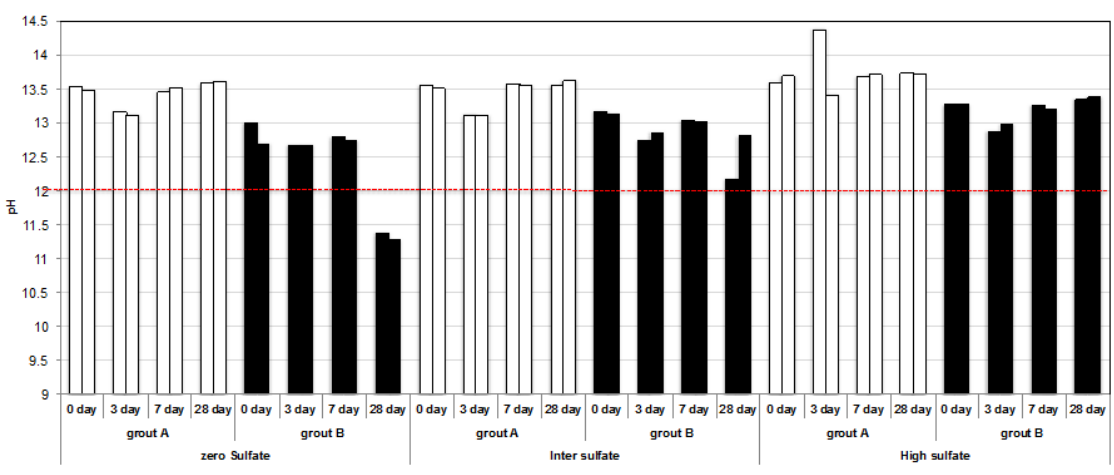

Figure 4.11:pH Results by Ex-Situ Leaching for Grout Cylinder Test 


\subsection{Modified Incline Tube Test (MIT)}

The MIT test was used to verify corrosion activity of steel stand embedded in deficient grout in large scale test assemblies that would better represent material conditions found in Florida bridges where PT strand corrosion occurred. The primary objective was to identify steel corrosion in deficient grout such as that found in the Florida bridges, but the causes of that grout segregation was not yet fully identified and the mechanism of the formation of grout segregation in relevant materials continues to be controversial. Based off of findings from other research, it was assumed that large-scale samples would be required to promote adequate levels of grout segregation (Hamilton, 2015). The modified inclined tube test was adopted here. Other grout mixing variables included the use of excess mix water and the use of expired grout materials. Enhancement of chloride and sulfate ion content was included to help elucidate the roles of those chemicals in corrosion development.

Steel corrosion probes were embedded along the length of the large mockup tendon samples. Two corrosion probes were located within $1 \mathrm{ft}$. of the top of the inclined tendon. Three corrosion probes were located at lengths $1<1<5 \mathrm{ft}$. from the top of the tendon. Averages for measurements for the two top corrosion probes on each tendon and its replicate tendon and averages for the bottom three probes on each tendon and its replicate tendon were reported. 


\subsubsection{Visual Observation}

Severe material segregation was observed in the elevated portion of MIT test (Figures 4.12-13). Variability of the level of segregation was observed in different samples. It was apparent that the elevated portion of the zero and medium sulfate samples ( $A$ and $E$ ) had higher segregation as exhibited by having higher content of soft material.

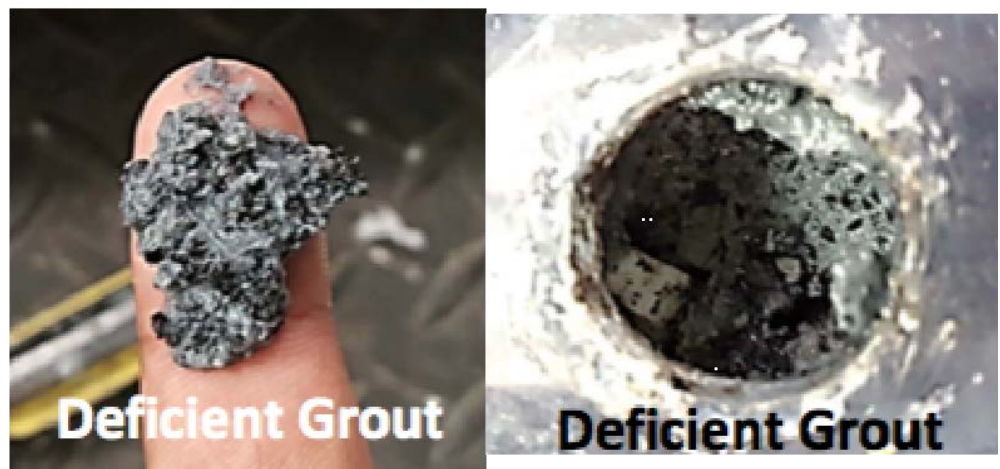

Figure 4.12: Photos of Deficient Grout from MIT Test. (The location showed was adjacent to a probe location at $\sim 0.3 \mathrm{ft}$. from the top of sample A)

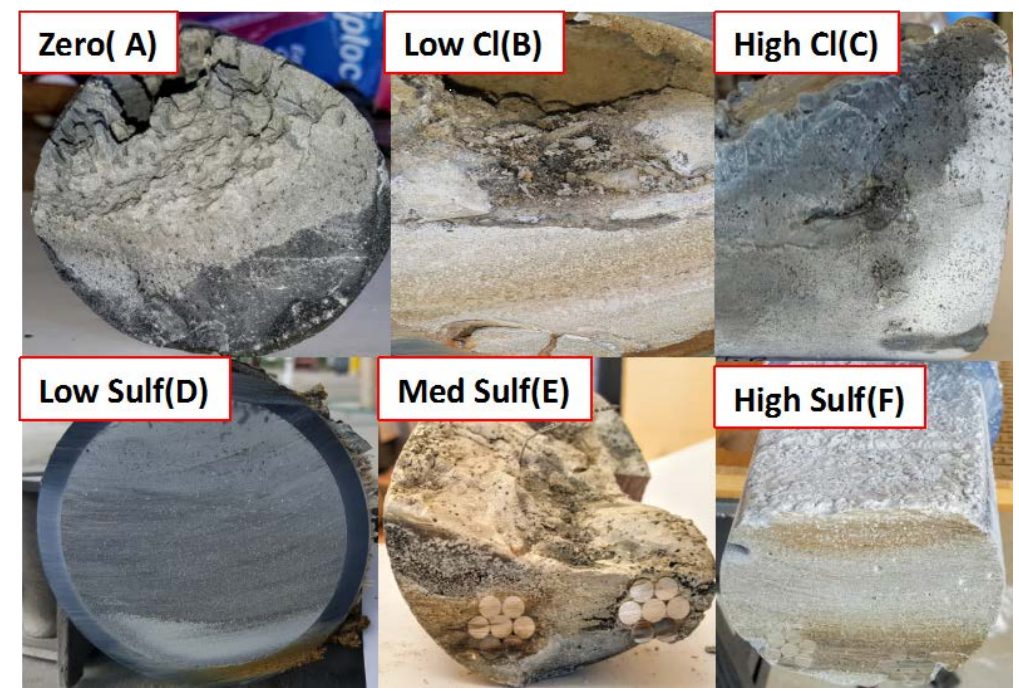

Figure 4.13: Photos of Deficient Grout in the Elevated Portion of MIT Test 


\subsubsection{Moisture Content}

Figure 4.14 show moisture content analysis of grout for MIT test samples. Mostly all the elevated portion in MIT test samples had higher moisture content than the bottom section. The moisture content of segregated grout samples with zero and medium sulfate additives ( $\mathrm{A}$ and $\mathrm{E}$ ) were as high as $70-80 \%$.

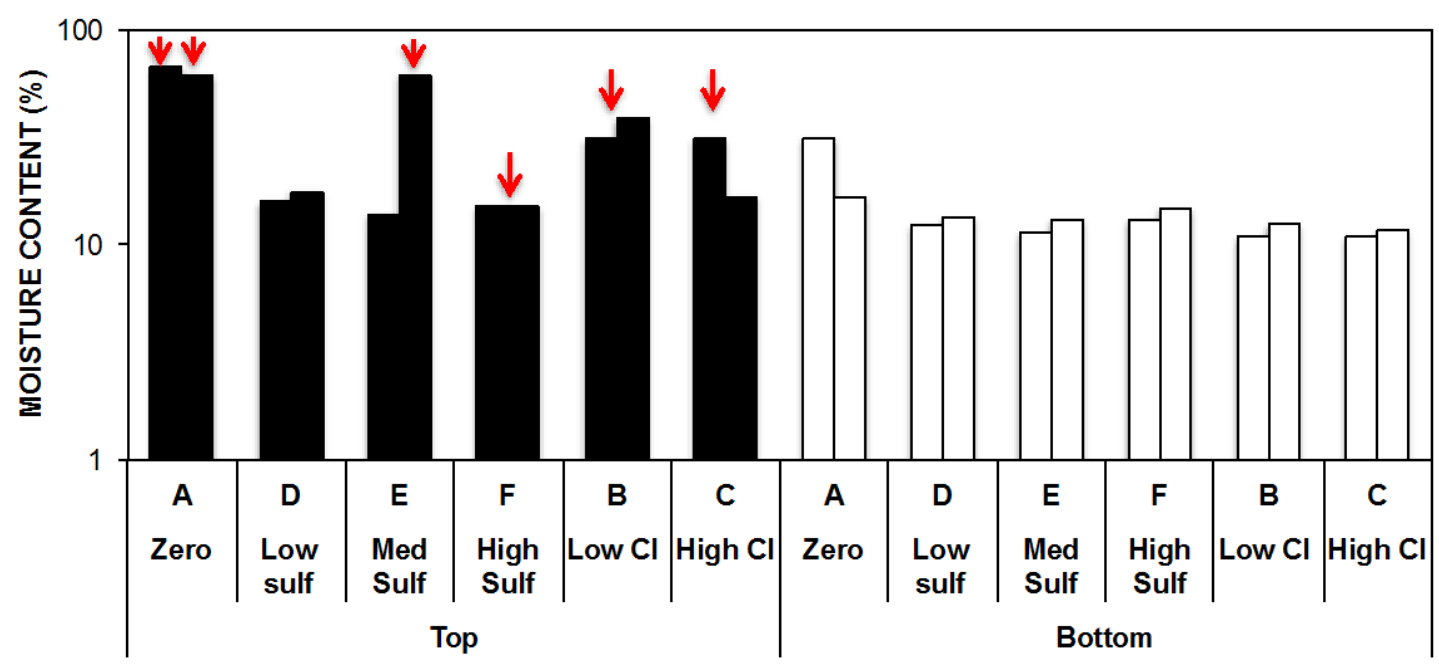

Figure 4.14: Moisture Content of the Grout from MIT Test Samples (red arrows show where corrosion occurred)

\subsubsection{Electrical Properties}

Solution resistance measurements are shown in Figure 4.15; variability in the measurements is shown with high and low dash marks. Lower solution resistance was observed in all the elevated portion of MIT test samples, while all the bottom section had higher solution resistance. 


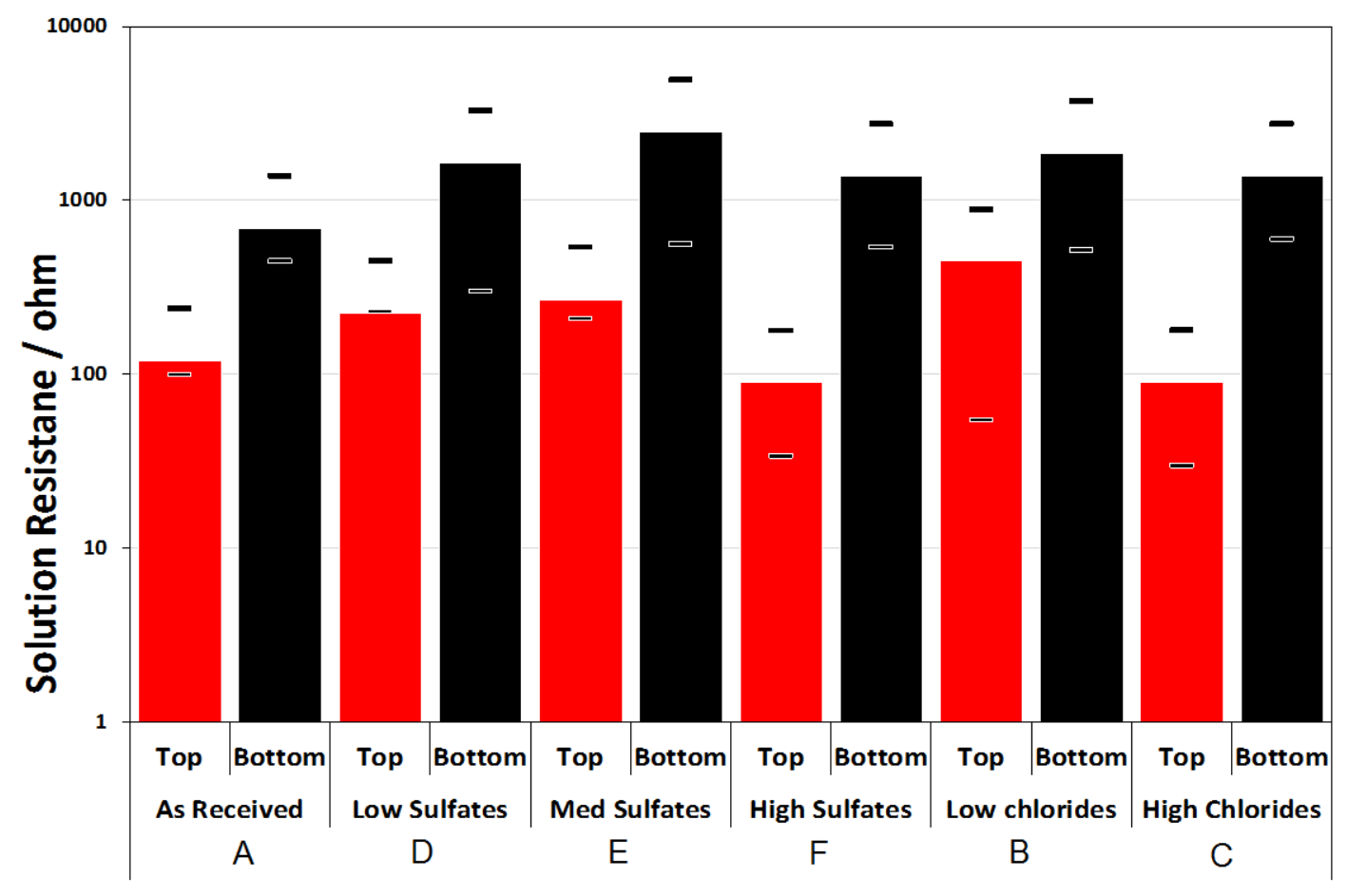

Figure 4.15: Solution Resistance of Grout from MIT Test Samples

\subsubsection{Chemical Analysis}

As part of the work, identifying sulfate ion accumulation in laboratory created (and defined) deficient grout was of importance. After completion of corrosion investigation, different samples were collected from $14.7 \mathrm{ft}$. and $7 \mathrm{ft}$. for sulfate/chloride analysis and $\mathrm{pH}$ measurement (Figure 4.16-19). Higher sulfate concentration was observed in elevated portion. On the other hand, in order to have the profile of chemical characteristic of grout in MIT test samples(Case A), samples were collected along the length of tendons close to each of the corrosion probes (Figure 4.18). 


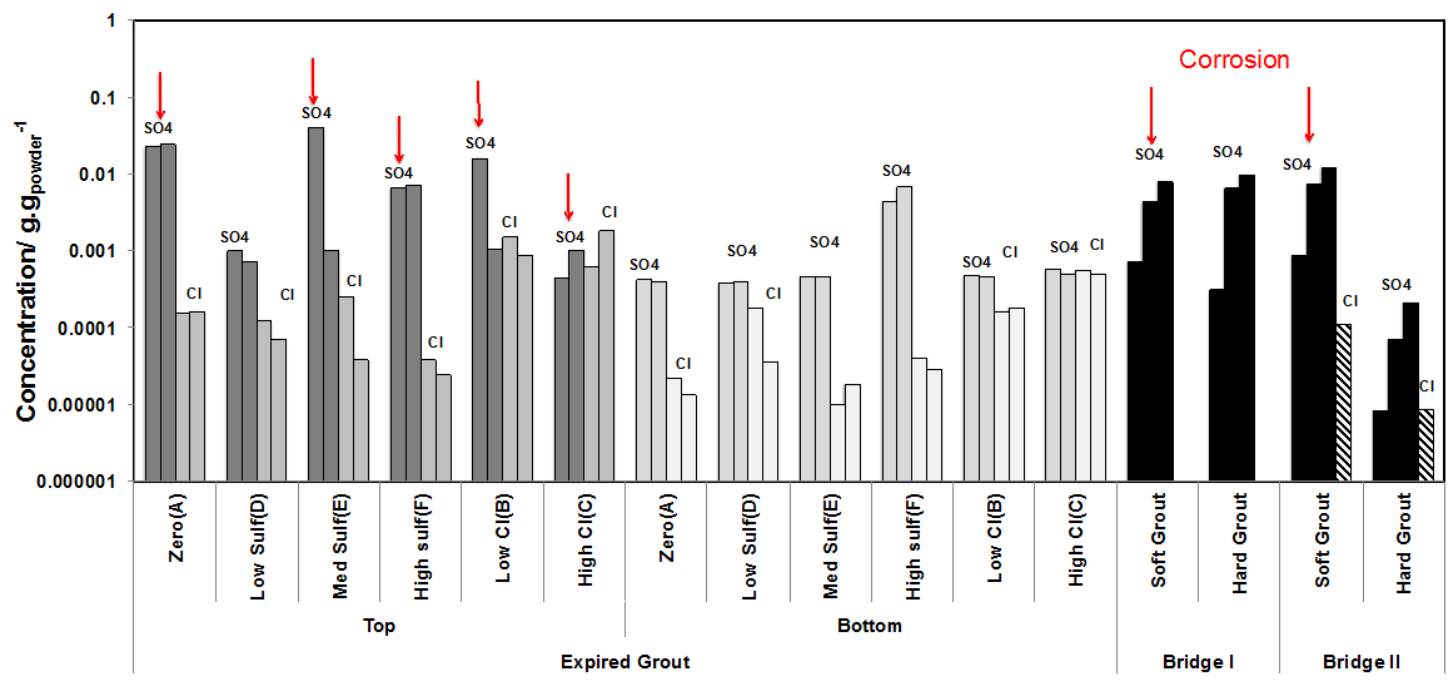

Figure 4.16: Sulfate and free Chloride Concentration of Grout from MIT Test Samples (red arrows show where corrosion occurred)

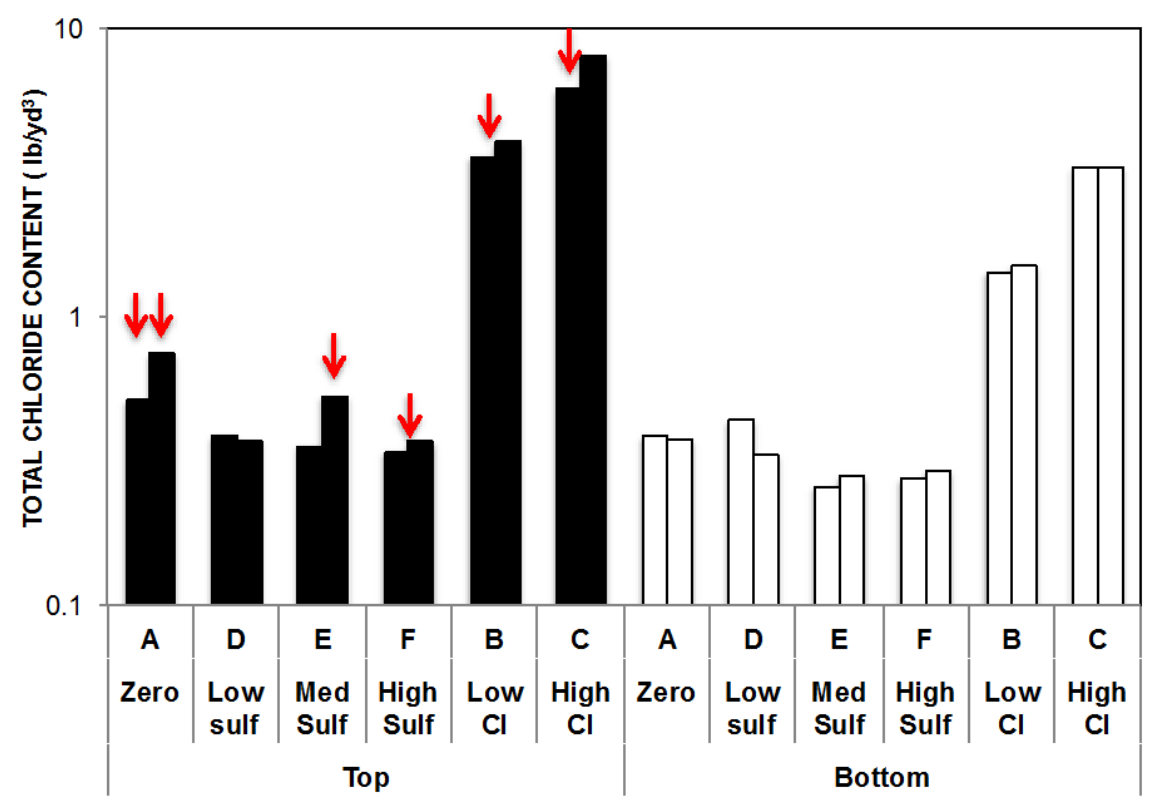

Figure 4.17: Total Chloride Content of Grout from MIT Test Samples (red arrows show where corrosion occurred) 

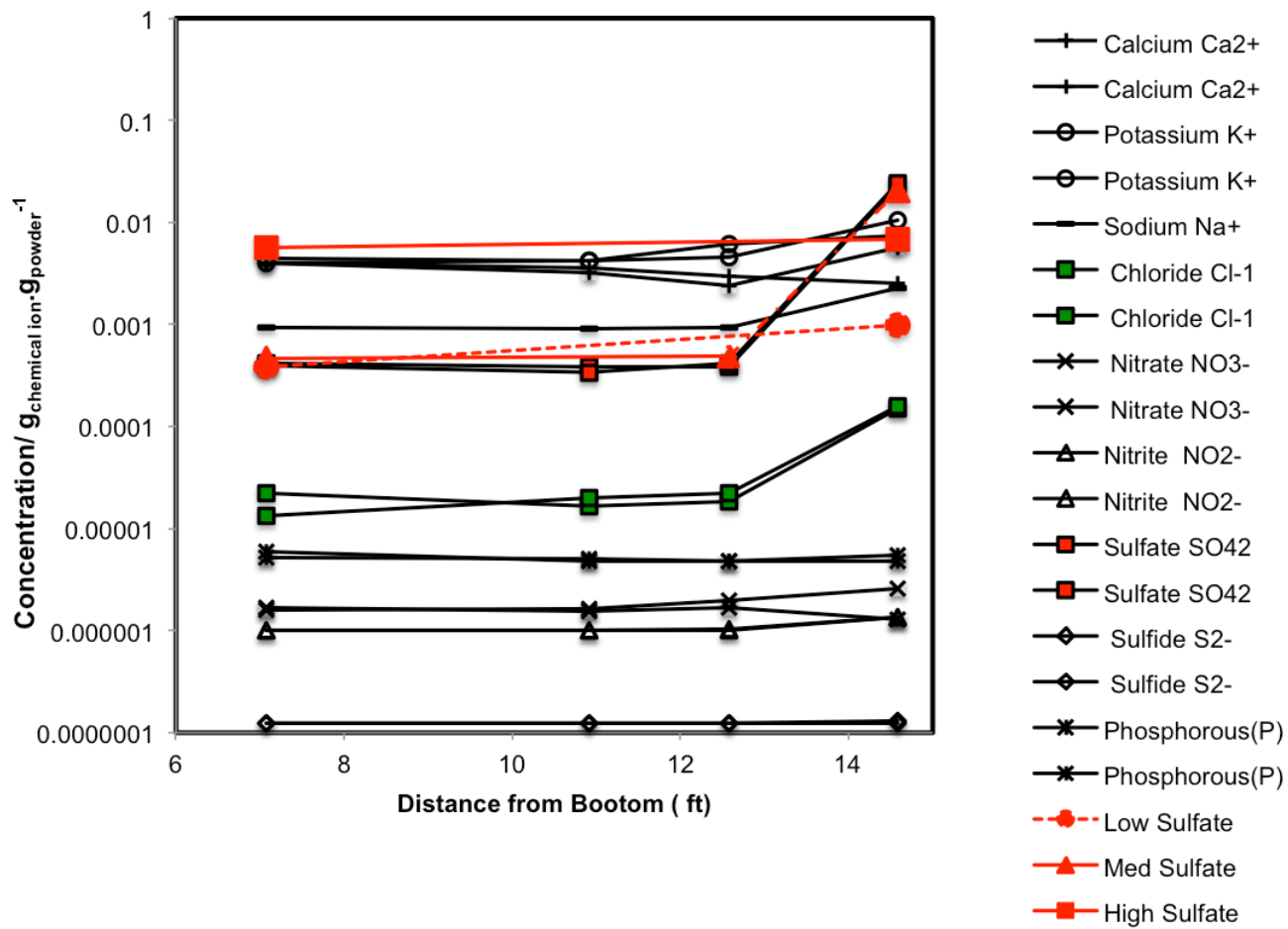

Figure 4.18:Chemical Characteristic Profiles along $15 \mathrm{ft}$. of MIT Tests (Case A)

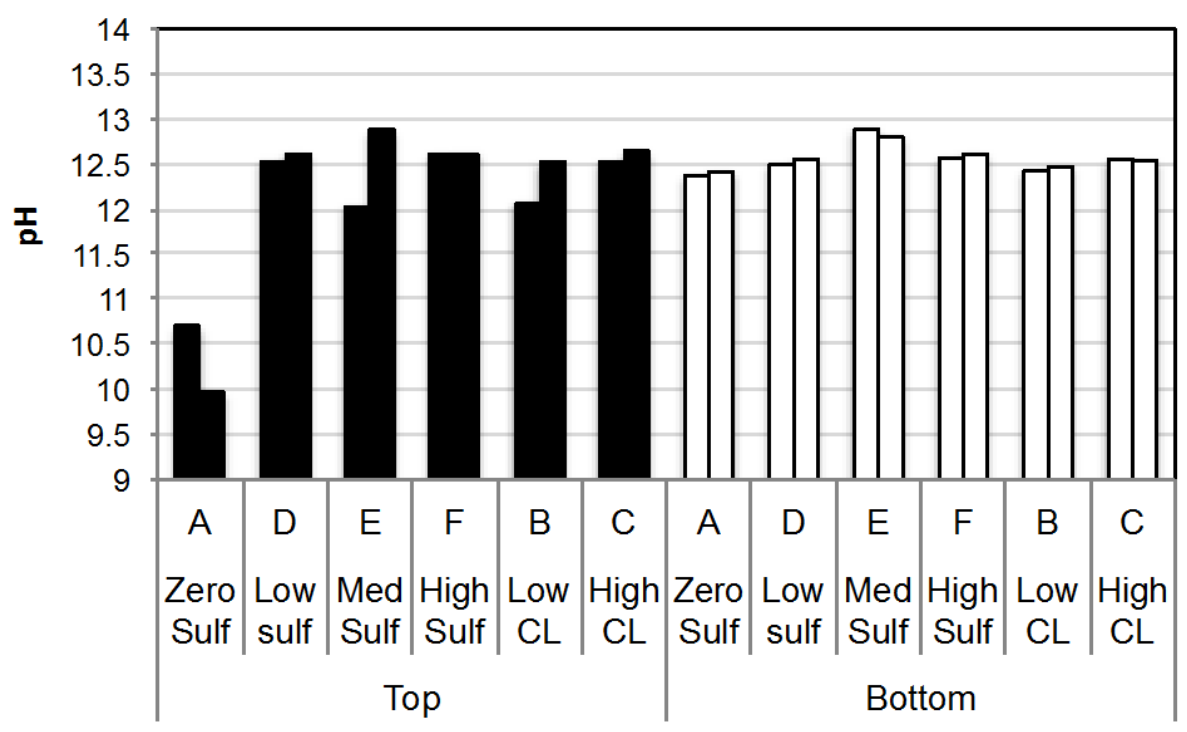

Figure 4.19:pH Measurements of Grout from MIT Test Samples by Ex-situ Leaching 
The results of $\mathrm{pH}$ tests from the ex-situ leaching method are shown in Figure 4.19. Results showed that the $\mathrm{pH}$ was typically greater than 12 . For the grout sample with zero additives (A), the leaching method resulted in a $\mathrm{pH}$ lower than 11; however testing with the $\mathrm{pH}$ indicator showed $\mathrm{pH}$ greater than 11(Figure 4.20). The results for all other test locations sprayed with $\mathrm{pH}$ indicator are shown in Appendix A.

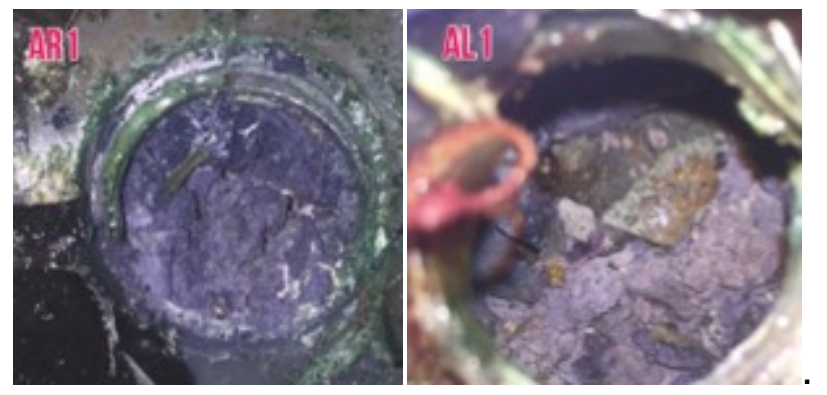

Figure 4.20: Photos of pH Results for the First Corrosion Probe Located at $0.5 \mathrm{ft}$. from the Top of MIT Test Samples with Zero Additives (A)

\subsubsection{Corrosion Behavior}

Figure 4.12 shows the OCP and corrosion current density trends with time from initial tendon casting. Of note more active average potentials and greater average current densities were seen for probes located in the upper $1 \mathrm{ft}$. region of the tendons regardless of the level of external sulfate and chloride augmentation. 

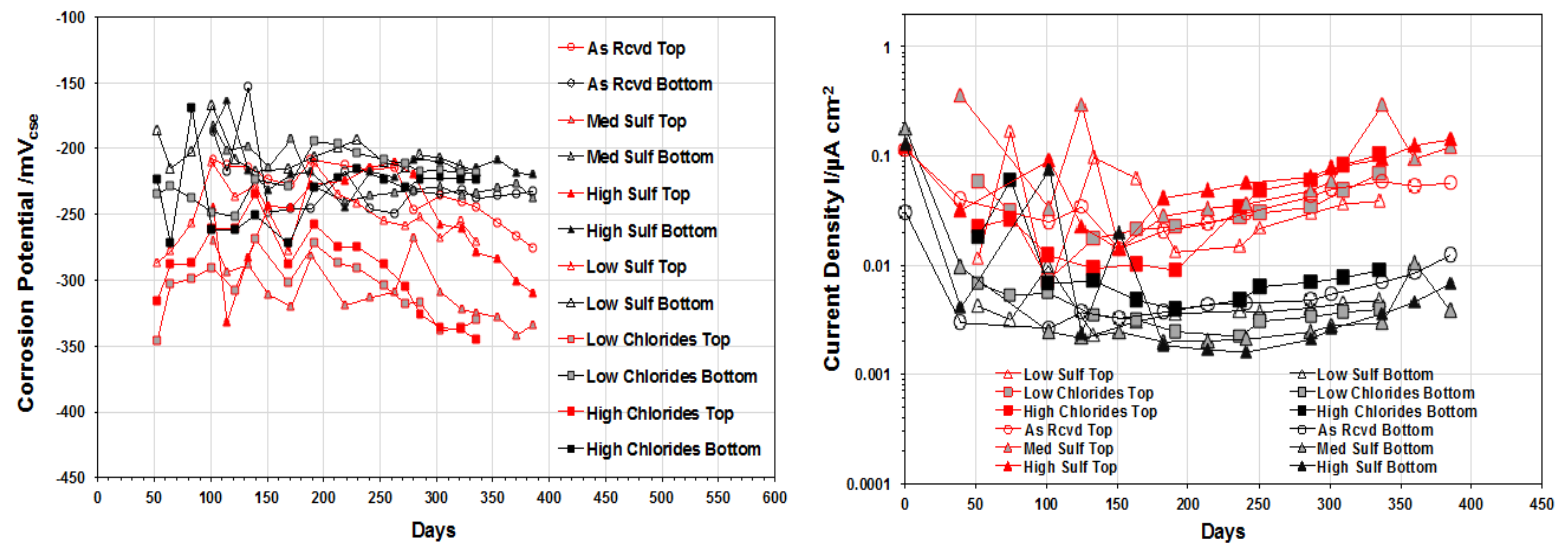

Figure 4.21: Corrosion Potential and Current Density for MIT Test (Low Sulf: 2,000ppm /Med Sulf: 20,000ppm/High Sulf: 150,000 ppm/Low Cl:0. 08\% and High Cl:0. $2 \%$ by Cement)

\subsubsection{Corrosion Autopsy}

Further investigation was applied on MIT test samples after all other testing. Figure 4.22 show, the corroded embedded strands in MIT test with different additives. No corrosion was observed in samples with low $(2,000 \mathrm{ppm})$ sulfate concentration.

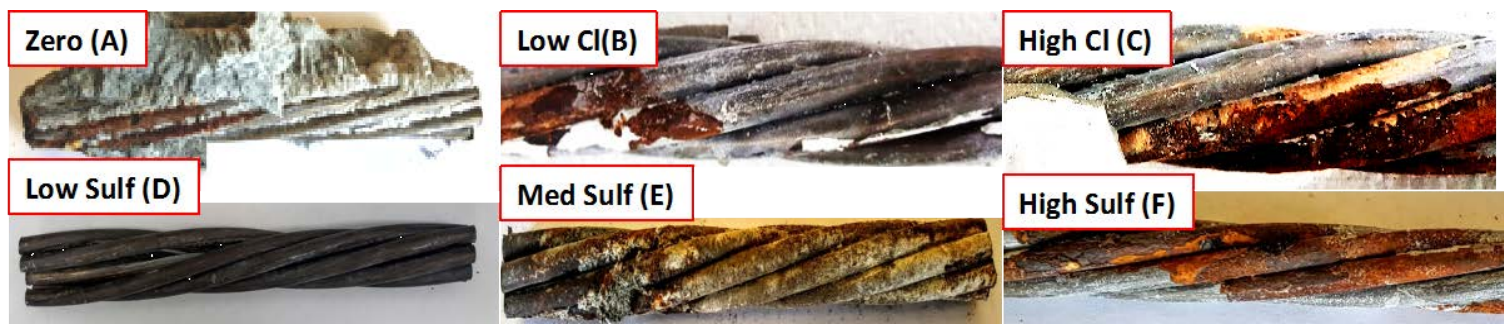

Figure 4.22: Photos of Embedded Strands in MIT Samples

Petrography of grout samples was carried out to differentiate grout segregations of MIT test samples and field sample from bridge I. Two grout samples from the MIT test, one from deficient grout located near the top of the 
samples and one from hardened grout located at the bottom and two grout samples from bridge I (one from deficient grout and one from hardened grout) were tested. Figures (4.23-25) show that the segregated grout in MIT test was representative of the deficient gout in field samples.

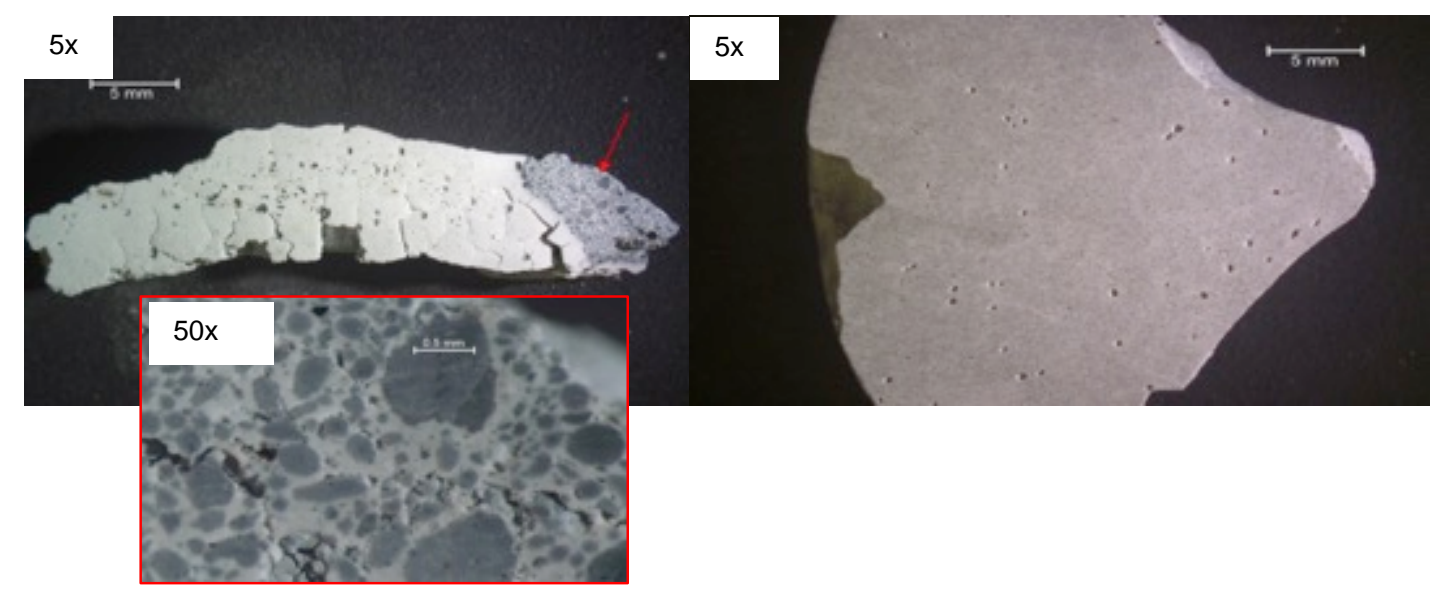

Figure 4.23: Micrograph of Segregated Top and Bottom section in MIT test Samples with no Additives (Case A), at 5x, 50 x Magnification

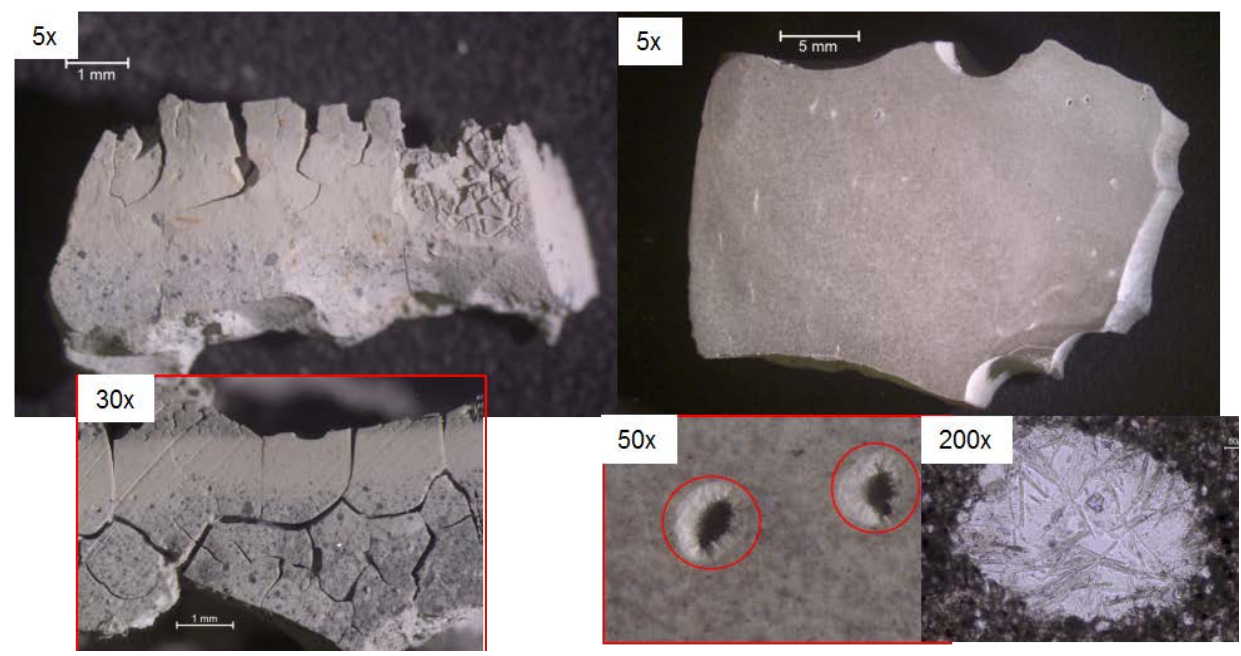

Figure 4.24: Left Side is the Micrograph of Top Segregated Section of Field Samples at 5 and 30 Magnification and Right Side is the Micrograph of Bottom Section at 5x, 50x, 200x Magnification 

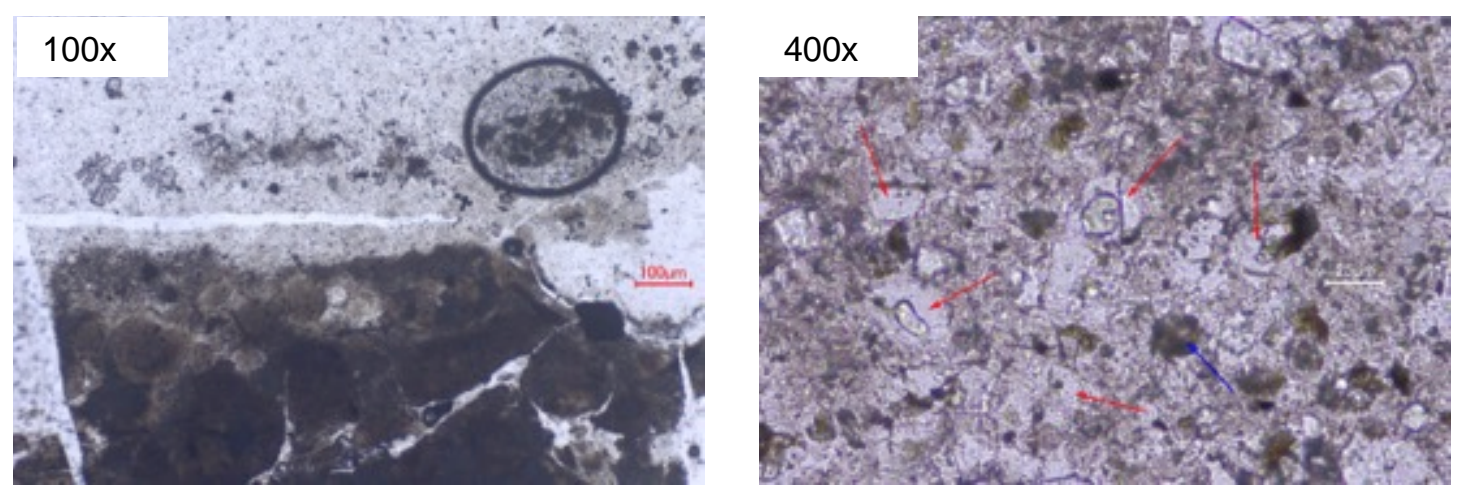

Figure 4.25: Micrograph of Segregated Top and Bottom Section in MIT Test Samples no Additives (Case A), at 100x and 400x Magnification

\subsection{Inverted Tee Test (INT)}

INT test samples were fabricated to determine the corrosion characteristics of steel in simulated tendon environments. These small laboratory samples were made to identify corrosion initiation due to sulfate content, chloride content and combine sulfate/chloride with varying grout exposure condition and varying grout products. Pre-exposed grout from Product A and B were cast in small PVC tee with $20 \%$ extra water. Figure 4.26 shows one set of samples after casting.
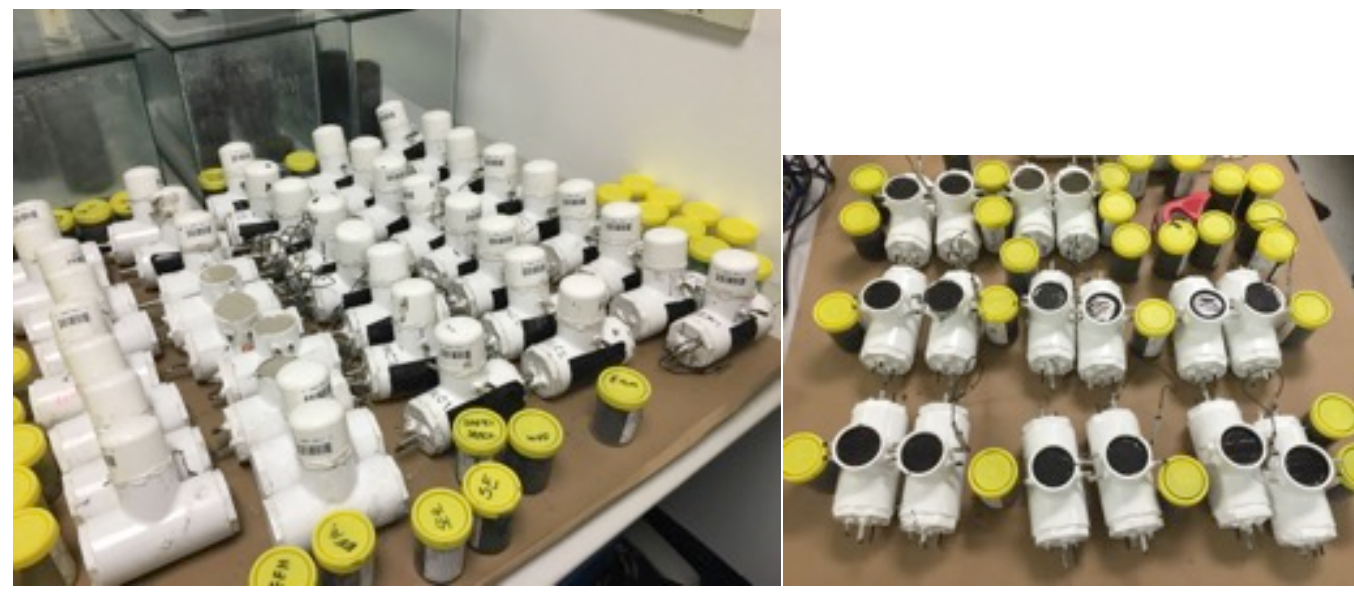

Figure 4.26: INT Test Samples after Casting

Carbon steel wires were embedded in tee header and tee body for each 
sample. In addition to adverse grout mixing condition, a control set of the samples was cast with grout in as-received condition.

\subsubsection{Visual Observation}

Similar grout deficiency was observed in MIT and INT test samples cast with Grout A. Figures 4.27-28 show the surface of deficient grout in the tee header after one and 300 days from casting for different set of samples. Samples with preexposed Grout B also showed segregated porous material in tee header (Figure 4.29-30). As shown in Figure 4.31, the tee body was entirly filled with hardend grout fo all smaples ( Grout A and B ).

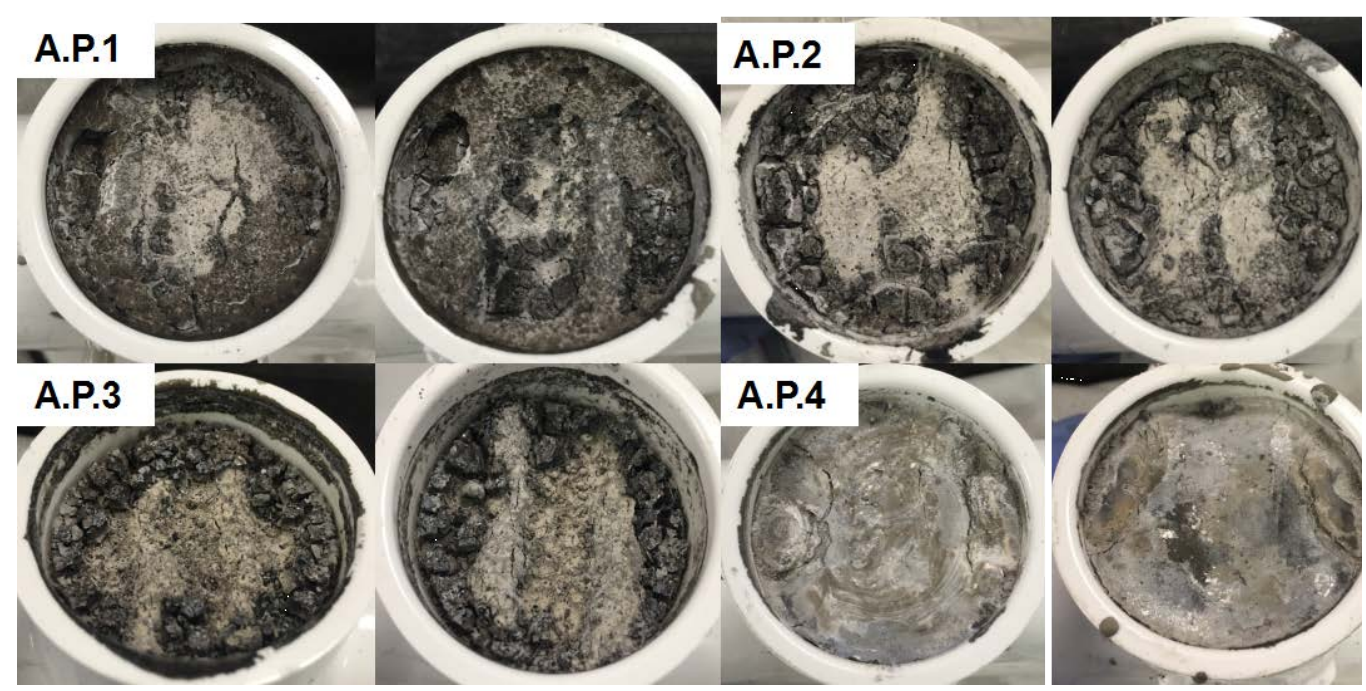

Figure 4.27: Photos of Deficient Grout Surface in INT Test in the Tee Header with Pre-exposed Grout A (Cases A.P.1-4) after 1 Day from Casting 


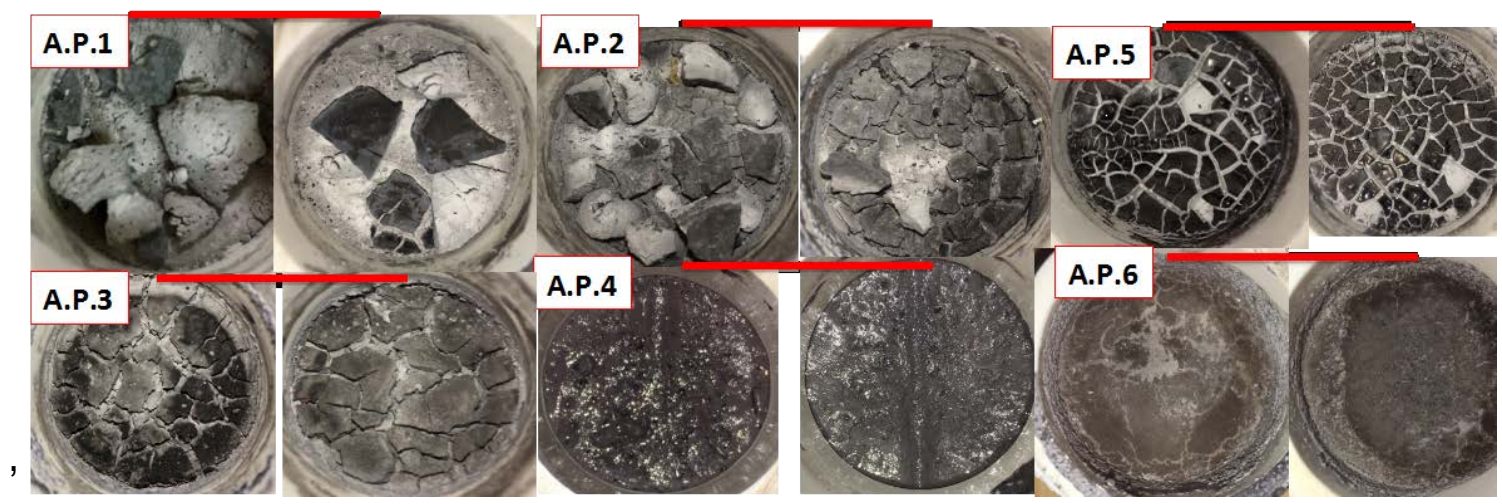

Figure 4.28: Photos of Deficient Grout Surface in INT Test in the Tee Header with Pre-exposed Grout A (Cases A.P.1-6) After 300 Days from Casting

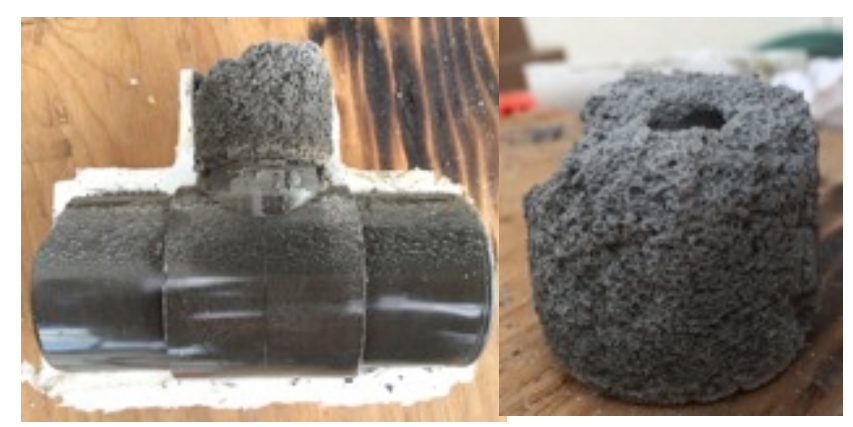

Figure 4.29: Photo of the Prototype for INT Sample Cast with Pre-exposed Grout B

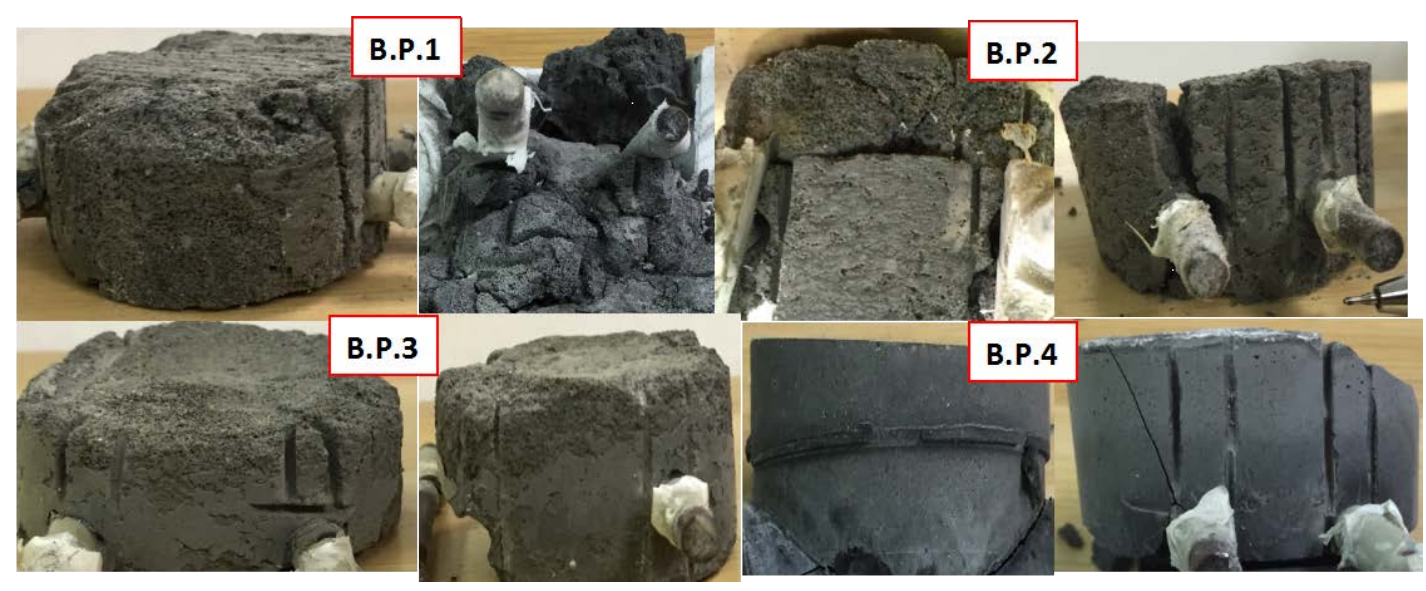

Figure 4.30:Photos of segregated grout in Tee header from INT Test Samples Cast with Pre-Exposed Grout B (Cases B.P.1-4) 


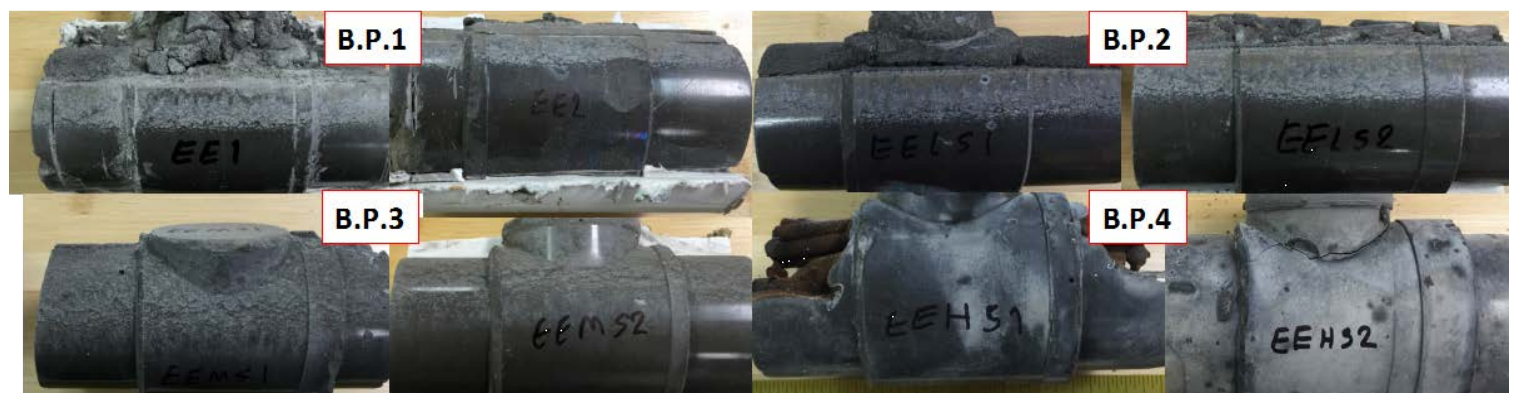

Figure 4.31: Photos of Grout in Tee Body from INT Test Cast with Pre-Exposed Grout B (Cases B.P.1-4)

INT samples with pre-exposed Grout A (A.P.1-6) showed variable level of segregation in the different case. As shown in Figures 4.32-33 the grout in tee header mostly consist of soft material while uniformly hard material formed in the tee body (Figure 4.34). The extent of grout segregation in cases with zero and medium sulfate concentration (A.P.1 and A.P.3) was greater than others.
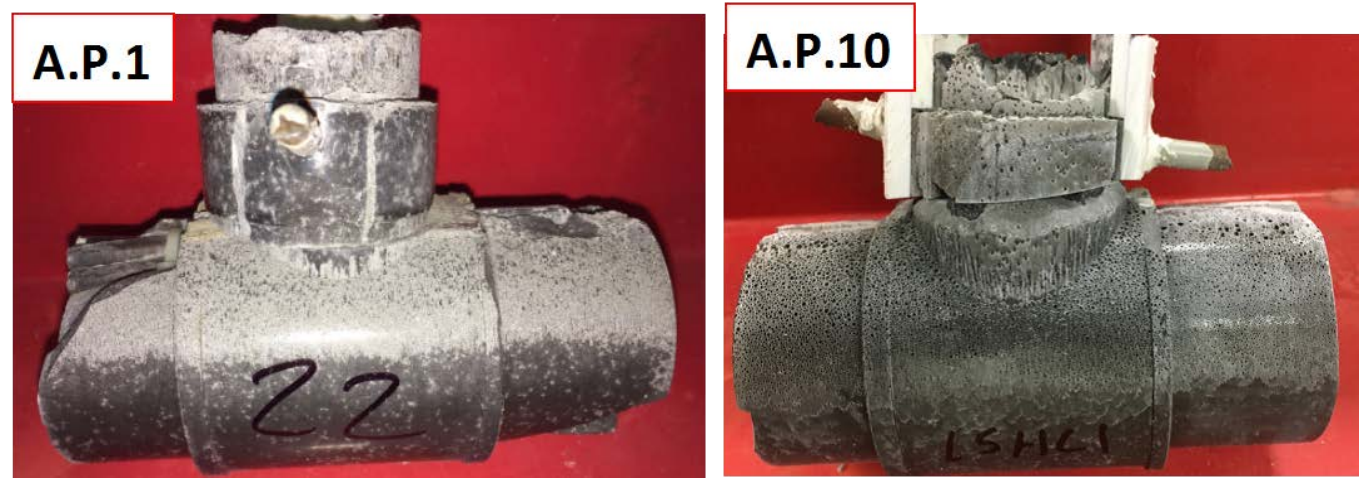

Figure 4.32: Photos of INT Samples Cast with Pre-exposed Grout A (Cases A.P.1 and A.P.10) 


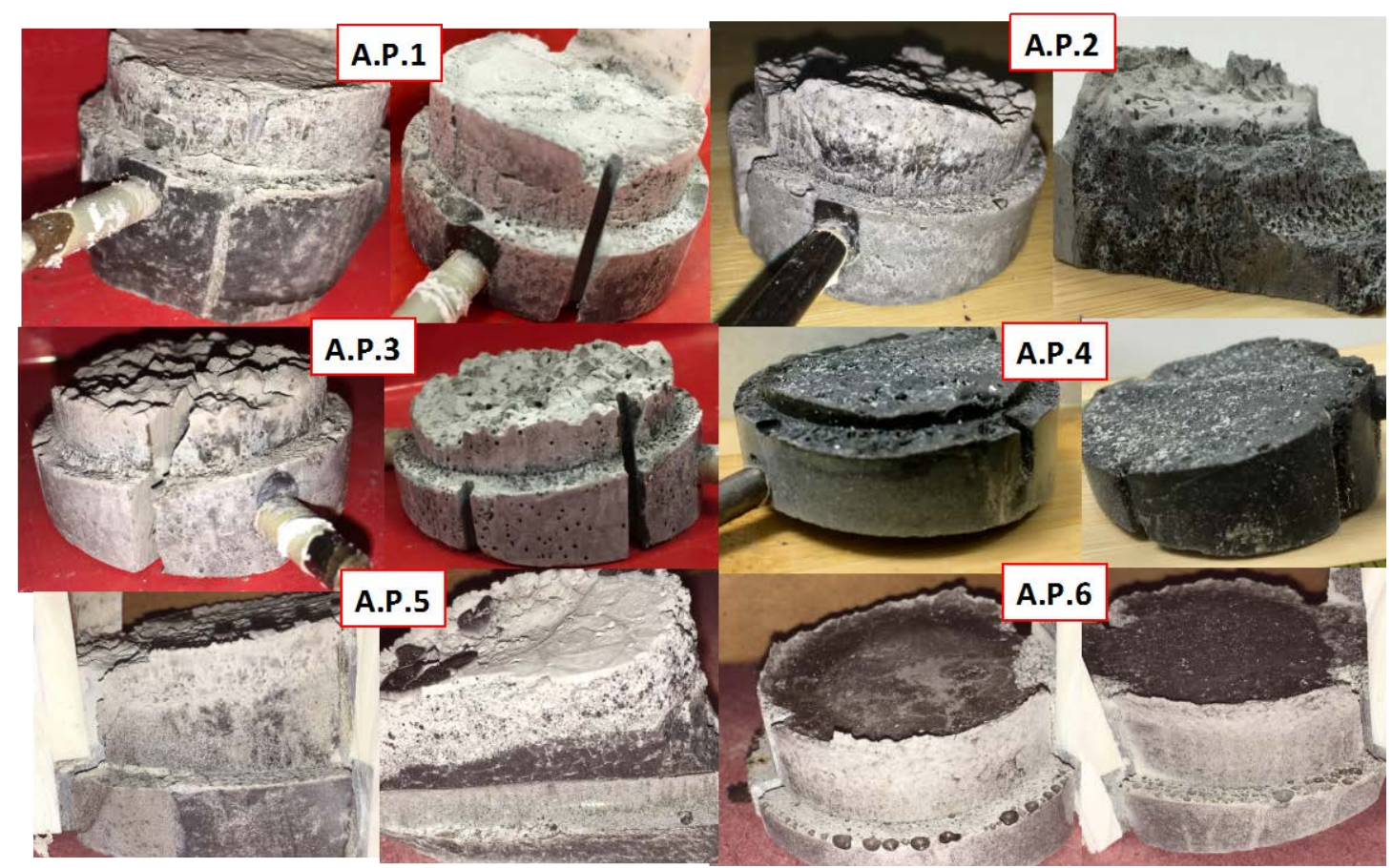

Figure 4.33: Photos of Segregated Grout in Tee Header from INT Test Cast with Pre-Exposed Grout A (Cases A.P.1-6)

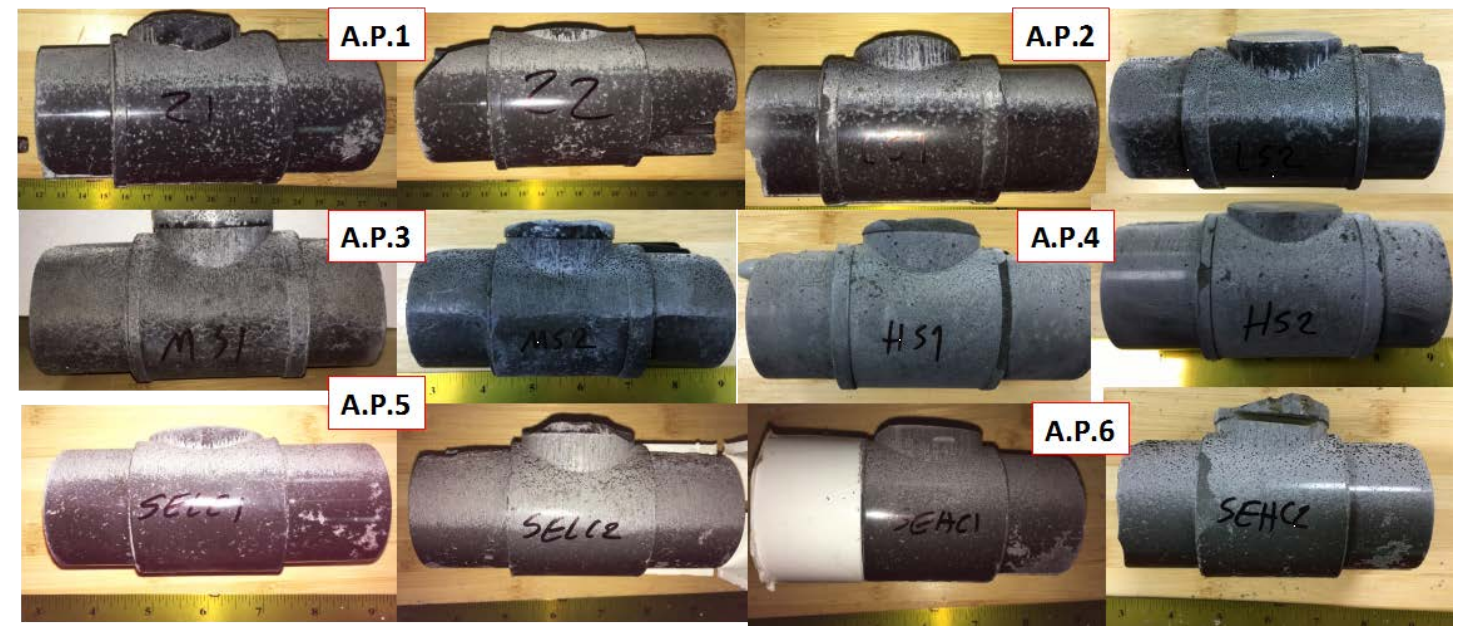

Figure 4.34: Photos of Grout in Tee Body from INT Test Cast with Pre-Exposed Grout A (Cases A.P.1-6) 


\subsubsection{Combination of Sulfate and Chloride Content}

Figure 4.35 shows the surface of the deficient grout in tee header after 300 days from casting for cases A.P.7-12. Varied level of grout segregation was observed in the tee header, depending on the sulfate and chloride concentration (Figure 4.36), It was clear that cases A.P.7-8 and A.P.10-11 had higher segregation as exhibited by having higher content of soft material. Overall the soft material at tee header formed 4 layers with different characterization (Figure 4.37). Like other cases described in the previous section, uniform hard material formed in the tee body (Figure 4.38).

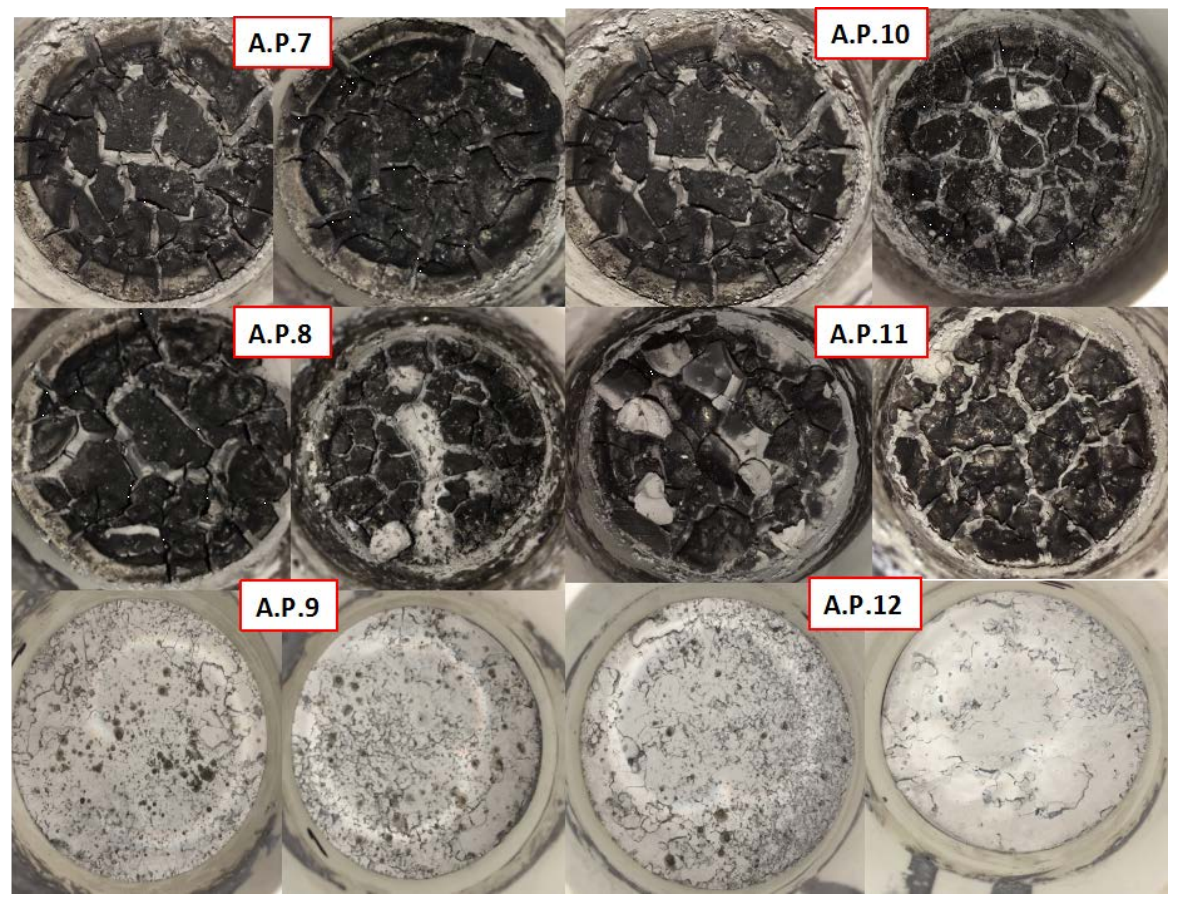

Figure 4.35: Photos of Deficient Grout Surface in INT Test in the Tee Header with Pre-exposed Grout A (Cases A.P.7-12) After 300 Days from Casting 


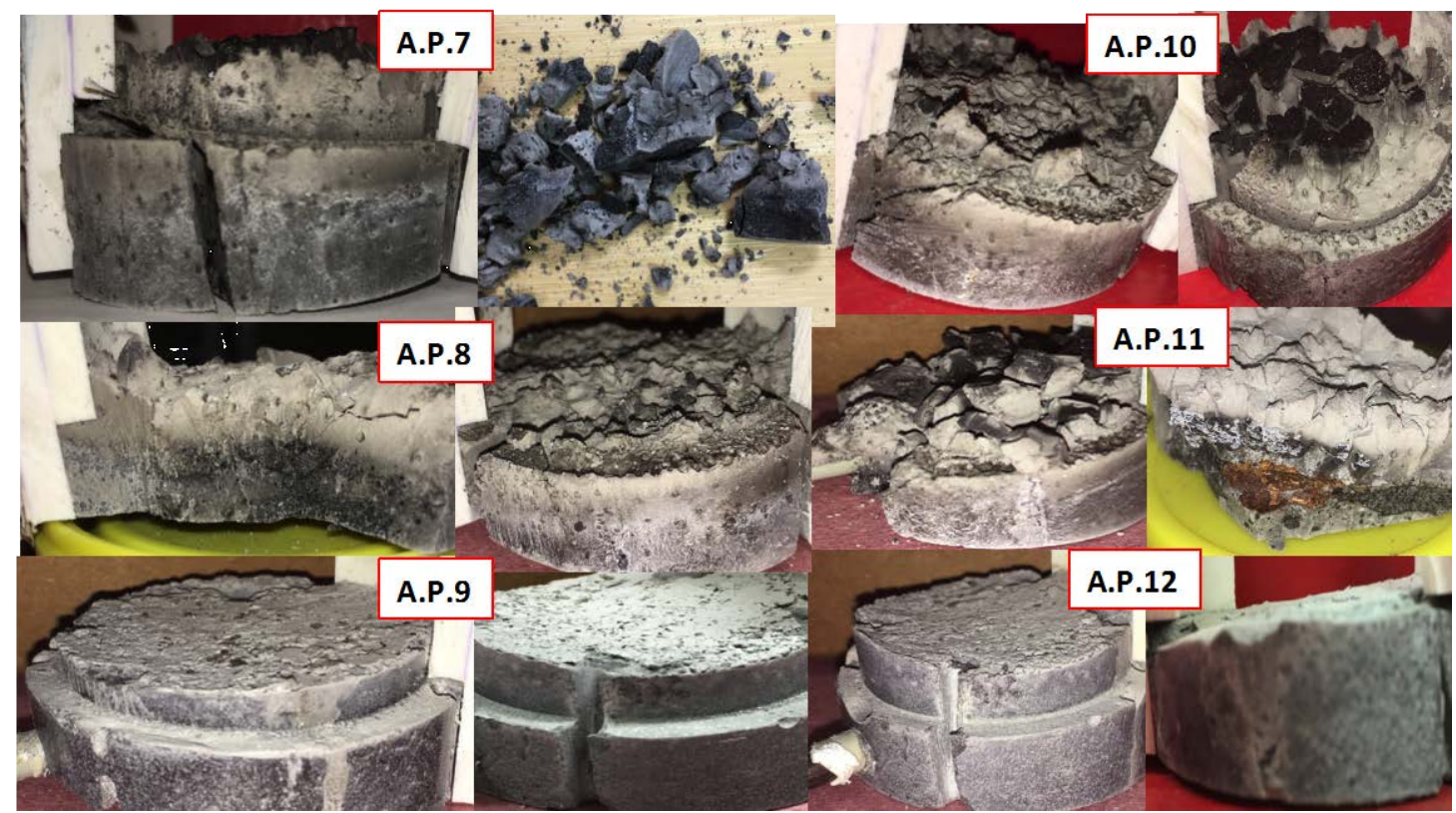

Figure 4.36: Photos of Segregated Grout in Tee Header from INT Test Cast with Pre-Exposed Grout A (Cases A.P.7-12)

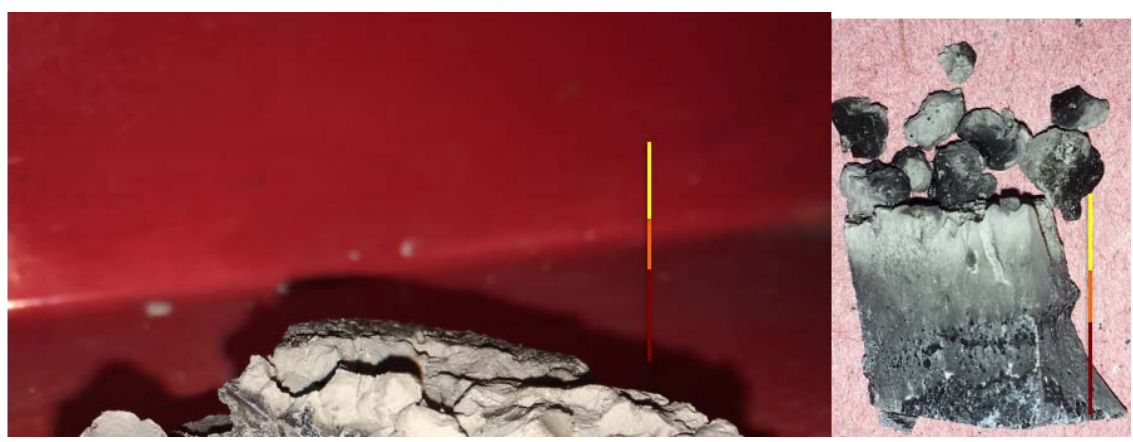

Figure 4.37: Layer Differentiation in Soft grout from INT test with Pre-Exposed Grout A (Cases A.P.8) 


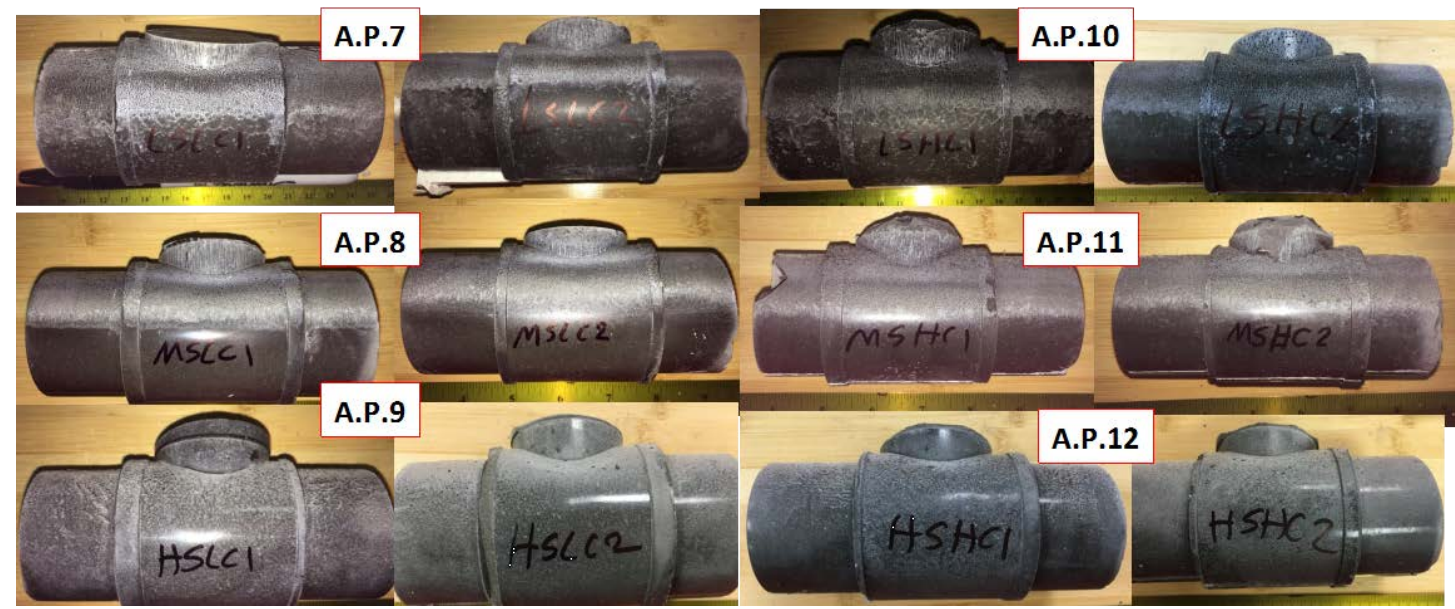

Figure 4.38: Photos of grout in Tee Body from INT test cast with Pre-Exposed Grout A (Cases A.P.7-12)

\subsubsection{Moisture Content}

Figure 4.39-40 show the result of the moisture content for grout from INT test samples (B.A.1-3, B.P.1-4, A.A.1-3 and A.P.1-6) .As shown in Figure 4.39, no significant differentiation was observed for INT test samples cast with Grout B in either the tee header or the body for cases B.A.1-3 and B.P.1-4 (in different as received and pre-exposed condition).

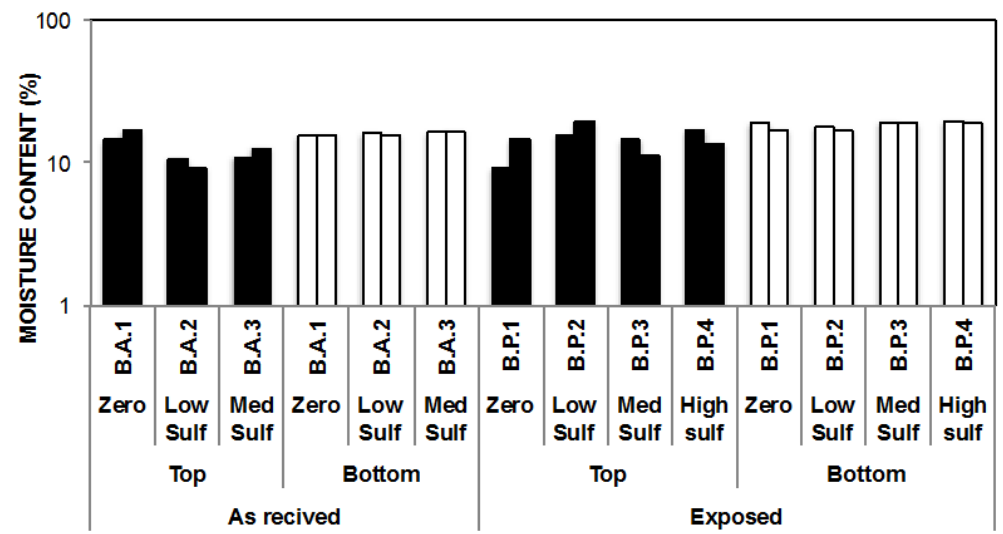

Figure 4.39: Moisture Content of Grout from INT Test Samples Cast with Grout B (Cases B.A.1-3, B.P.1-4) 
However, in INT test samlples cast with pre exposed Grout A, the deffcient grout in tee header showed higher moisture content comparing to the material in the tee Body (Figure 4.40).

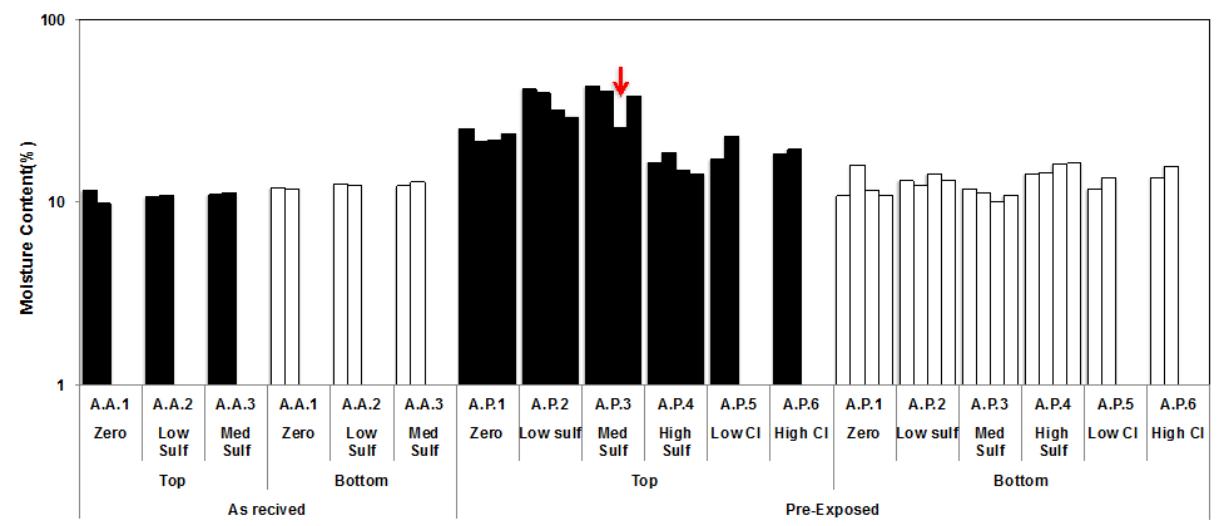

Figure 4.40: Moisture Content of Grout from INT Test Samples Cast with Grout A (Cases A.A.1-3 and A.P.1-6) (red arrows show where corrosion occurred)

\subsubsection{Combination of Sulfate and Chloride Content}

High level of moisture content ( $\sim 60 \%)$ was observed for grout in the tee header for cases A.P.7-8 and A.P.10-11, while the moisture of the bottom section were all lower than $20 \%$ (Figure 4.41).

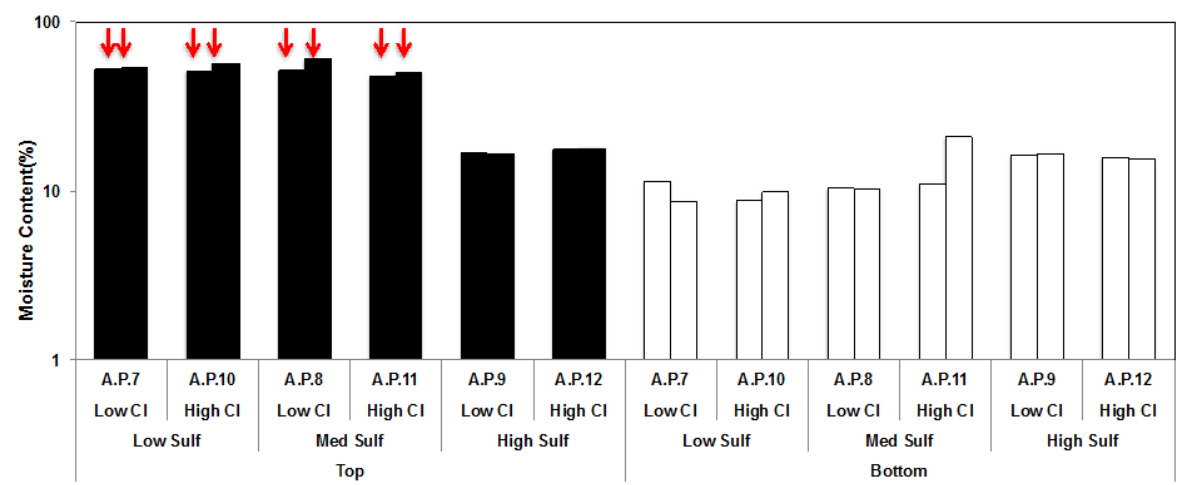

Figure 4.41: Moisture Content of Grout from INT Test Samples Cast with Grout A (Cases A.P.7-12) (red arrows show where corrosion occurred) 


\subsubsection{Electrical Properties}

Solution resistance was measured for INT tests samples. As Figures 4.4243 show Grout A had lower solution resistance than Grout Bulk resistivity was calculated following ohm 's Law.

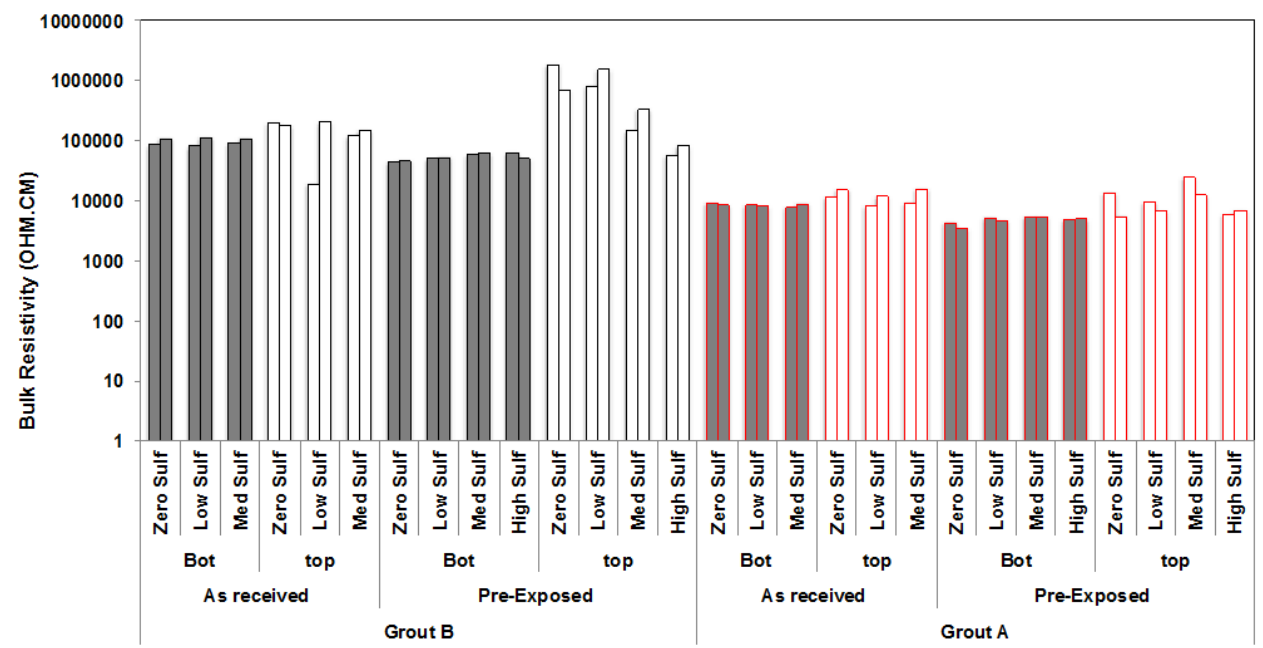

Figure 4.42: Bulk Resistivity for INT Test Samples (Cases B.A.1-3, B.P.1-4, A.A.1-3 and A.P.1-4)
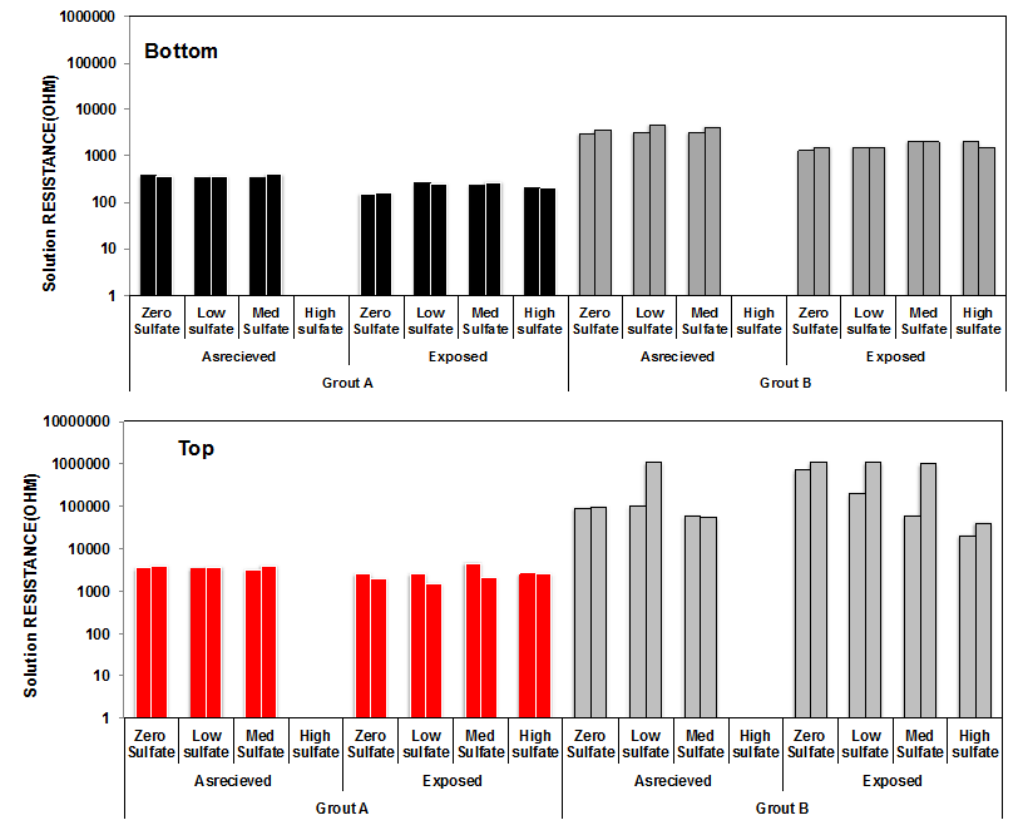

Figure 4.43: Solution Resistance for INT Test Samples (Cases B.A.1-3, B.P.1-4, A.A.1-3 and A.P.1-4) 


\subsubsection{Chemical Analysis}

Samples were collected from the tee header and body for sulfate, total chloride content and $\mathrm{pH}$ analysis. Figures $4.44-45$ shows sulfate and total chloride concentration for INT test samples cast with Grout B. In agreement with the moisture content result, there was no differentiation in results of the analysis for samples from top and bottom section.

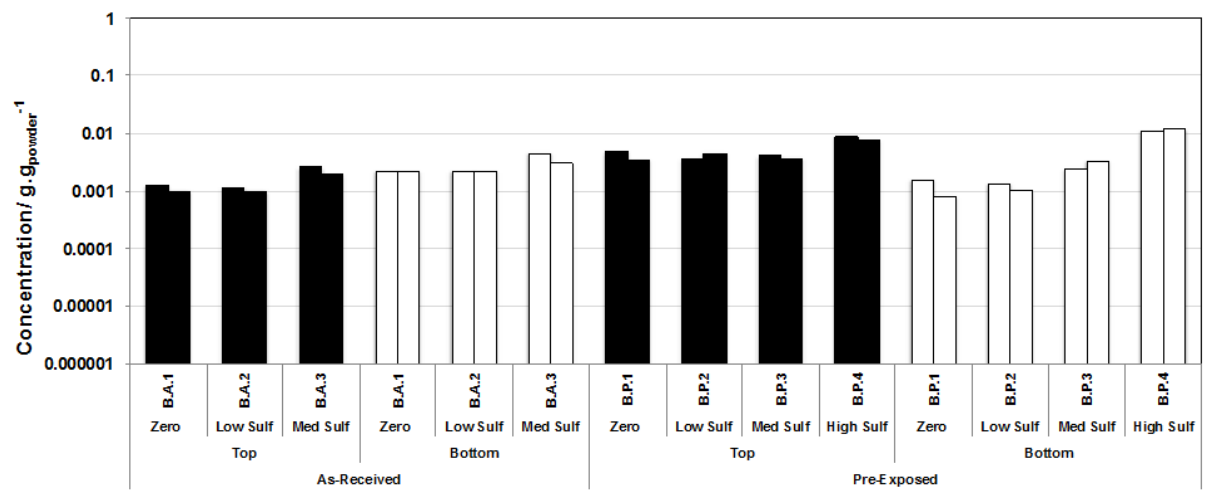

Figure 4.44: Sulfate concentration of Grout from INT Test Samples Cast with Grout B (Cases B.A.1-3, B.P.1-4)

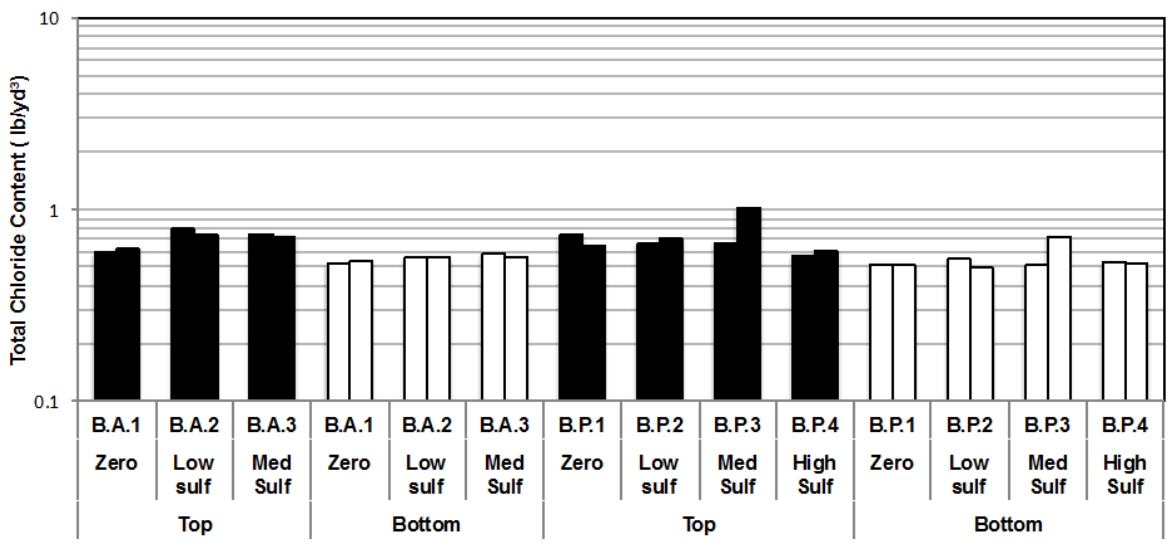

Figure 4.45: Total Chloride Content of Grout from INT Test Samples Cast with Grout B (Cases B.A.1-3, B.P.1-4) 
However, INT test with Grout A (A.A.1-3 and A.P.1-6) showed higher sulfate and total chloride accumulation for the segregated grout in the tee header (Figure 4.46-7). Corrosion developed in the case A.P.8 with 20,000 ppm sulfate concentration.

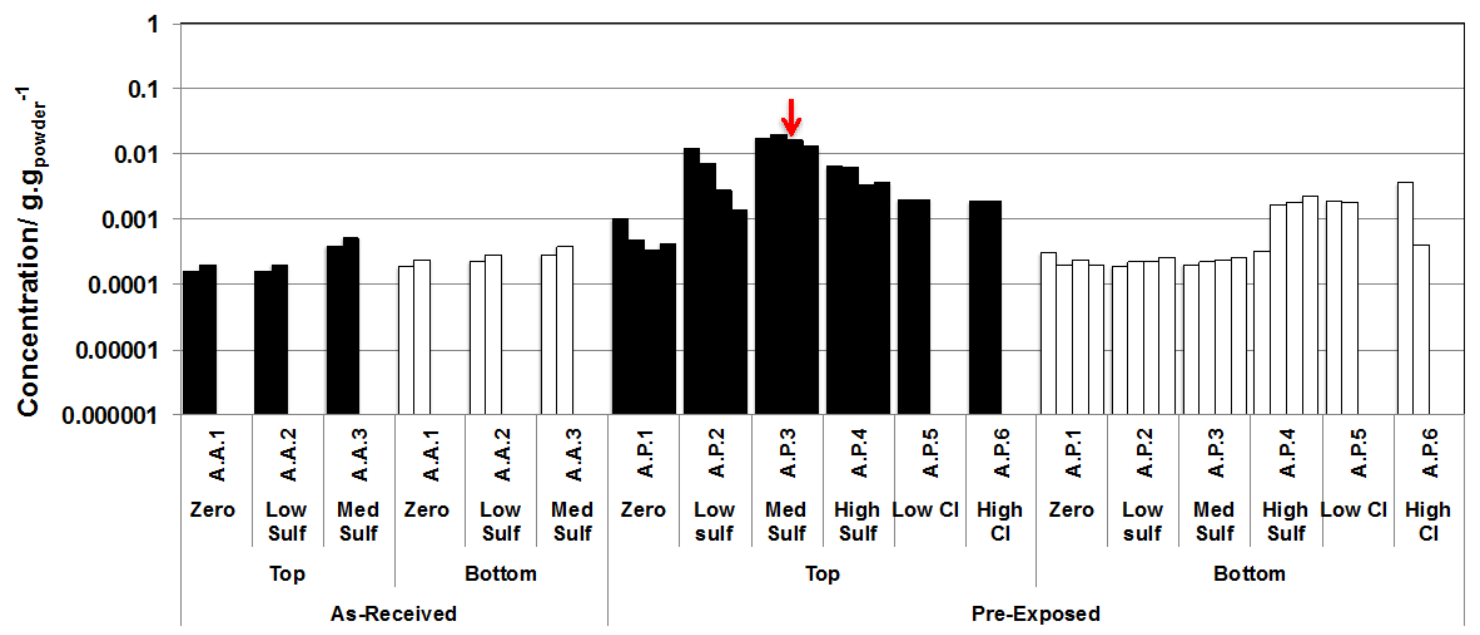

Figure 4.46: Sulfate Concentration of Grout from INT Test Samples Cast with Grout A (Cases A.A.1-3 and A.P.1-6) (red arrow show where corrosion occurred)

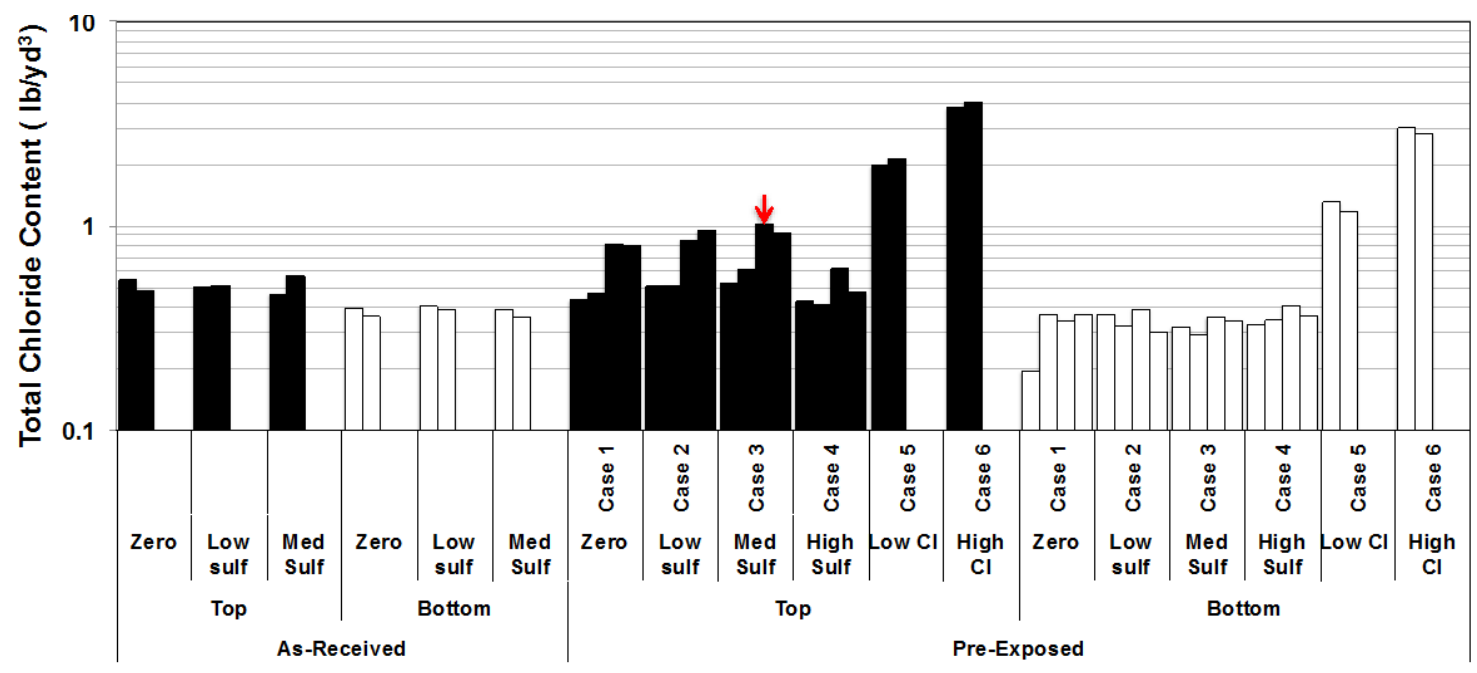

Figure 4.47: Total Chloride Content of Grout from INT Test Samples Cast with Grout A (Cases A.A.1-3 and A.P.1-6) (red arrow show where corrosion occurred) 
As shown in Figures 4.48-49 shows, the $\mathrm{pH}$ for the INT test samples were in the range of $12-13$ for all cases, with the exception of the corroded samples, where the $\mathrm{pH}$ dropped below 12.As part of the work here, as well as the ex-situ leaching method, all the samples were sprayed with $\mathrm{pH}$ indicator, and all showed the same value $(\mathrm{pH}>11)($ Appendix $\mathrm{A})$.

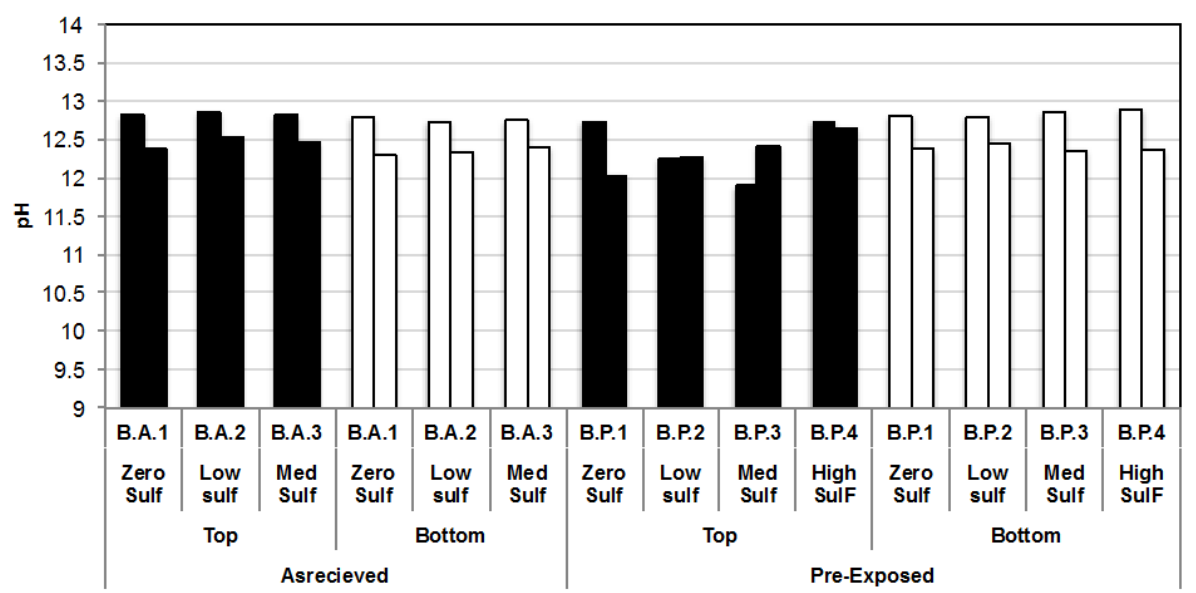

Figure 4.48:pH Measurements of Grout from INT Test Samples Cast with Grout B (Cases B.A.1-3, B.P.1-4), by Ex-situ Leaching

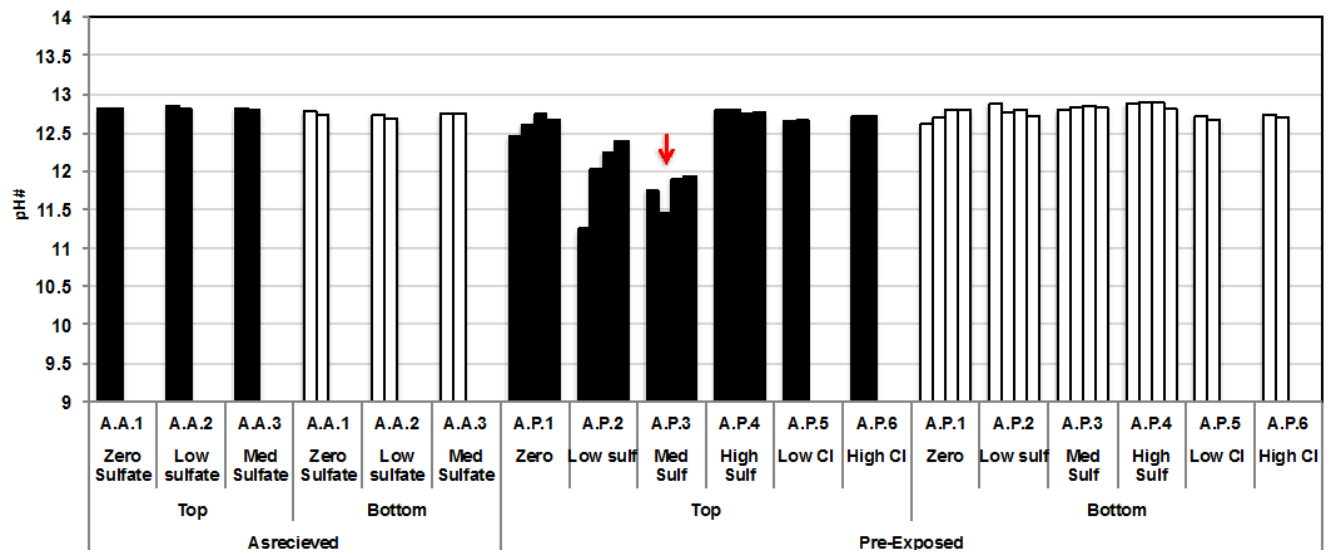

Figure 4.49:pH Measurements of Grout from INT test Samples Cast with Grout A (Cases A.A.1-3 and A.P.1-6), by Ex-situ Leaching (red arrow show where corrosion occurred) 
The samples from the tee header and body (Cases A.P.1 and B.P.1) were analyzed for cations and anions such as calcium, sodium, potassium, sulfate, chloride, phosphate, nitrate, nitrite and sulfide (Figure4.50-51). As the results show, the samples were mostly differentiated by the amount of calcium, sodium and sulfate. INT test samples with pre-exposed Grout A (A.P.1) at the tee header showed lower calcium, and higher sodium and sulfate concentration.

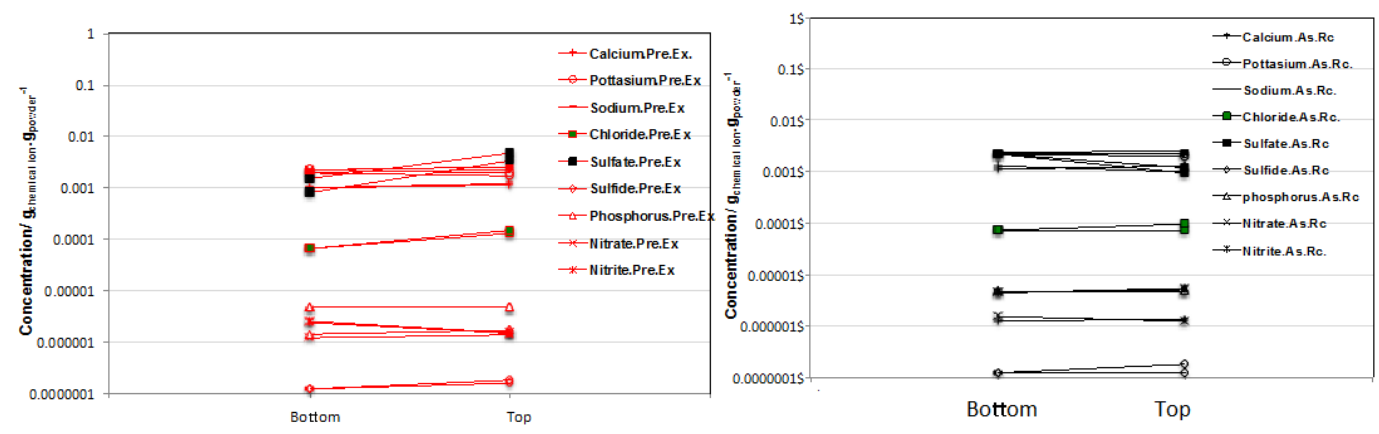

Figure 4.50:Chemical Characteristic Profiles of INT Tests Cast with Grout B (Case B.P.1)
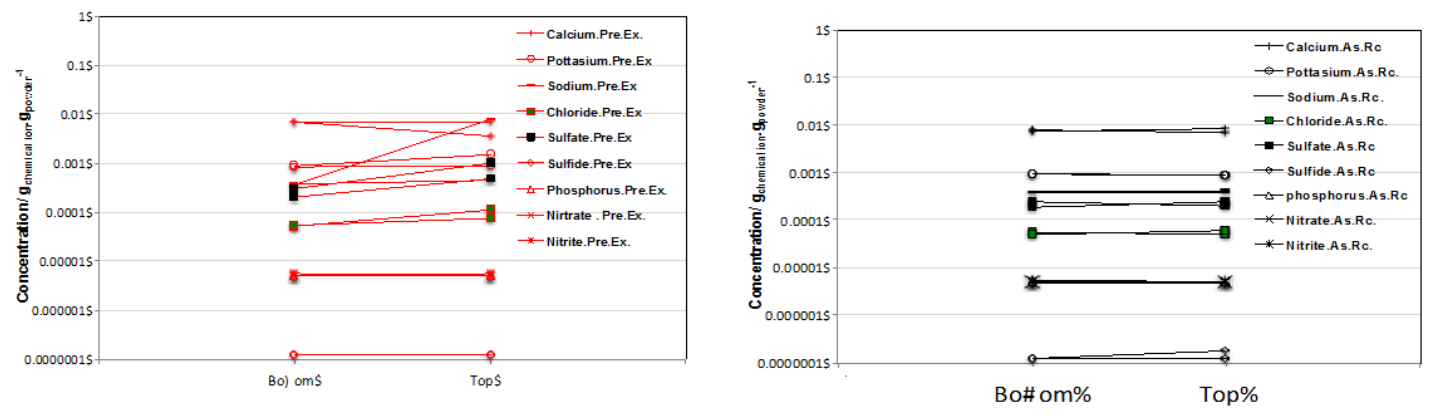

Figure 4.51:Chemical Characteristic Profiles of INT Tests Cast with Grout A (Case A.P.1) 


\subsubsection{Combination of Sulfate and Chloride Content}

As shown in Figures 4.52-53, the segregated part of INT test samples A.P.7-8 and A.P.10-11 had high sulfate concentration ( $\left.>0.01 \mathrm{gsulfate} / \mathrm{g}_{\text {Powder }}\right)$ and similar chloride content as cases A.P.5-6. These samples were severely corroded and as shown in Figure 4.54, the pH drop below 12 in these samples.

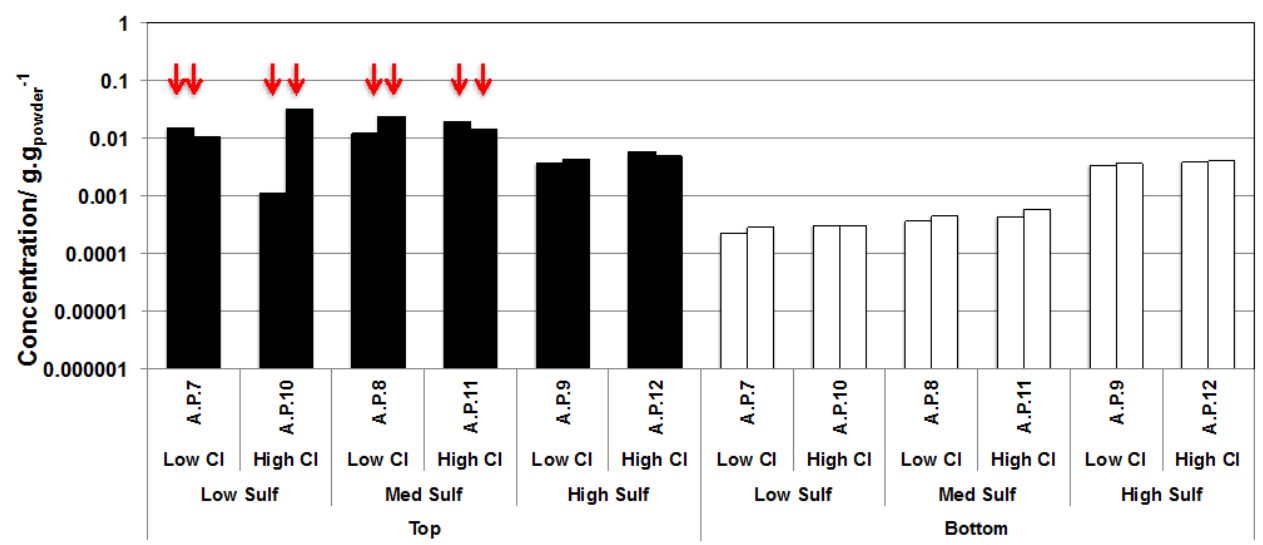

Figure 4.52: Sulfate Concentration of Grout from INT Test Samples Cast with Grout A (Cases A.P.7-12) (red arrows show where corrosion occurred)

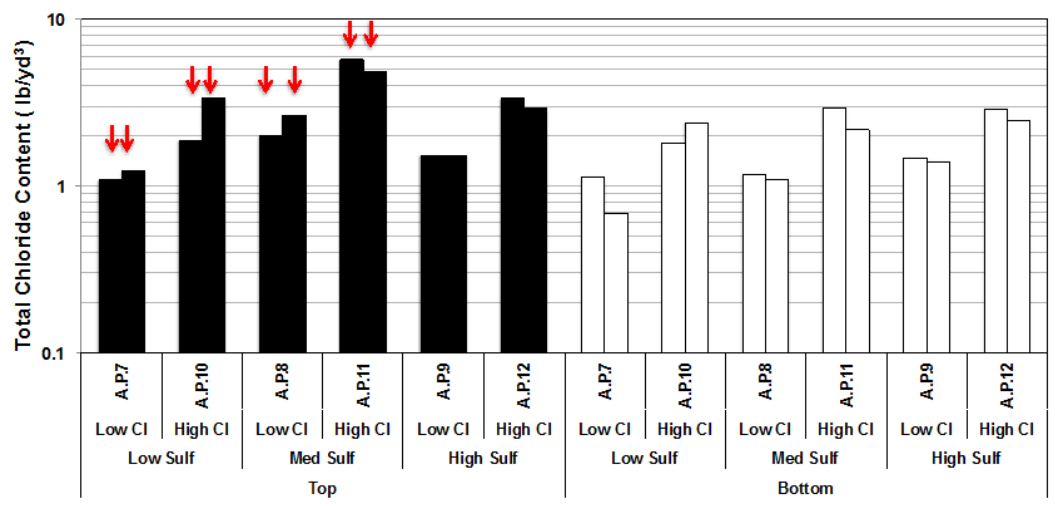

Figure 4.53: Total Chloride Content of Grout from INT Test Cast with Grout A (Cases A.P.7-12) (red arrows show where corrosion occurred) 


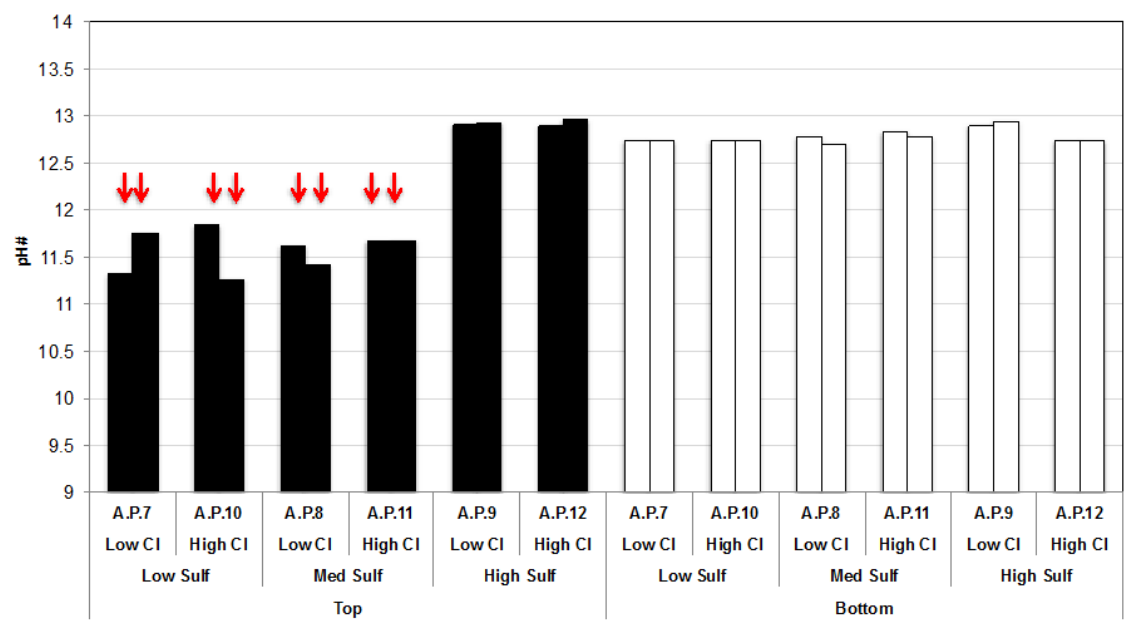

Figure 4.54:pH Measurements of Grout From INT Test Samples Cast with Grout A (Cases A.P.7-12), by Ex-situ Leaching (red arrows show where corrosion occurred)

\subsubsection{Corrosion Behavior}

Corrosion current density and open circuit potential were measured for INT samples cast with Grout A and B (Cases: B.A.1-3, B.P.1-4, A.A.1-3 and A.P.1-12). As shown in Figure 4.55, Grout B was in passive like condition with no corrosion activity regarding in any condition (B.A.1-3, B.P.1-4).

INT samples with Grout A showed stable condition in cases A.A.1-3 while in samples with pre-exposed Grout A, the steel in tee header show higher current density and lower corrosion potential comparing to the steel in tee body (Figure 4.56-7). The INT samples with chloride addition (A.P.5-6), also showed passive like behavior (Figure 4.56).

As shown in Figure 4.57, case A.P.3 was in active condition. The current density reached $1 \mu \mathrm{A} / \mathrm{cm}^{2}$ and the corrosion potential was $-300 V_{\text {sce }}$. 

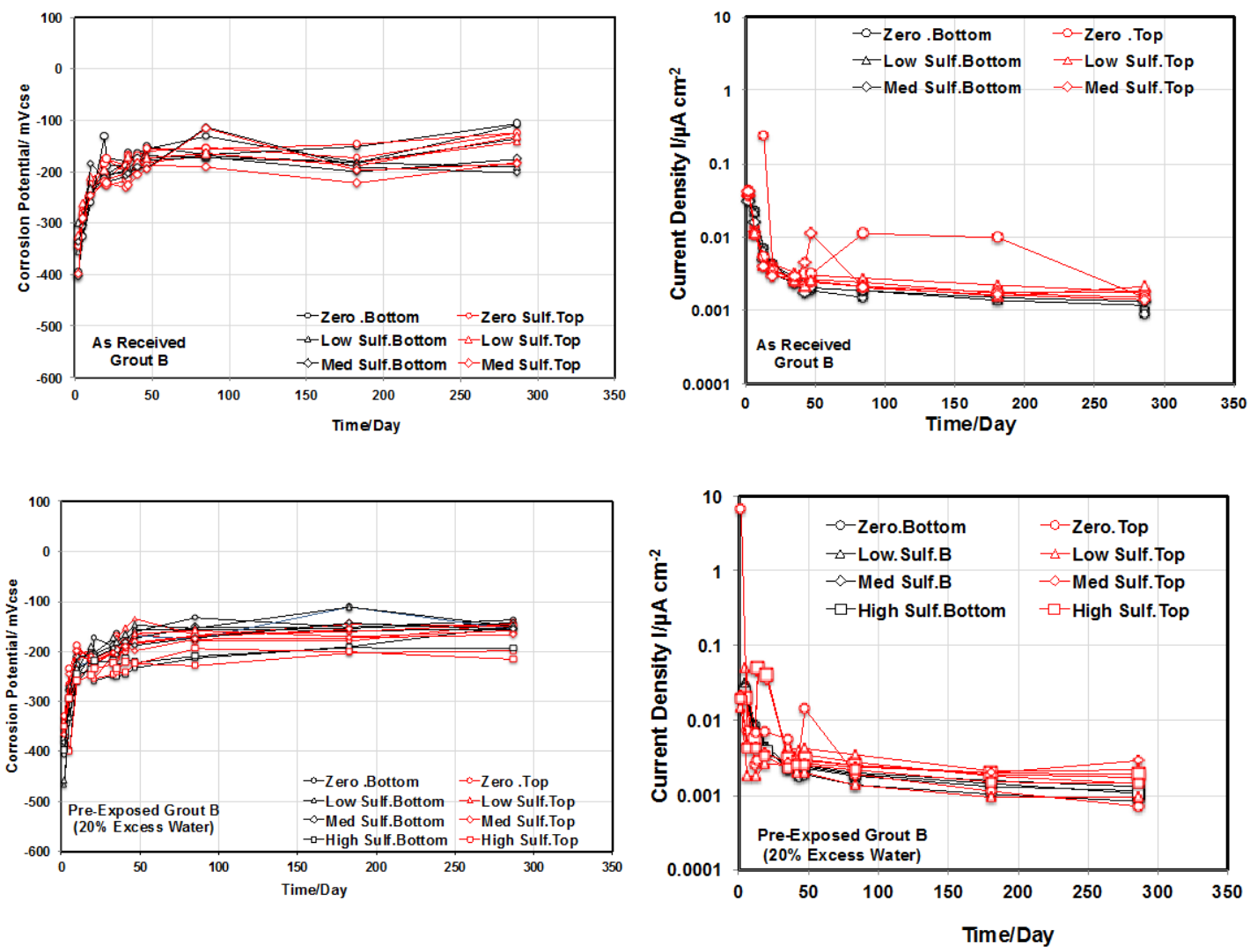

Figure 4.55: Corrosion Potential and Current Density for INT Test, Cases: B.A.13, B.P.1-4 (Low Sulf: 2,000ppm /Med Sulf: 20,000ppm/High Sulf: 100,000 ppm)
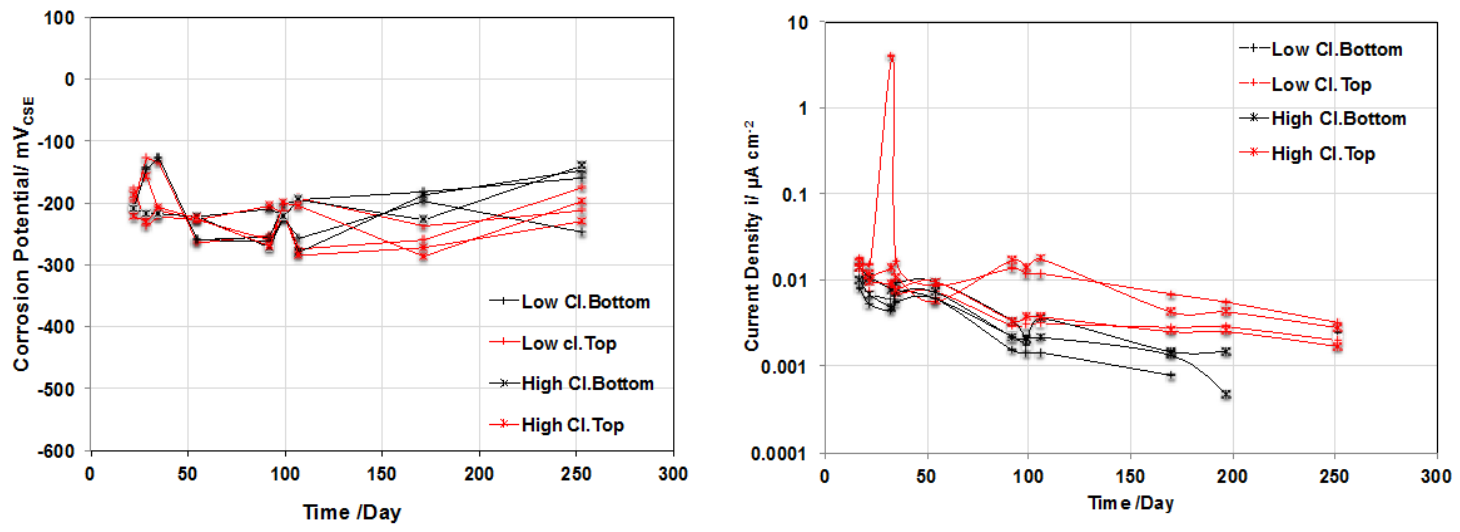

Figure 4.56: Corrosion Potential and Current Density for INT Test, Cases: A.P.56 (Low Cl:0. 08\% and High Cl:0. 2\% by Cement) 

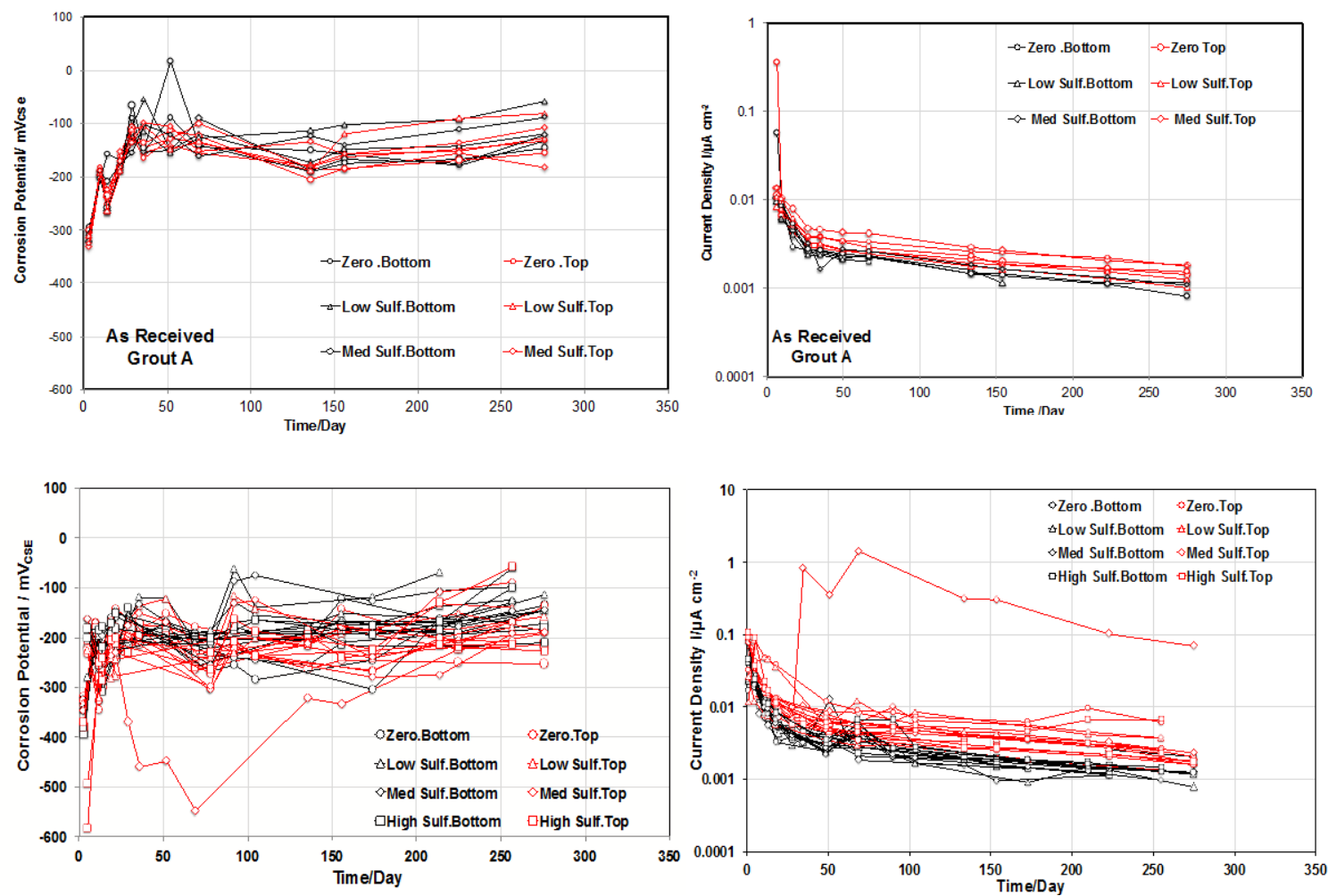

Figure 4.57: Corrosion Potential and Current Density for INT test, Cases: A.A.1-3 and A.P.1-14 (Low Sulf: 2,000ppm /Med Sulf: 20,000ppm/ High Sulf: 100,000 ppm)

\subsubsection{Combination of Sulfate and Chloride Content}

Grout A was more susceptible to form deficient grout similar to that observed in the field where corrosion occurred. Testing incorporated samples that cast other set of sample were casted with pre-exposed Grout A and $20 \%$ extra water and varied level of sulfate and chloride content. Figures (4.58) show corrosion potential and corrosion current density for cases A.P.7-12. As Figure 4.58 show, INT samples (Cases A.P.7-8 and A.P.10-11), had corrosion potential as low as $-500 \mathrm{~V}_{\text {sce }}$ and corrosion current density as high as $6 \mu \mathrm{A} / \mathrm{cm}^{2}$. 

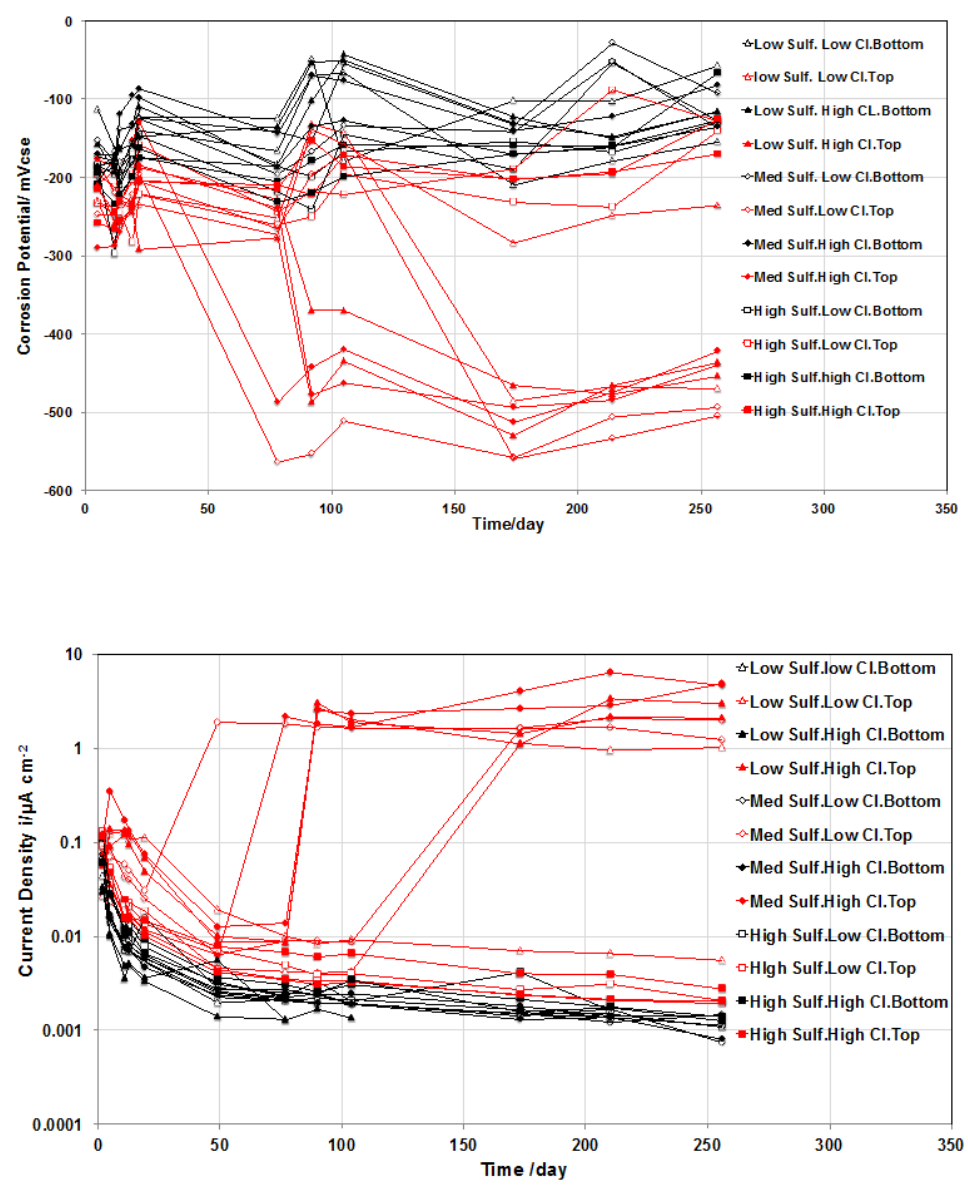

Figure 4.58: Corrosion Potential and Current Density for INT test cases: A.P.712. (Low Sulf: 2,000ppm /Med Sulf: 20,000ppm/High Sulf: 100,000 ppm/Low $\mathrm{Cl}: 0.08 \%$ and High $\mathrm{Cl}: 0.2 \%$ by Cement)

\subsubsection{Corrosion Autopsy}

After all the chemical and corrosion testing, further investigation was carried out on the cases with corroded wire including SEM and EDS analysis. Figure4.59 shows the corroded wire in the case A.P. 3 with 20,000 ppm sulfate concentration, which is surrounded by soft and white chalky material. The presence of corrosion product was also observed in SEM analysis (Figure4.60). Photos of all steel wire in segregated portion of INT test samples have shown in (Appendix B). 

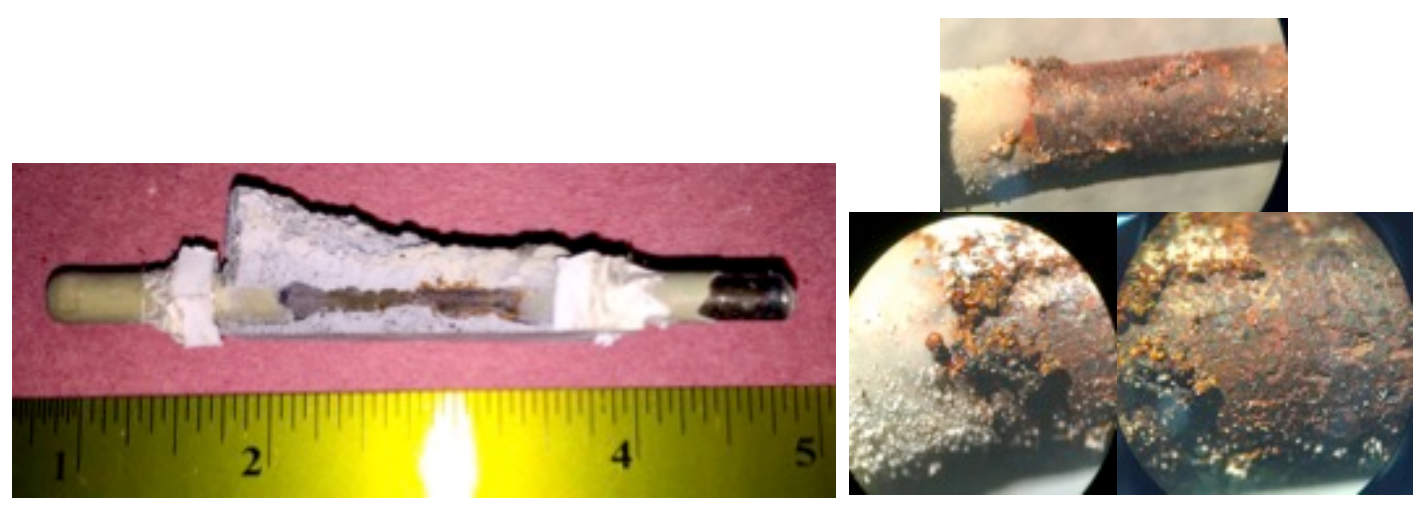

Figure 4.59: Photos of Corroded Wire in Segregated Part of INT Test Samples (Case A.P.3)

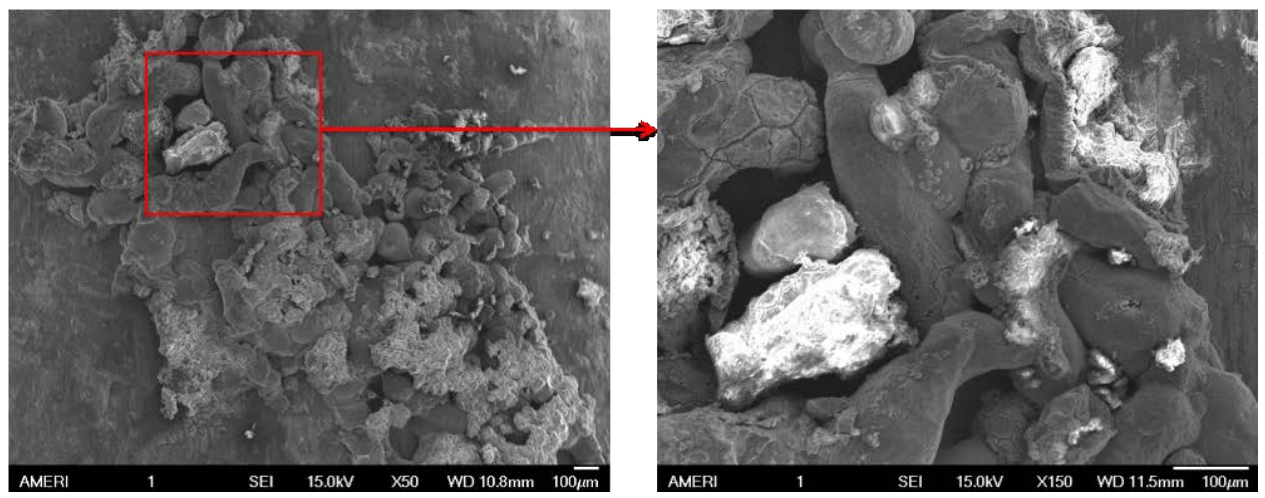

Figure 4.60: SEM Micrograph for Case A.P.3

4.3.6.1. Combination of Sulfate and Chloride Content

Corrosion products were formed on steel wire in tee header in cases A.P.7-8 and A.P.10-11, with presence of mild pitting corrosion. Figure 4.61-62 show the corroded wire in tee header in different cases. As it was mentioned 
earlier, $\mathrm{pH}$ dropped below 12 in these cases in the tee header (Figure 4.61-62).

SEM and EDS analysis were carried out for case A.P.11. (Figure 4.63-64) 
Figure 4.61: Photos of Corroded Wire in Segregated Part of INT Test Samples (Case A.P.7-8) A, B Small Fragments of Samples Sprayed with pH Indicator 
Figure 4.62: Photos of Corroded Wire in Segregated Part of INT Test Samples (Case A.P.9-10) A, B Small Fragments of Samples Sprayed with pH Indicator 

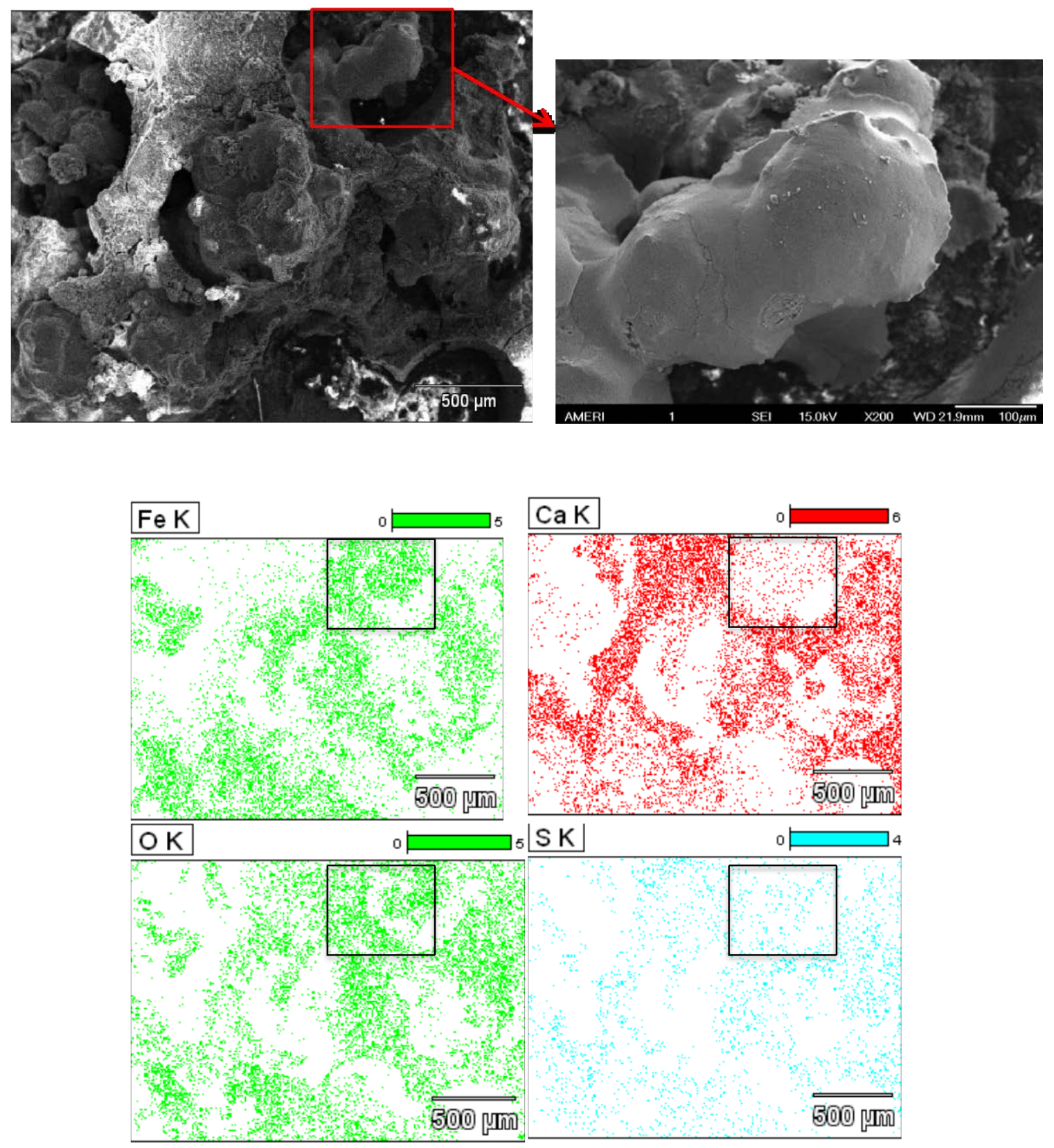

Figure 4.63: SEM Micrograph and EDS Elemental Maps of Corrosion Product for (Case A.P.11.1) 

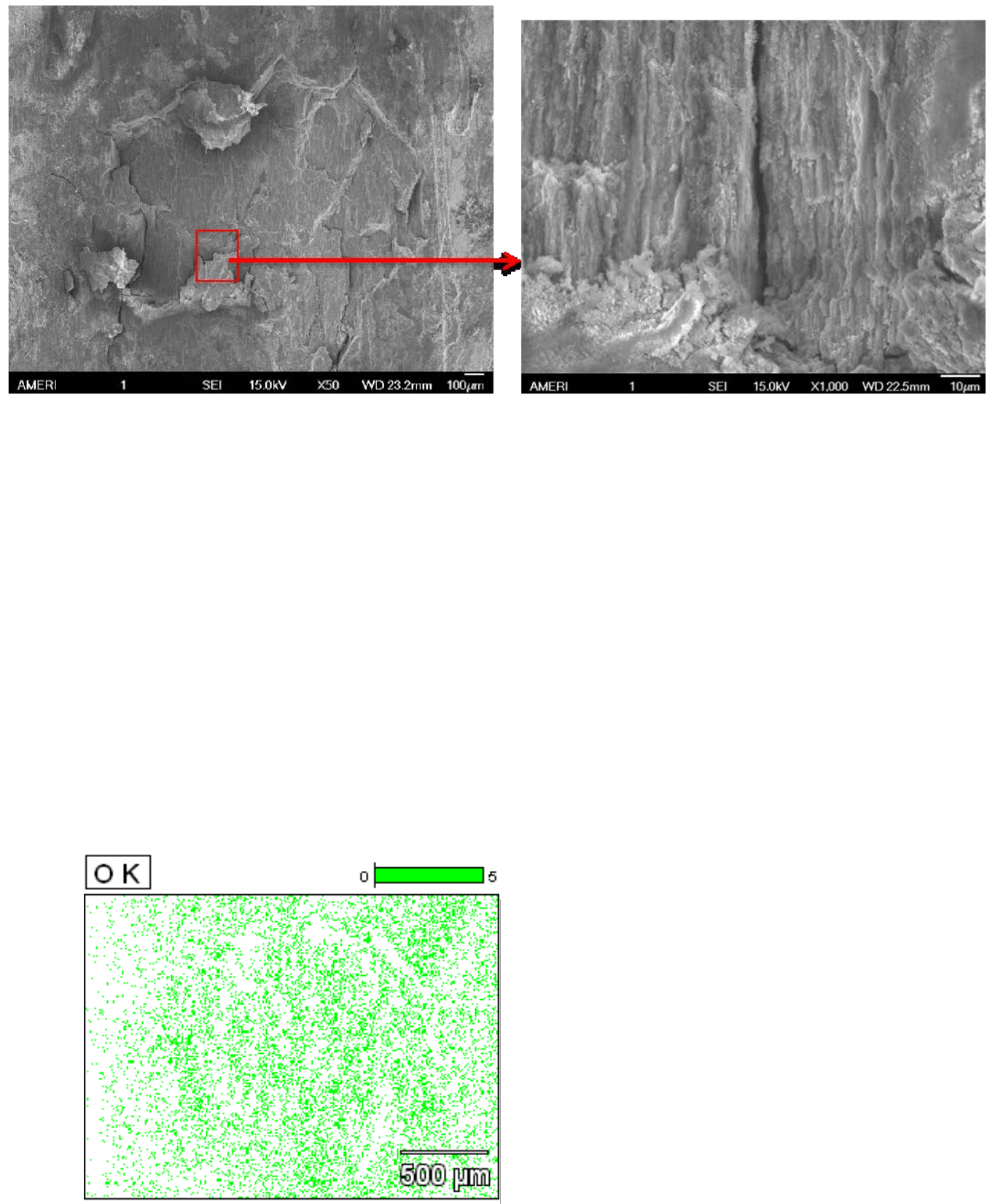

Figure 4.64: SEM Micrograph and EDS Elemental Maps on Pitting Corrosion for Corroded Wire in (Case A.P.11.1) 


\section{Discussion}

\subsection{Grout Segregation}

Grout Cylinder Test: In the pre-exposed grout, exposure of the raw grout material to $100 \% \mathrm{RH}$ for 3,7 , and 28 days as well as application of excess mix water was thought to create grout material deficiencies. As shown in Figure 4.2, grout product A generally formed uniform well-hardened samples (with minor material stratification) regardless of the pre-exposure conditions and the extra introduced water but grout product B after exposure and casting with excess water formed two segments where the bottom portion was generally uniform and well hardened and the top portion consisted of a light and friable material. As shown in Figure 4.3, the relative percent volume of the top segregated material in grout product $B$ was $10-20 \%$. The top portion is referred to as being segregated, but it is noted that the modality of physical deficiency of the created segregated grout was not overtly representative of the soft grout observed in the Florida bridges. Expired Grout A samples were made from the outflow material during pumping operations for the Modified Incline Tube Test (MIT). The outflow material nevertheless did show stratification of material along the height of the cast cylinders and the material at the top did appear less cohesive than the bulk material (Figure 4.6). 
Modified Incline Tube Test (MIT): The grout segregation in the MIT test were severe at top section with zero and medium sulfate concentration (Cases A and E), (Figure 4.12-13), which also had the highest moisture content (Figure 4.14).

The severe segregation of grout in Modified Incline Tube (MIT) Test was similar to the soft grout observed in the Florida bridges. Petrography analysis was carried out for 4 samples, to differentiate top and bottom section of the large-scale samples with zero additives (Case A) and with the top and bottom section of field sample from bridge I.The results show that the deficient grout from MIT test and field samples were consisted of silica fume admixture, some carbonate flour and a very scant amount of fully hydrated Portland cement. The polished section exhibited a clear cold joint (severe segregation) demarcation between a paste-rich cementitious zone with extensive micro cracking and a darker silica fume-rich paste that was consistent with severe segregation of the silica fume nodules (Figure 4.23), while the bottom section mostly consisted of Portland cement and less silica fume (Figure 4.23). Due to the severe segregation, estimates of the water to cement $(w / \mathrm{cm})$ ratio was especially challenging. The $w / \mathrm{cm}$ ratios likely range from 0.40 to 0.70 or higher. Samples from the bottom section were more uniform and consistent in composition and likely had water to cement $(\mathrm{w} / \mathrm{cm})$ ratios estimated at 0.40 to 0.45 .

Figure 4.23 shows a severe segregation with a darker, silica fume-rich paste on the right of the sample with abundant shrinkage micro cracking in top section of large-scale samples with no additives at 5x magnification. Figure 4.25 also 
shows segregated paste with plentiful dark-colored silica fume nodules at the bottom of the photo and very soft and porous portlandite and carbonate fine-rich paste. The bottom section formed from well to fully hydrated alite Portland cement clinker particles (red arrows) and moderately hydrated belite Portland cement clinker particle (blue arrow) in thin section of grout under transmitted plane polarized light (Figure 4.25).

Similar conditions were observed for the field samples from Bridge I. Figure 4.24 shows segregation and abundant shrinkage micro cracking. And it was reported the material was very soft (Mohs $<2$ ). In the other hand, the bottom section of field sample (Bridge I) showing a gradation of darker to lighter-colored paste with presence of entrained-sized air voids that are partially filled with ettringite and portlandite (red circles) (Figure 4.24).

Inverted Tee test (INT): Small -scale samples from the INT test which were cast with 32 days exposure and $20 \%$ extra water did show some differentiation at tee header compared to the grout in the tee body. The bottom section of both Grout A and B formed hard material with dark color (Figure 4.31,4.34.4.38). Segregated grout typically formed in the PVC tee header. Pre-exposed Grout B formed friable weak material at the top section (Figure 4.29,4.30). Pre-exposed Grout A samples also were visually differentiated (Figure 4.32-33) .As shown in Figure 4.35 and 4.36, varying severity of material separation were observed depending on the sulfate and chloride level .Generally enhanced level of segregation was observed in samples with zero additives( A.P.1 ) as well as low to medium sulfate 
concentration.(A.P.3, A.P.7-8 and A.P.10-11) . Four different layers were observed at top Tee section of these samples .As shown in Figure 4.37 the top section consist of dark gray dry porous material, lighter gray wet material, white wet plastic and black sedimented silica (Lau et al., 2013).

The samples with high-admixed sulfate concentration (case A.P.4, A.P.9 and A.P.12) formed a harder material at the top section. Bleed water (5 to $10 \mathrm{ml}$ ) with $\mathrm{pH}$ of 12.86 accumulated in the ones without chloride additives (A.P.4). Even though this excess water was present here, the grout did not form the soft deficient grout seen in the other cases (Figure 4.33, 4.36).

\subsection{Moisture and Void Content}

Grout Cylinder Test: In agreement with visual observation of severe grout segregation, the cast pre-exposed Grout B samples with excess mix water had higher bulk moisture and void content than cast samples made with Grout A (Figure 4.4). At first look, the enhanced moisture presence in Grout B would allow for a high water-to-cement ratio grout mix that can be characterized by enhanced moisture presence within the porous material. The excess mix water there evidently had more significant contribution to material segregation than its preexposure to high humidity. The segregated top portion of cast samples from Grout B showed higher moisture content and void content. In preliminary work, Grout A was shown to contain significant amounts of crushed limestone and thus was thought to have high porosity. However, even with the enhanced moisture allowances in mixing, Grout A did not show significant differentiation in bulk 
moisture content and void space and overall had lower bulk moisture and void content than Grout B. Matured grout samples cast from expired Grout A with relatively less excess mix water generally showed similar bulk moisture and void content. In those expired grout samples, the grout cast with enhanced sulfate concentrations in its mix water did tend towards lower moisture and void content. This was thought to be due to the comparatively lower water availability for cement hydration in those samples mixed with sodium sulfate solution rather than plain water.

Modified Incline Tube Test (MIT): Varying levels of grout segregation was observed for the different cases in the MIT test was thought to be related to available moisture content after mixing. Severe segregation in MIT test was correlated with high moisture content as much as $60-70 \%$ in samples A and E (Figure 4.14). When addition of sodium chloride or sodium sulfate were added, the ratio of solid to water increased thus reduced the amount of available moisture for cement hydration, although very low level of chloride concentration was added to the mix condition (Case B and C), the moisture content was half of that for samples with no additives (case A)(i.e. $70 \%$ for and $35 \%$ for cases B, C). Similar results were observed with the addition of sodium sulfate. However, unexpectedly one of the samples with sulfate concentration $(20,000 \mathrm{ppm})$ (Case E) showed high moisture content similar to the zero samples (Case A).As shown in Figure 4.21 this samples also had high current density and low corrosion potential, which was though to be related to the accumulation of sulfate ion (Figure 4.16). 
Inverted Tee test (INT): Moisture content results for INT test samples cast with pre-exposed Grout B was measured to be similar for all test cases B.A.1-3 and B.P.1-4, $(<20 \%)$, however the results were thought to have testing error due to the early water loss( 1 day) immediately after casting and prior to capping the samples. It is recalled that the segregated grout from Grout B had high porosity. Test results from the Grout Cylinder test retained moisture within the pores from its conditioning in 100\% RH environments (Figure 4.39). Significant difference in moisture content was observed in the as-received and pre-exposed samples cast with Grout A (Figure 4.40). As expected, there was differentiation in the moisture content of the grout from the tee header and body, although with varying levels of severity for the different cases. The moisture content for grout from the tee body was $8-20 \%$ for all test cases consistent with values measured for hardened as received grouts and indicative of low propensity for corrosion development (Figure 4.40-41). The moisture content for the grout from the tee header was $16-60 \%$ for all test cases and corrosion developed in grout with moisture content in the range of $38-60 \%$ (Figure $4.40-41$ ). Interestingly no corrosion developed on steel embedded in the tee header for samples in test cases A.P.4, A.P.9 and A.P.12, where additions of 100,000 ppm sodium sulfate and up to $0.2 \%$ chlorides, but can be in explained in part due to the relatively low moisture content (less than 20\%) and therefore greater electrical resistivity. It is noted again that corrosion did develop in grouts that had chloride additions (test case A.P.7-8 and A.P.10-11) that in it were not expected to facilitate corrosion initiation $\left(0.08-0.2 \% \mathrm{Cl}^{-}\right)$. As mentioned earlier, the effect of grout segregation on cement content was not 
directly considered here and furthermore ion transport in grout segregation might be important.

This high level of moisture content correlated well with sulfate concentration and corrosion properties of samples casted with combine low to medium sulfate and low to high chloride content (Cases A.P.7-8 and A.P.9-10) (Figure 4.52 and 4.58). It is clear that the level of sulfate content is very essential for segregation of the material.

\subsection{Electrical properties}

Grout Cylinder Test: Wet resistivity and mass trends are shown in Figure 4.5 for clarity the data shown in Figure 4.5 were averages from duplicate samples. Also the initial grout resistivity prior to conditioning in $100 \% \mathrm{RH}$ is shown as separate points arbitrarily placed at day 0.1 on the logarithmic time scale. For the pre-exposed grouts, the mass uptake as shown as cumulative mass fraction increase, generally showed continued mass increase even after $\sim 40$ days in $100 \% \mathrm{RH}$. Moisture uptake trends were inconclusive for the separated segregated grouts due to minor crumbling of the friable material. The wet resistivity also continued to increase with prolonged conditioning likely reflective of the continued hydration of the relatively young grout material. Contrastingly, the older expired grout samples showed terminal wet resistivity values, but unexpectedly showed continued mass increase presumably due to water uptake.

Grout product B used in the pre-exposure test samples (as described earlier) showed propensity for material segregation. The friable segregated 
material that had higher bulk moisture content and greater void presence than its hardened grout counterpart was shown to have relatively high wet resistivity (about an order of magnitude higher than the hardened portion of the same material). The resistivity of the segregated grout from the as-received (non-pre-exposed) condition could not be measured individually due to the initial cohesion of the segregated grout portion to the hardened grout portion. Thus, the measurements of the Grout B samples from the as-received condition (non-pre-exposed raw material) showed higher resistivity than the separated hardened grout samples from the pre-exposed materials.

The segregated grout samples from material pre-exposed to high humidity for 7 days showed greater resistivity values than those pre-exposed for only 3 days. Grout A and B used in the pre-exposure grout samples did not show consistent differentiation of mass increase and resistivity due to pre-exposure times. This would indicate minor influence of pre hydration by exposure in high humidity. The resistivity of samples made from Grout $A$ in the pre-exposure conditions was in the order of those in the expired condition. The grout samples in the expired condition made with varying sulfate additions did show differentiation in resistivity and those trends in resistivity values correlated well with the moisture uptake as well as the bulk moisture and void content described earlier (i.e. higher resistivity for grouts with lower moisture presence).

Modified Incline Tube Test (MIT): Solution resistances are shown in Figure 4.15 for samples from the MIT test. All other tendons indicated lower grout 
resistances in the upper portion of the tendon. The lower resistances are expected to correspond to lower grout resistivity. The low grout resistivity should characterize higher moisture content, more permeable grout, or related grout deficiency. Grout deficiency appears more sever at high elevation (Figure 4.13 and 4.23).

Inverted Tee test (INT): Solution resistances and bulk resistivity are shown in Figure4.42, 4.43 for samples from the INT test. As it shown Grout A has lower solution resistance and bulk resistivity than Grout B in both as received and preexposed conditioned. Consequently Grout A assumed to be less corrosion resistance.

In these INT test samples, the electrode in the tee header had a greater distance from the reference electrode and the electrode from tee body had shorter length $(3 \mathrm{~cm})$, This will cause higher solution resistance for the top section as we see in Figure 4.43. In order to compare grout resistivity, 2-points resistance measurements were made using two local electrodes in the tee header as well as the two local electrodes in the tee body. The distance between each pair of local electrodes was $3 \mathrm{~cm}$. The surface area of the identified top electrode was $4.9 \mathrm{~cm}^{2}$. For the bottom electrode pair, the surface area of the electrodes were similar (21 $\mathrm{cm}^{2}$ and $25.9 \mathrm{~cm}^{2}$ ) the surface area of $21 \mathrm{~cm}^{2}$ was assumed for calculation. As Figure 4.42 shows, bulk resistivity of top part of pre-exposed Grout A was not significantly different from the bottom part, which can be attributed to the water loss before capping the samples. Furthermore there was no differentiation of bulk 
resistivity as function of sulfate content .In pre-exposed Grout B, the top friable material had higher bulk resistivity than the bottom, due to the existence of higher void content (Figure 4.4, 4.30). As it shown in Figure 4.42 in pre-exposed Grout B, there is an indication of sulfate content differentiation for the top section.

It was thought that moisture availability could affect the resistance measurements. For Grout A, the segregated grout is expected to have lower resistivity due to the expected enhance moisture content, this was observed in Grout Cylinder test where moisture was measured in $100 \% \mathrm{RH}$. However, in the INT tests, the initial high moisture content in the deficient grout quickly evaporated prior to capping of the samples. Nevertheless, in the moisture content analysis discussed earlier, the deficient grout in the tee header had moisture content greater than $20 \%$ and the hardened grout in tee body had moisture content less than $20 \%$. Therefore the small difference in resolved resistivity may be due to the increased resistance of the dried friable at the surface of the deficient grout that can characterized as having large unfilled pores. For Grout B, a similar situation arises. The segregated grout in B had large pores. These pores are not saturated even in the case in Grot Cylinder test where the samples were held at $100 \% \mathrm{RH}$. This may be due to the self-desiccation of the hydrating grout. In the Grout Cylinder and INT tests, bulk resistivity of the segregated Grout B was high. The effect of sulfate presence could not be elucidated in both Grout A and B. 


\subsection{Sulfate Content}

It was documented earlier that bridge tendon locations with deficient grout that had severe strand corrosion typically also contained high sulfate ion concentration. As part of the current work, identifying sulfate ion accumulation in laboratory created (and defined) deficient grout was of importance.

\subsubsection{Sulfate Test Procedure}

Since there is no standardize method for measuring the sulfate content of cement material, three leaching procedure were chosen for the samples which were collected from the outflow of pumped grout in MIT test to reach the most conservative leaching procedure for the rest of the research. As the source and form of sulfur-bearing ions in field-extracted grout materials (and its relation to corrosion initiation) has not been completely verified, lab samples incorporated intentional sodium sulfate contamination and lab testing incorporated heating of samples to promote dissolution of sulfate ions in the leachate. Other leaching parameters as presented in the Methodology section were considered as well. Procedure to heat and to use greater leaching volumes was described in standardized methodologies to determine sulfate ion concentrations. However, the initial sulfate content in the grout pore water was thought to be important. Greater leaching volumes and temperatures (although facilitating dissolution) were thought to inflate the level of sulfate ions in the grout pore water.

Sulfate levels were initially measured as concentration of sulfate ions in leachate, but units of $\mathrm{g}_{\text {sulfate }} / \mathrm{g}_{\text {powder }}$ were reported instead in order to normalize for 
leachate volume and powder sample mass. One discrepancy that remains in the reported values is the non-standardization of the powder sample mass in terms of drying by the methodologies employed. This discrepancy also remains in field sample testing. The moisture content of grout samples (especially in powder form) may rapidly change due to environmental exposure and time of exposure. However, drying of the powder may lead to aggregation of sulfate due to the need to maintain consistency in samples mass per leaching method.

Results of initial testing of sulfate ion content in expired grout samples are shown in Figure 4.6, Leaching Method 3 (that required larger grout powder mass) was only conducted in the central portion of test samples for the expired Grout samples. Similar leaching methods were used in earlier work on a Florida bridge that had tendon failure due to deficient grout (Bridge I). Grout samples from a second Florida bridge (Bridge II) that had steel corrosion in the presence of deficient grout were similarly test. Results from both bridges were shown for comparison.

It was apparent that the reported sulfate content for the expired Grout samples and Florida Bridge I had variability by leaching methods (Figure 4.7-8). Generally, it was observed that for replicate powder samples, higher sulfate content was resolved by leaching Method 1 that employed methodologies to dry the powder sample and to use higher leachate temperature and greater volume, While Lower sulfate concentrations were resolved by leaching Methods 2 and 3 . This was not unexpected per caveats described above. Leaching Method 3 did 
yield higher sulfate concentration for expired Grout with 20,000 ppm sodium sulfate in the mix water solution. Some rational on this observation is provided later but additional testing is needed for verification. The test results indicated that material separation possibly due to enhanced moisture content at the top of the sample can affect the pore water chemistry. It was apparent that there was enhanced sulfate content in the top portions (albeit at relatively thin segments) of the test samples. Added sodium sulfate contamination also provides greater availability of sulfate ions. In comparison to the resolved sulfate content measured in grout from Bridge I and II, it is seen that separation of grout material cast in lab conditions can allow for accumulation of sulfate ions without external sulfate sources.

Enhanced sulfate content measured in expired grout mixed with intermediate added sulfate content $(20,000$ ppm sodium sulfate mix water) by leaching Method 3 in comparison to the other leaching methods of the same material may provide insight on the role of moisture, sulfate content, and grout deficiency. It was assumed (based on the high levels of sulfates measured in the top layers of expired Grout where no externally added sulfate contamination was introduced and also the high levels of sulfates measured in deficient grout in Florida bridges) that internal sulfate content may accumulate due to capillary action and changes in pore water chemistry due to grout segregation in presence of high moisture content. Factors such as pore water $\mathrm{pH}$, pore water constituency, and solubility of hydrated cement phases can affect the availability of free sulfates. The expired grout without added sulfate had greater moisture content than expired grout with added sulfates as discussed earlier. The greater moisture content in the 
former evidently caused greater level of grout deficiency at upper portions of the grout sample where there was indeed enhanced sulfate content than the rest of the sample. The mobile internal sulfate ions in the pore water would seem to be transported with free moisture towards the upper region of the sample. In the case of expired grout with high level of added sulfate content, the lower moisture content would presumable cause less grout segregation and thus minimize accumulation of internal sources of sulfate ions. The measured sulfate levels there would then presumably be due to the dissolution of the added sodium sulfate. In the case of expired grout with intermediate level of added sulfate content, the greater excess moisture presence would lead to greater degree of grout segregation, which would then allow accumulation of free internal sulfate ions in addition to that added by dissolution of sodium sulfate. Indeed the trends in possible inflation of sulfate ion content in pore water due to higher leaching temperatures and greater leachate volumes in leaching Methods 1 and 2 do not contradict the scenarios proposed above. In the expired grout that contained high level of added sulfate and had lower moisture content, the enhanced leaching procedures caused a significant increase in the sulfate ion content (presumably due to enhanced dissolution of sulfates that were maintained in cement solid phases or crystalline form such as ettringite). In the expired Grout that contained no added sulfates but had higher moisture content, the enhanced leaching procedures was less pronounced (presumably due to the already incurred dissolution of sulfate caused by the excess moisture content and grout degradation). The preceding provides some remark on observed 
behavior it serves to provide insight on possible grout material degradation as well as corrosion behavior in deficient grout.

\subsubsection{Grout Cylinder Test}

Pre-exposed grout samples were analyzed by leaching method 1 which was found to be more conservative by providing the highest $\mathrm{SO}_{4}{ }^{2-}$ ions. Method one was used for all other testing in this project. In Grout Cylinder test, pre-exposed Grout B was found to have higher sulfate concentration comparing to Grout A (Figure 4.9), which may be due to the less well manifested grout segregation of Grout A in GC test configuration. Material separation possibly due to enhanced moisture content at the top of the sample can affect the pore water chemistry, which will cause transport of more sulfate ions in top portion (Figure 4.10). Differentiation in level of free sulfate can be seen in in top, bottom and mix part of the samples. As it shown in Figure 4.9 the sulfate concentration was mostly affected by $20 \%$ extra mixed water rather than the role of exposure to the high humidity which can be kind of neglected, specially in Grout A. However in Grout B depending on available water content in zero and intermediate sulfate samples, exposure had some effect in level of sulfate solubility. Exposing the material in high humidity for longer duration can enhance level of sulfate solubility due to the availability of higher water content. This process also depend on amount of sulfate concentration, as its shown the exposure duration wasn't enough for the samples with high sulfate concentration or near saturation, extending the exposure time made no changes in sulfate concentration of these samples. 
As compared to the results of the resolved sulfate content measured in grout from Bridge I and II, it was observed that the segregation duo to $20 \%$ extra mixing water can allow for accumulation of sulfate ions without external sulfate sources.

\subsubsection{Modified incline tube test (MIT)}

Expired grout in the MIT test showed similar differentiation of sulfate by tendon location as Grout Cylinder test with expired grout. High level of sulfate concentration was found at the top Section of MIT test samples (Figure 4.16). It was noted that highest sulfate concentration (>0.01 gsulfate/gPowder) found in samples without extra sulfate source (Case A). The same level of sulfate observed in samples mixed with 20,000 ppm sodium sulfate (Case E). Which is also attributed to the enhance moisture content at these samples (Figure 4.14). Severe deficiency at top section of tendons with zero and medium sulfate concentration were visually differentiated. In comparison to the resolved sulfate content measured in grout from Bridge I and II, it is seen that separation of grout material can allow for accumulation of sulfate ions without external sulfate sources,

\subsubsection{Inverted Tee test (INT)}

Corresponding to the low level of moisture content less than 20\% (Figure 4.39), in the INT test samples cast with Grout B, (cases B.A.1-3 and B.P.1-4) sulfate content was also low, 0.001 gsulfate $/ g_{\text {Powder }}$ in all samples (Figure 4.44). There was no difference between top and bottom for samples in as received condition, while in pre- exposed condition samples with zero additives and low 
sulfate showed higher sulfate accumulation at top section which can be due to the initial segregation in these samples. Overall the of presence dry voids in these samples wont promote corrosion initiation, sulfate level up to $0.001 \mathrm{~g}$ sulfate $/ \mathrm{g}_{\text {Powder }}$ in pre-exposed Grout B was found to not initiate corrosion due to its low water availability after initial test.

As expected, Sulfate accumulation was very low in most of the INT test samples with as-received Grout A (Figure 4.46). In pre-exposed condition sulfate aggregation tend to be higher in tee header of the samples with low and medium sulfate concentration. In test case A.P.3, severe corrosion developed in the presence of 20,000 ppm sodium sulfate additions, which was consistent to corrosion behavior and visual observation. This sample was severely corroded and surrounded with deficient material with $\mathrm{pH}$ lower than 12. (Figure 4.59)(Appendix A).

Furthermore it is shown in Figure 4.57 and 4.58 that corrosion consistently developed in deficient grout that had enhanced sulfate content such as in cases A.P.3, A.P.7-8 and A.P.10-11, where the sulfate ion content was > 0.01 gsulfate/g Powder. Testing in the MIT test showed similar values. In the combined presence of sulfates and chlorides, there is congruent effect to enhance corrosion development. This may cause enhanced corrosion rates or may be associated with changes in cement chemistry as described by other litretures. (Pradhan, 2014; Maslehuddin and Paget.1997; Dehwah et al., 2002,2003; Saleem et al., 1996; AlAmoudi et al., 1993,1995;Holden et al., 1983; Yonezawa, 1989; Zuquan, et al 
2007). Supporting results were found in corrosion potential, corrosion current density and visual observation, (Figure 4.58 and 4.61-62). These samples were in highly corroding condition .It is thought that assessment of corrosion susceptibility by chloride values alone in deficient grout is insufficient as sulfate ion presence and grout characteristics are also important.

\subsection{Role of $\mathrm{pH}$}

Most of the severe deterioration mechanisms of reinforced concrete structures including corrosion, carbonation and acid attack are related to the level of alkalinity of concrete. Although the $\mathrm{pH}$ of ordinary Portland cement concrete is usually between 12.5 and 13 , which can protect the steel form corrosion, the reduction in $\mathrm{pH}$ can happen due to deterioration mechanisms such as chloride/Sulfate activities, carbonation and also using pozzolans such as silica fume to obtain big strength. Generally as we see in pourbaix diagram (Figure 5.1) Iron is in passive state in $\mathrm{pH}$ range of 10-13 (Jones, 1992). 


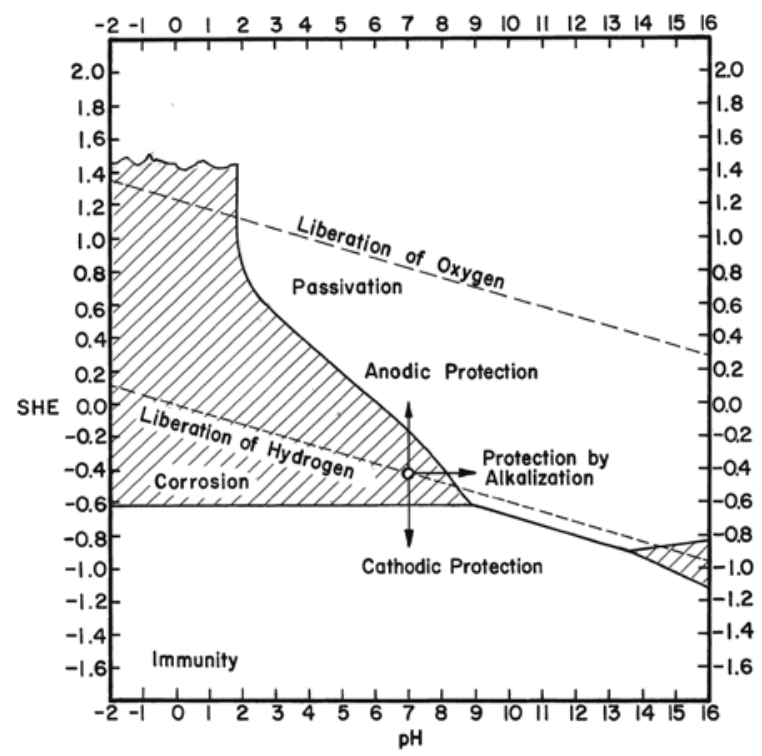

Figure 5.1: Pourbaix Diagram for Iron (Jones, 1993)

5.5.1. Role of $\mathrm{pH}$ in aqueous sulfate environment (Krishna Vignheshwaran et.al, 2016)

The test setup was made to determine if sulfates in alkaline solutions can depassivate steel or if early presence of sulfates in alkaline solution may provide conditions that would adversely affect stable passive film formation. As the role of sulfates in alkaline solutions in initiating corrosion has not been widely disseminated, only general electrochemical methods and visual analysis was conducted to gauge the issue. Small cells filled with solution were made to analyze the role of sulfates in alkaline solution $(\mathrm{pH} \sim 12.5$ and $\sim 13.3)$ Electrochemical testing included monitoring of corrosion potentials with a saturated calomel reference electrode (SCE) and linear polarization resistance measurements. 
In the second set of testing, short term tests were made to determine the anodic behavior of steel in alkaline sulfate solution. As in the first set of testing, base sulfate-free solutions as well as solutions with admixed sulfate solutions containing $2,000 \mathrm{ppm}$ or $20,000 \mathrm{ppm}$ sodium sulfate in the two different alkaline solutions. Anodic polarization measurements were made initially from -1VSCE to $+500 \mathrm{mVSCE}$ with a slow scan rate $0.05 \mathrm{mV} / \mathrm{s}$. Comparative testing of samples preconditioned at the open-circuit potential and at -1VSCE for 1 day were made. The samples pre-conditioned at OCP conditions were temporarily held at -1VSCE for 30 minutes prior to testing to minimize transient behavior when the scan started at the large -1VSCE cathodic polarization condition
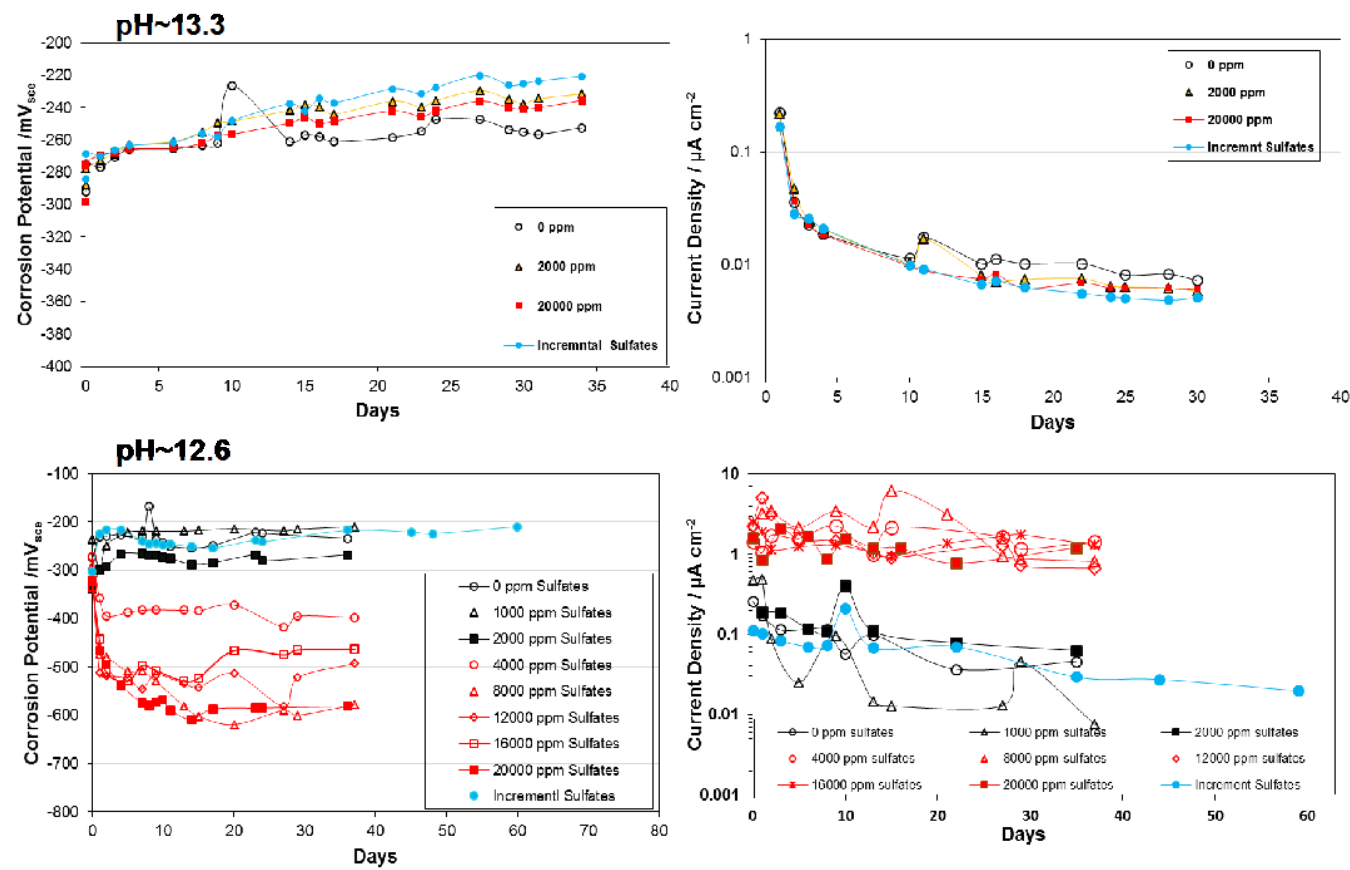

Figure 5.2: Corrosion Potential and Corrosion Current Density for Steel in Alkaline Sulfate Solution (Krishna Vignheshwaran,et.al.2016) 

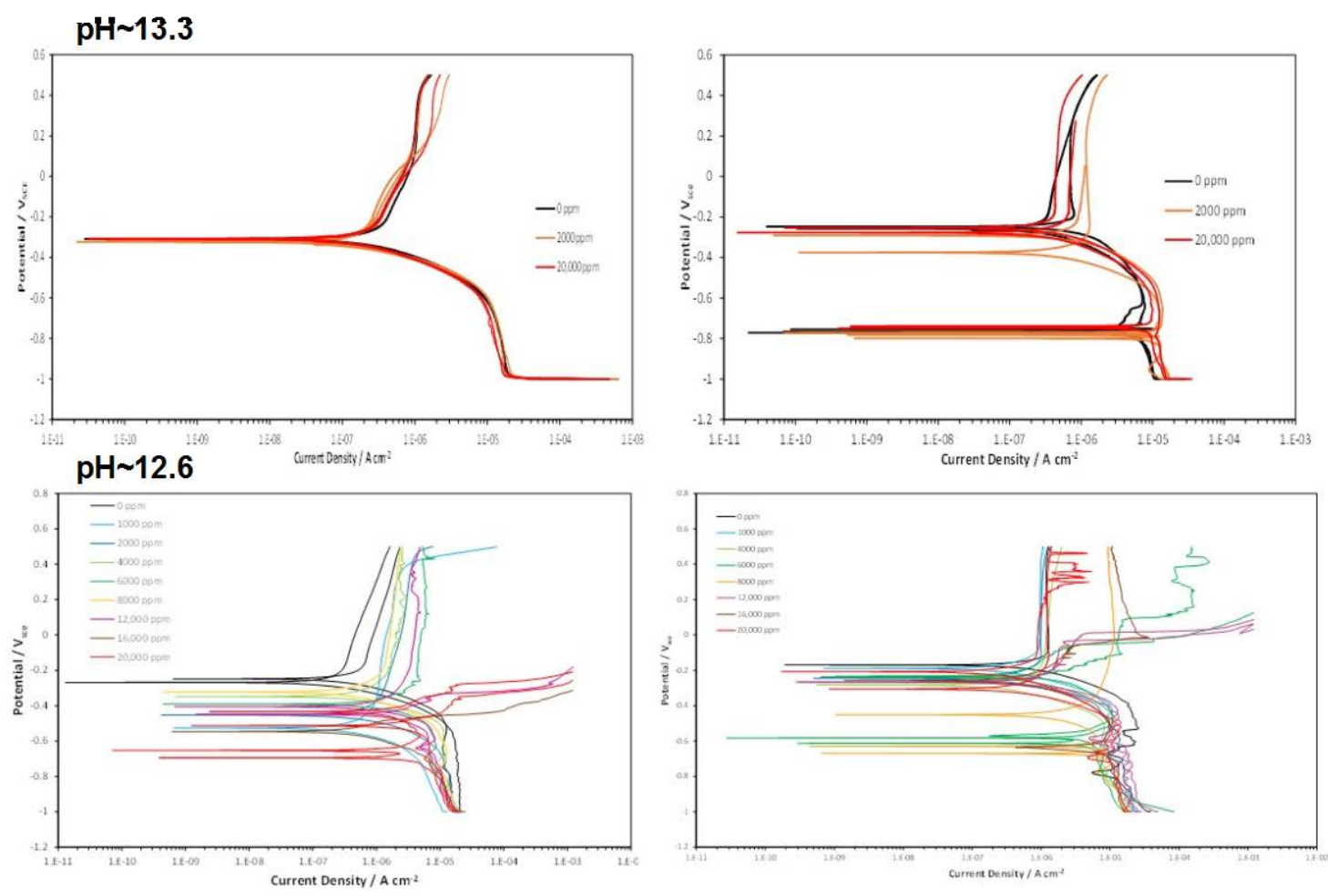

Figure 5.3: Anodic Polarization Graphs. Left: 30-Min cathodic polarization. Right: 1-Day cathodic polarization (Krishna Vignheshwaran, et.al.2016)

As was shown in electrochemical testing of the steel in sulfate solution, $\mathrm{pH}$ was one of the important factors in steel depassivation. Arzola et al.2003 reported that corrosion rate will be increase at sulfate concentration $\left(\log \left[\mathrm{SO}_{4}{ }^{2-}\right]>-2.25\right.$ (550 ppm)) in $\mathrm{pH}$ level less than 12.

Preliminary work indicated results of small cells filled with solution were made to analyze the role of sulfates in alkaline solution $(\mathrm{pH} \sim 12.5$ and $\sim 13.3$ ) comprised of saturated calcium hydroxide solution with the addition of sodium sulfate. The first two set of graphs in Figure 5.2 show the results of linear polarization tests and open circuit potential in $\mathrm{pH} 13$ sulfate solutions. Sulfates 
showed no effect on initiating or enhancing corrosion in any of the test conditions at $\mathrm{pH}$ 13.3. It was apparent that stable passive film can develop for steel immersed in $\mathrm{pH} 13.3$ solution with little adverse effect from sulfate ion presence and sulfate ions cannot destabilize already developed passive film. The anodic polarization curves were not well differentiated by sulfate ion presence at $\mathrm{pH} 13.3$ solution (Figure 5.3) (Krishna Vignheshwaran, et.al.2016).

The last set of graphs in Figure 5.2 shows the results of linear polarization tests and open circuit potential in $\mathrm{pH} 12.5$ sulfate solutions. Severe corrosion developed in the case where the steel was immersed in 20,000 ppm sodium sulfate solution. Large amounts of corrosion product formed on the steel sample. The results would indicate that in $\mathrm{pH} 12.5$ solutions, sulfates may not be able to depassivate steel, but the early presence of sulfates may destabilize passive film growth (Krishna Vignheshwaran,et.al.2016).

The $\mathrm{pH}$ of deficient grout extracted from corroded bridge tendons was typically $\sim 13$, but lower pore water $\mathrm{pH}(>12.5)$ in the deficient grout material have been measured (Figure 4.19, 4.49, 4.54, Appendix A). Anodic polarization tests of steel in sulfate solutions at $\mathrm{pH} \sim 12.5$ were conducted. Unlike in the $\mathrm{pH} 13.3$ solution, differentiation in anodic behavior was observed with the presence of sulfate ions. As shown in the last set of graphs in Figure 5.3 corrosion potentials of the steel samples in the 30-minute cathodically pre-conditioned case in the presence of sulfate ions were more negative than that of steel in sulfate free. Also, the apparent corrosion current density was significantly larger for steel in the 
presence of sulfate ions. Also, development of OCP at -650mVSCE in solution with 20,000 ppm sodium sulfate shows initial instability of the passive layer. Heavy confined corrosion was observed on those samples. As it shown in Figure 5.3, in 1-day cathodic pre-conditioning samples pitting corrosion occurred and it was visually inspected on the samples.

As initial assessment, the possible role of sulfates in steel corrosion initiation were thought to be related to localized corrosion process by reaction such as $\mathrm{Fe}^{2+}+$ $2 \mathrm{H}_{2} \mathrm{O}+\mathrm{SO}_{4}{ }^{2-} \rightarrow \mathrm{Fe}(\mathrm{OH})_{2}+\mathrm{H}_{2} \mathrm{SO}_{4}{ }^{2-}$ (15)

5.5.2. Role of $\mathrm{pH}$ in cementitious system

Grout Cylinder Test: Pore water $\mathrm{pH}$ of Grout A and B in different set of exposure in the Grout Cylinder test is shown in Figure 4.11. The pH was in the range 12-13 of in all samples with some exception, As it was reported earlier, Grout A formed hard uniform material and Grout B formed weak friable material at the top which tend to have lower $\mathrm{pH}$ due to less cement ratio.

Modified incline tube test (MIT): In MIT test samples, the $\mathrm{pH}$ was reported to be in range of 12.5 -13.Zero samples (Case A) with highest moisture content and less cement ratio had $\mathrm{pH}$ of less than 10.5 . Which is really close to carbonation limits, (Figure 4.19). However, the same sample was sprayed with $\mathrm{pH}$ indicator and $\mathrm{pH}$ measurements did not give any color indication of drop in $\mathrm{pH}$. The $\mathrm{pH}$ was reported to be around 11. (Figure 4.20) All top section of big tendons had higher 
current density and the $\mathrm{pH}$ was found to be $12.5-13$, and sulfate concentration reported to be high in zero, med sulfate and low chloride samples with highest Moisture content compare to all.

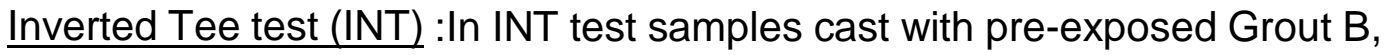
the top section with zero additives had $\mathrm{pH}$ of 12 (Figure 4.48), Even though the material was highly permeable, there was no introduction of corrosion activity, due to the low level of sulfate and moisture content. Grout A showed similar behavior with the exception of pre-exposed sample mixed with medium sulfate concentration (Figure 4.49). The wire was surrounding with white chalky material and corroding in the tee header (Figure 4.59), the $\mathrm{pH}$ was measured to be less than 12 (Figure 4.49, Appendix A), the moisture content was as high as $40 \%$ and the sulfate content was reported to be as high as $0.01 \mathrm{~g}$ sulfate $/ \mathrm{g}$ Powder .

Similar trends were observed in samples with combine sulfate and chloride content. Corroded samples (case A.P.7-8 and A.P.9-10) had pH lower than 12, which can be, cause following the previous reaction (15) (Figure 4.54). Congruent presence of sulfate and chloride will results in enhances accumulation of free sulfate and chloride ions. As it shown in the Figure 5.4, Mindess, 2003 stated that If the $\mathrm{pH}$ drop below 11.5, the passive iron oxide layer is destroyed and causing the normal, porous oxide layer (rust) to form during corrosion. This critical deduction in $\mathrm{pH}$ occurs when first the alkalis and the calcium hydroxide are converted to carbonate. However all the reported $\mathrm{pH}$ were above 11.5 and as Broomfield, 2000 and S.K. Lee, 2014 reported, if the $\mathrm{pH}$ of the grout was above 
10.0, therefore carbonation did not occur during the accelerated corrosion development. And the only cause of corrosion can be defined by common effect of lower $\mathrm{pH}$ (less than 12), High sulfate, high moisture and less cement content.

In INT test, pre-exposed Grout A in tee header tend to have lower pH which is due to the presence of corrosion products and the segregation and accumulation of silica fume, that may take part for the consumption of hydroxyl ions ion and slight decrease in pH. (Lau et al, 2013).

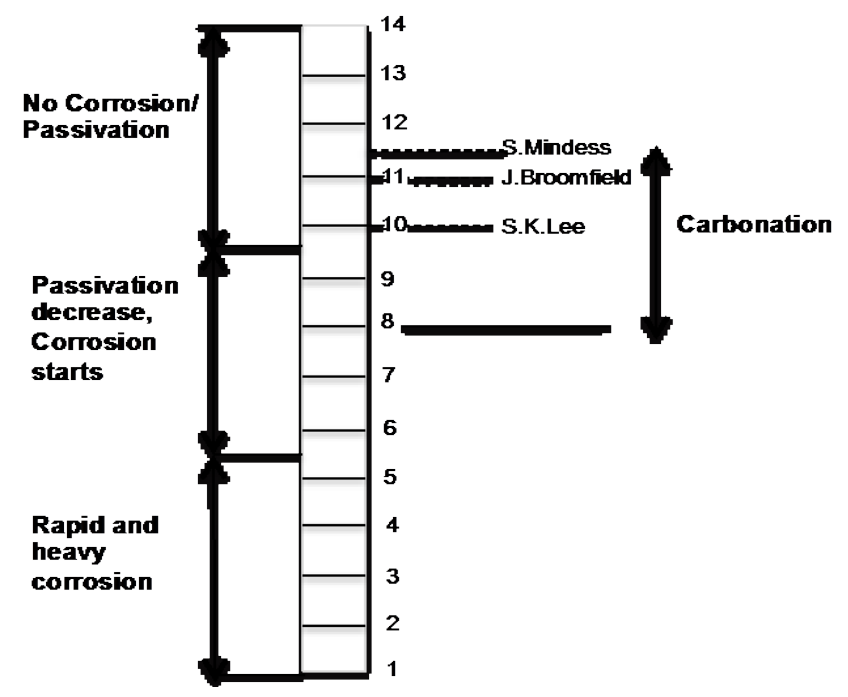

Figure 5.4: Corrosion of Steel in Concrete as a Function of $\mathrm{pH}$

\subsection{Role of Total Chloride}

Chloride presence in the grout of post-tensioned tendons can initiate steel strand corrosion. Elevated levels of chloride as high as 5.27 percent by weight of cement were recently documented (S.K.Lee. 2014) in a commercially available pre-packaged grout product for post-tensioned tendons, which well exceeded the maximum chloride limit. Recent research on the chloride threshold limits for 
chloride content in pre-packaged grout products presented findings that strand corrosion initiated at chloride contents above 0.2 percent by weight of cement (S.K.Lee, 2014) However, the proposed limits were analyzed without consideration of possible development of grout deficiencies such as that observed in the recent tendon failures in Florida. Analysis of deficient grout in the Florida post-tensioned bridges where severe corrosion developed indicated low chloride content, enhanced sulfate ion concentration, high pore water $\mathrm{pH}$, and enhanced moisture content.

Modified incline tube test (MIT): In order to assess the role of deficient grout on strand corrosion development, laboratory samples were created with $20 \%, 15 \%$ excess water to enhance deficient grout materials and included enhanced sulfate (2000, 20,000, and 100,000 ppm) and chloride (low $0.08 \%$ and high $0.2 \%$ by mass cement) content. The segregated grout water chemistry including combinations of enhanced sulfate and chloride ion presence was thought to provide aggressive corrosion conditions. Generally as the chemical analysis showed, the level of water leachate chloride content was very low in all MIT and INT test samples (Figure 4.16) beside the samples which was already mix with some level of chloride content.

As it shown in Figure 4.21 corrosion could develop in MIT test samples initially cast with as little as $0.08 \%$ (by cement content) extra chlorides when in the presence of deficient grout with enhanced sulfate. Sulfate and chloride concentrations may accumulate in the deficient grout due to segregation (Figure 
4.17). Furthermore, the deficient grout contains lower cement content.

Inverted Tee test (INT) :In INT test, no active corrosion condition was observed in samples, which cast with pre-exposed Grout A, B containing Low 0.08\% to High $0.2 \%$, Chloride Content (cases A.P.5-6) .As it was mentioned before, INT test samples couldn't achieve the high level of deficiency as it was reported in Florida Bridges. However, severe corrosion condition was monitored in presence of low to Medium Sulfate concentration with low to high Chloride content (cases A.P.7-8 and A.P.10-11). Which is associated to congruent role of high sulfate content in deficient grout.

The total chloride in the segregated grout layers was measured (Figure $4.17,4.45,4.47,4.53)$. On first inspection, it would appear that there was enrichment of total chloride content in the grout from the tee header and top section, which would indicate ionic transport due to the grout segregation. Although this cannot be ruled out, the total chloride test preparation methods may oversample the segregated grout due to uniform sample mass requirements and the inevitable moisture loss from initial conditions during sample preparation and therefore result in higher reported chloride concentrations. For chloride analysis, a grout unit density of 3,105 lb/yd ${ }^{3}$ was assumed (Lau et al., 2014) but this value is likely to be variable by the severity of grout segregation. With these uncertainties understood, the reported results should be considered qualitatively (values are given for comparison). The results show that in test cases A.P.5-6, the grout in the tee header and body had enhanced chloride ( 0.06 to $0.12 \%$ by total grout mass in 
header and 0.03 to $0.1 \%$ by total grout mass in body) but corrosion did not develop. However in test cases A.P.7-8 and A.P.10-11, where similar chloride levels were present ( 0.03 to $0.18 \%$ by total grout mass in header), severe corrosion developed in the deficient grout. It is noted that corrosion did not develop in the tee body even though there was enhanced chloride content there as well ( 0.03 to $0.09 \%$ by total grout mass in body). The enhanced sulfate additions apparently had effect in the corrosion development. It was reported in the literature that the presence of sulfate ion may reduce the chloride binding capacity of cement and release the chloride ion into pore solution( Dehwah et al., 2002,2003).

Overall according to the result of total chloride analysis MIT and INT tests, it can be concluded that possible significant chloride accumulation can be found in deficient grout.

\subsection{Corrosion behavior}

\subsubsection{Modified incline tube test (MIT)}

Steel corrosion probes were embedded along the length of the large mockup tendon samples. Two corrosion probes were located within $1 \mathrm{ft}$. of the top of the inclined tendon. Three corrosion probes were located at lengths $1<1<5 \mathrm{ft}$. from the top of the tendon. Averages for measurements for the two top corrosion probes on each tendon and its replicate tendon and averages for the bottom three probes on each tendon and its replicate tendon were reported. 
As Figure 4.21 shows the OCP and corrosion current were greater for probes located in the upper $1 \mathrm{ft}$. region of the tendons regardless of the level of external sulfate and chloride augmentation. Active corrosion potentials <$300 \mathrm{mV}$ SCE and corrosion current densities $>0.05 \mathrm{uA} / \mathrm{cm}^{2}$ were observed for steel sensors in grout in upper tendon elevations containing enhanced external additions of chlorides and sulfates. Active corrosion current densities are not unexpected for the tendons containing chloride augmentation. Even though relatively low chloride content was admixed (less than $0.2 \%$ by cement mass). Testing by Lee et al indicated $0.2 \%$ chloride content by cement content may be considered as an upper threshold bound for PT grouts (Lee 2012,2014) but the cement content in the deficient grout is expected to be lower and there may be accumulation of chlorides as well in segregated portions of the cast grout.

Enhanced corrosion conditions (albeit smaller than compared to others test conditions at upper elevations) were measured for the grout without chloride or sulfate external additions (Case A). As it was described, it is possible that sulfate accumulated at significant concentrations at the upper elevations of the tendon where there may be deficient grout. The corrosion potential difference between steel in the upper elevation and lower elevation can be as much as $100 \mathrm{mV}$. If these electrodes were to be coupled such as that to be expected for strand embedded in grout, it can be expected for macrocell coupling to occur. If the anodic characteristics of the steel in the deficient grout at upper elevations show Tafellike behavior, enhanced corrosion currents may occur. The measured enhanced 
corrosion of steel in the top portions of the tendon samples without enhanced chloride concentrations may be analogous to the observed corrosion of steel in deficient grout observed in field conditions. As described earlier, the deficient grout created in the lab samples had analogous enhanced moisture and sulfate content as well as lower permeability. One of the corroded steel probes embedded in the top portion of a tendon initially cast with 20,000 ppm sodium sulfate in the grout mix water is shown in Figure 4.12 along with a photo of the deficient grout.

As shown in Figure 4.15, electrical solution resistance was lower for the grout from the upper elevations of the large mockup tendons than lower elevations indicating more permeable grout associated with grout deficiency .The lower resistance at the top of the samples is consistent with the higher corrosion current density measured for the plain steel sensors it is striking that poorer grout quality (by comparison of Rs) was consistently observed in the upper elevation of the tendon. The enhanced external addition of chloride and sulfates did not appear to be a major factor in the solution resistance in the top or bottom of the tendons.

\subsubsection{Inverted Tee test (INT)}

As mentioned earlier, grout segregation was expected due to the aggravated mix conditions, and the deficient grout was expected to accumulate in the tee header due to volume displacement. As steel electrodes were placed within the tee header and tee body, corrosion conditions due to grout segregation may be assessed. Results from similar testing of large-scale tendon mockups following a modified inclined tube test showed that enhanced corrosion could develop in the deficient 
grout that formed near the high elevation outlet. It is noted that the extent of grout segregation in these INT test samples were not as severe as in the MIT test or as that observed in the field. Pre-exposed grout from product A and B were casted in 5.35" wide PVC tee with $20 \%$ extra water. Carbon steel wires were embedded at Top and bottom section of the small tee shape PVC samples. All the measurements were applied to both steel wires. As well as the casting the worst condition of the grout, control set of the samples were created to represent the good condition of the grout without pre-exposing or extra mixing water (A.A.1-3 and B.A.1-3). Figure 4.55 shows, Grout B had passive like corrosion condition, the corrosion potential was in the range of $(-100,-200 \mathrm{mV}$ cse $)$ and current density was $0.01-0.001 \mu \mathrm{A} / \mathrm{cm}^{2}$, in as-received and pre-exposed condition. One set of samples with pre-exposed grout and high sulfate concentration (B.P.4) showed lower corrosion potential than the others, in range of $-220 \mathrm{mV}_{\text {cse}}$, which was expected to have higher current density, but Its current was in the range of all other samples $\left(0.001-0.01 \mu \mathrm{A} / \mathrm{cm}^{2}\right)$.

According to previous results, even though it was expected that the adverse properties of segregated top part of pre-exposed Grout B affect corrosion behavior, there was no indication of active corrosion in those segregated part, which were also observed after opening and investigating the samples. These segregated material characterize as poor cohesive balk material, which found to have higher void and moisture content, sulfate and solution resistivity while preserving in high humidity condition. As it shown in Figure 4.39, moisture content was the same for all the samples, which were cast with different grout condition. 
INT test samples with as-received Grout A (A.A.1-3) did not show active corrosion behavior for both tee header and tee body section. As Figure 4.57 shows the OCP and corrosion current density (icorr) for test samples (cases A.P.1-4) where only sulfate additions were made to the pre-exposed Grout A. There was differentiation in OCP and $i_{\text {corr }}$ for steel embedded in the tee header and tee body consistent with trends of enhanced corrosion activity in deficient grout observed in the large scale mockups and in the field. However the conditions here appeared less adverse. The corrosion potential of steel in the tee body and tee header was $\sim-150 \mathrm{mV} \mathrm{CSE}_{\mathrm{CS}}$ and $-250 \mathrm{~m} \mathrm{~V}_{\mathrm{CSE}}$, respectively. In comparison corrosion potentials in deficient and hardened grout in the MIT test and in the field were less than $350 \mathrm{mV}$ CSE and greater than $-200 \mathrm{mV}$ CSE, respectively. In the INT tests here, one sample with 20,000 ppm sodium sulfate addition (A.P.3) exhibited severe active corrosion conditions where $\mathrm{i}_{\text {corr }}$ exceeded $1 \mathrm{uA} / \mathrm{cm}^{2}$. As shown in Figure 4.59-60, significant corrosion developed on the steel embedded in deficient grout that accumulated in the tee header. The $\mathrm{pH}$ of the grout there was greater than 11 as shown by $\mathrm{pH}$ spray indicator.

Additions of sodium chloride (cases A.P.5-6) were made to levels associated with minimum chloride limits in cementitious materials $(0.08 \%$ and $0.2 \%$ chloride by cement content). Vestigial chloride content was assumed to be negligible. The total chloride content was measured but the effect of grout segregation on cement content was not directly assessed here. The physical consistency of the grout in the tee header for these samples was not the wet and 
highly friable material characteristic of corrosive deficient grout observed elsewhere (Figure 4.36). With that in mind, the electrochemical characteristics were indicative of low corrosion conditions (Figure 4.56). Like other cases, the corrosion current density, albeit at relative low values, were differentiated by the segregated layers. The OCP for steel in both the tee header and body was $200 \mathrm{mV}$ CSE. Corrosion current densities were less than 0.01UA.cm². It was apparent that the levels of chloride located within the grout layers in these samples did initiate corrosion development.

\subsubsection{Combined Sulfate and Chloride}

It was reported in the literature that the combined presence of sulfate and chloride ions in solution could enhance the corrosion rate of steel. As literatures reported (Pradhan, 2014; Maslehuddin and Paget.1997; Dehwah et al., 2002,2003; Saleem et al., 1996; Al-Amoudi et al., 1993,1995; Holden et al., 1983; Yonezawa, 1989; Zuquan, et al 2007) the presence of sulfate ions in chloride solution did influence the corrosion rate. The presence of sulfate ion will reduce the chloride binding capacity of cement, therefore releasing the chloride ion into pore solution which can cause steel depasivation by increasing in sulfate ion concentration. Combine presence of chloride and sulfate ions increases the concentration of free chloride and sulfate ions in the pore solution compared to the specimens contaminated with only sodium chloride or sodium sulfate. This increase in the chloride and sulfate concentration is attributed to the simultaneous 
reaction of $\mathrm{C}_{3} \mathrm{~A}$ with both chloride and sulfate ions to produce Fridels salt and calcium sulphoaluminate respectively.

In the testing here (cases A.P.7-8 and A.P.10-11), samples with chloride levels where corrosion is not expected to develop (and indeed were not observed in cases A.P.5-6), also incorporated sodium sulfate additions to examine the combined effect. Severe corrosion developed in the deficient grout within the tee header for cases with as low as 2,000 ppm sodium sulfate addition in combination with chloride additions as low as $0.08 \%$. As shown in Figure 4.58 , the steel in deficient grout with combined presence of sulfates with low level chlorides had active corrosion potentials $<-400 \mathrm{mV}$ SCE and current densities as high as $6 \mathrm{uA} / \mathrm{cm}^{2}$. As seen in Figure 4.61-62, severe corrosion developed in the deficient grout with $\mathrm{pH}>11$ as determined by $\mathrm{pH}$ spray indicator. All the deficient part changed to lighter purple color ( $\mathrm{pH}$ 11-12). The $\mathrm{pH}$ was also measured by ex-situ leaching method; $\mathrm{pH}$ was reported to be in range of 11.5-11.7 (Figure 4.54). All the $\mathrm{pH}$ level were above 10 , therefore carbonation did not occur during the accelerated corrosion development. (S.K Lee, 2014). As SEM and EDS analysis showed the corrosion product containing iron and oxygen mixed with grout material was detected for Case A.P.11.1.In addition, there was a evidence of pitting corrosion which mostly filled by $\mathrm{FeO}_{2}$ (Figure 4.63-64).

New threshold limit can be purposed for chloride ions, it can be recommended that Chloride concentration should be lower than $0.08 \%$ by cement, 
considering possible existence of deficient grout and high sulfate content

As we see in Figure 4.58, samples with high sulfate concentration $(100,000 \mathrm{ppm})($ cases A.P.9 and A.P.12) showed no active behavior in presence of Low and high Chloride, which can be attributed to the over saturation condition, low moisture content and high resistivity. As long as enough water is available in system, sufficient amount of free sulfate ion can cause active corrosion in specific $\mathrm{pH}$.

\subsection{Overall discussion}

As other literatures (Arzola et al., 2003,Krishna Vignheshwaran et al., 2016) and the work here showed, changes in pore water chemistry can affect the initiation of steel corrosion in the presence of sulfate ions. Corrosion was observed in samples with $\mathrm{pH}<12.6$, which is correlated well with electrochemical results as described in section 5.5.1 (Krishna Vignheshwaran et al., 2016). However in these test where $\mathrm{pH}>13.3$, corrosion did not develop, even though sulfate concentration were as high as 60,000 ppm .It was evident that corrosion initiation can't be defined by sulfate content alone, instead a ratio of $\left[\mathrm{SO}_{4}{ }^{2-}\right] /\left[\mathrm{OH}^{-}\right]$was adopted for analysis (Figure 5.5).The corrosion potential and corrosion current density of steel in the different test condition in the research were compiled to evaluate the pore water condition where corrosion can occur.

Two samples, with surface rust development, showed enhanced corrosion current density ( $\mathrm{i}_{\text {corr }} \sim 0.3 \mathrm{uA} / \mathrm{cm}^{2}$ ) with active corrosion potentials (OCP $\sim-0.3$ $\mathrm{mV}$ sce) at $\left[\mathrm{SO}_{4}{ }^{2-}\right] /\left[\mathrm{OH}^{-}\right] \sim 1$. At $\left[\mathrm{SO}_{4}{ }^{2-}\right] /\left[\mathrm{OH}^{-}\right] \sim 0.15$, two other samples had similar 
active corrosion electrochemical parameters, but the steel in this case did not develop significant rust during the time of the experiment. Nevertheless, $\left[\mathrm{SO}_{4}^{2-}\right] /\left[\mathrm{OH}^{-}\right]=0.15$ may be considered as a conservative limit. At this limit, the sulfate content in $\mathrm{pH}$ 12.6-13.3 pore solution corresponded to $\sim 600-3000 \mathrm{pm}$.
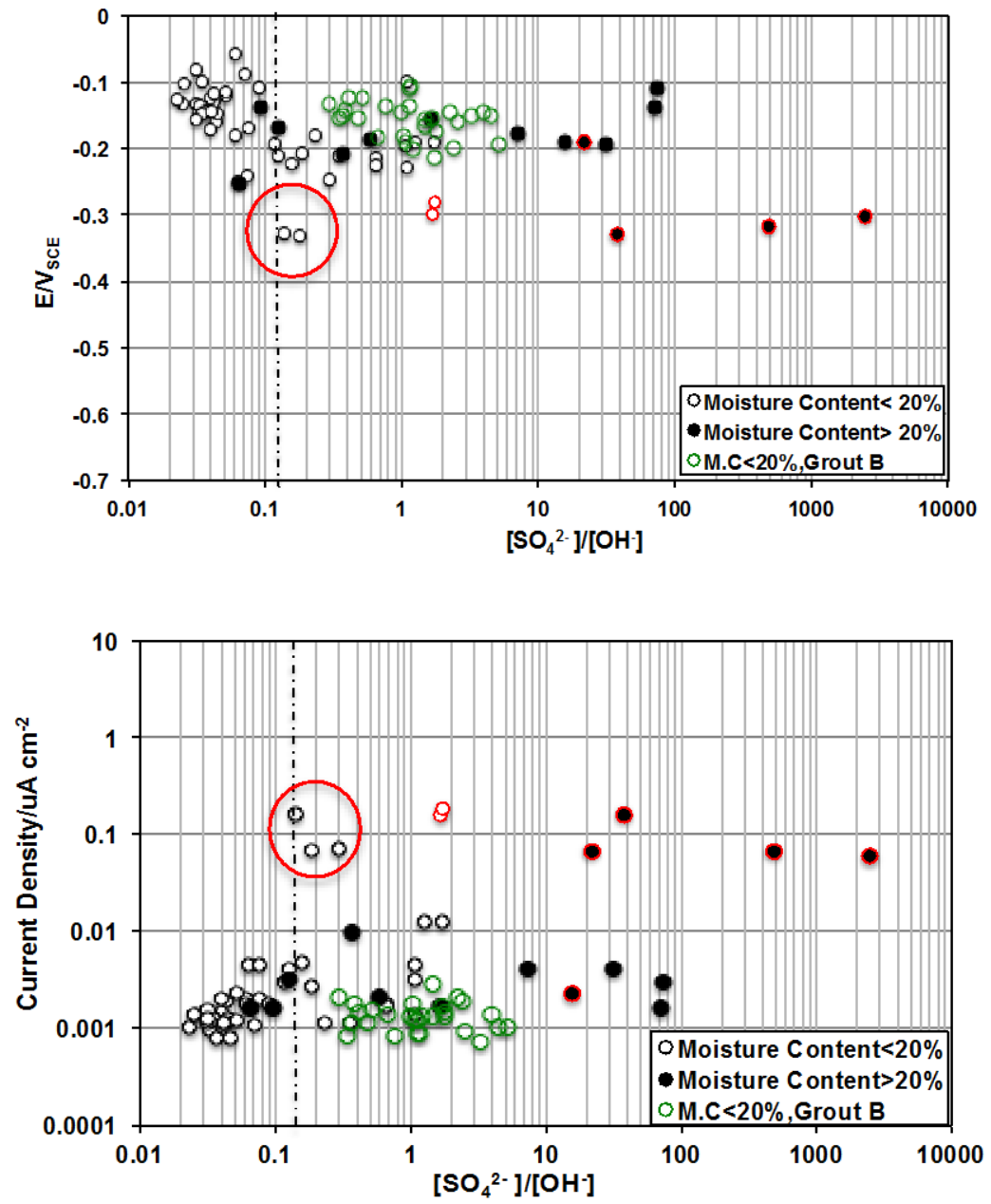

Figure 5.5: Sulfate /Hydroxyl Threshold Value Based on Corrosion Potential and Current Density. (Corrosion occurred in points with red outline)

To characterize the extent of sulfate accumulation, three levels were proposed based on experimental observations. Low sulfate accumulation was assumed to have concentrations less than $0.00042 \mathrm{~g}_{\text {sulfate }} / \mathrm{g}_{\text {Powder, }}$ which was the 
highest amount of sulfate measured in the as-received grout that did not have any grout degradation. A proposed high-end value was based on the sulfate level where corrosion typically developed in testing. The intermediate sulfate range was proposed as characterizing moderate sulfate accumulation.

Figure 5.6 shows the corrosion potential and current density versus total chloride content from compiled tests results. As part of the research some of the samples were mixed with or without chlorides. Steel corrosion initiated in conditions where sulfate levels ( $\left.\sim 0.0007 \mathrm{~g}_{\text {sulfate }} / \mathrm{g}_{\text {Powder }}\right)$ exceeded the low level of sulfate range. The value corresponded to the test sample conditions suggesting the $\left[\mathrm{SO}_{4}{ }^{2-}\right] /\left[\mathrm{OH}^{-}\right]=0.15$ limit for typical grout $\mathrm{pH}$ environments ( $\mathrm{pH}$ range: 11.5 to 13, all the testing from spray indicator also showed $\mathrm{pH}>11$ ).

As shown in Figure 5.6, sulfate accumulation by segregation can cause corrosion initiation. Furthermore, addition of low amount of chloride in deficient grout can significantly increase the corrosion rate of steel. The samples with chloride level from $0.0002-0.002$ (gchloride/g Powder) corroded when the deficient grout contained sulfates exceeding the low range of sulfate accumulation. Therefore it shown that low level of chloride ion presence would accelerate the corrosion rate, after initiation due to sulfate presence. It was apparent that assessment of corrosion susceptibility by chloride values alone in deficient grout is insufficient as sulfate ion presence and grout characteristics are also important. 

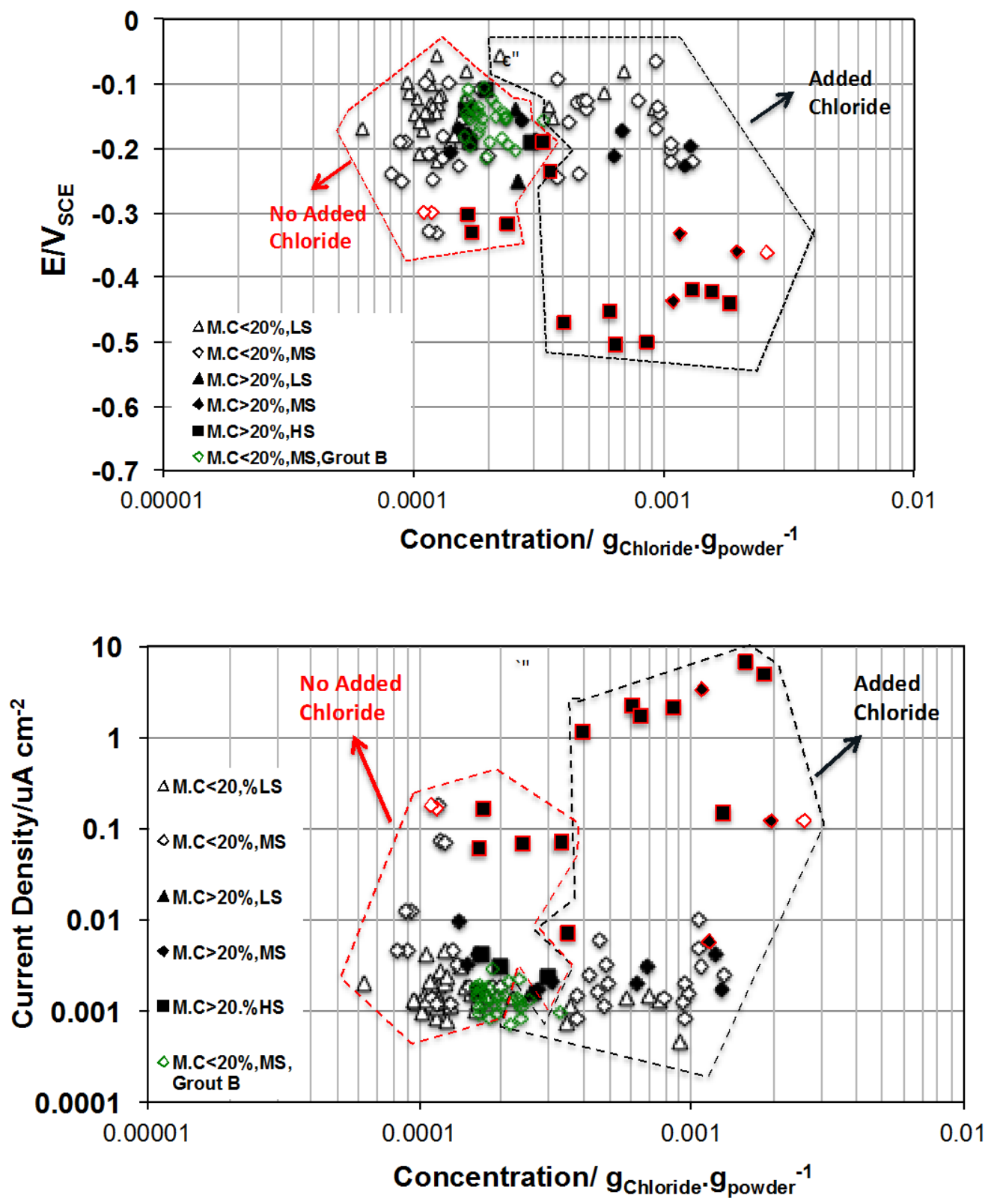

Figure 5.6: Corrosion Potential and Current Density versus Total Chloride Content (Corrosion occurred in points with red outline)

Low Sulfate $($ LS $)<0.00042 \mathrm{~g}_{\text {sulfate }} / \mathrm{g}_{\text {Powder }}$

$0.00042<$ Med Sulfate (MS) $<0.01 \mathrm{~g}$ sulfate $/ \mathrm{g}_{\text {Powder, }}$

High Sulfate $(\mathrm{HS})>0.01 \mathrm{~g}$ sulfate $/ \mathrm{g}$ Powder

\section{CONCLUSION}


- High moisture content promotes grout deficiency. Excess mix water appears more significant than up to 28 days of grout powder pre-exposure in $100 \%$ relative humidity.

- The level of grout deficiency caused by excess mix water and pre-exposure in $100 \%$ relative humidity can vary by grout product.

- Deficient grout where corrosion developed contained moisture content from 38 to $60 \%$.

- High sulfate concentrations can be accumulated in segregated deficient grouts without external sulfate sources and coincident with severe corrosion development

- Enhanced corrosion can occur in deficient grout created with expired grout and pre-exposed grout with excessive mix water.

- Corrosion may initiate by combined effect of $\mathrm{pH}$ in range of 11 to13, high sulfate, and high moisture and less cement content.

- Corrosion developed in deficient grout with 20,000-ppm addition of sodium sulfate to its mix water. Corrosion was also observed in deficient grout with as low as 2,000-ppm sodium sulfate when combined with chloride. In these cases, corrosion occurred when the sulfate ion concentration was $\sim 0.01$ g sulfate/g Powder.

- $\left[\mathrm{SO}_{4}{ }^{2-}\right] /\left[\mathrm{OH}^{-}\right]=0.15$ can be considered as a conservative limit for corrosion initiation of steel in grout.

- Additions of 0.08 and $0.2 \%$ chloride by cement in itself did not initiate 
corrosion in any of the stratified grout layers. Corrosion developed in deficient grout materials with similar low-level additions of chlorides (0.03 to $0.18 \%$ of total grout mass) when combined with as low as 2,000-ppm sodium sulfate in its mix water. The enhanced sulfate addition apparently had effect to initiate corrosion in presence of low-level chlorides.

- Low level of chloride ion presence can accelerate the corrosion rate of steel in deficient grout, after corrosion initiation due to sulfate presence.

- Assessment of corrosion susceptibility in deficient grout by chloride values alone is insufficient as sulfate ion presence and grout characteristics are also important. 


\section{REFERENCES}

A. Turnbull (Ed.), Pourbaix, Localized corrosion: behaviour and protection mechanisms, in Corrosion Chemistry within Pits, Crevices and Cracks, Teddington, Middlesex, National Physical Laboratory, 1984, pp. 1-15.

A.A. Sagues, "Corrosion of Post-Tensioning Strands," FDOT, Tallahassee, FL, 2005.

A.A.Ramezanianpour , P.Pourbeik , F.Moodi "Sulfate Resistance of Concretes Containing Rice Husk Ash" 5 National Congress on Civil Engineering, 2010

A.J. Al-Tayyib, and M.S. Khan, "Effect of Sulfate lons on the Corrosion of Rebars Embedded in

13. 1991. Pp. 123-

Al-Amoudi, Omar Saeed Baghabra, and Mohammed Maslehuddin. "The effect of chloride and sulfate ions on reinforcement corrosion." Cement and Concrete Research 23.1 (1993): 139-146. Mohem , look againg for reaction of salts

Al-Amoudi, Omar Saeed Baghabra, Mohammed Maslehuddin, and Yaser AB Abdul-Al. "Role of chloride ions on expansion and strength reduction in plain and blended cements in sulfate environments." Construction and Building Materials 9.1 (1995): 25-33.

Alam, Bashir, et al. "Sulphate Attack in High-Performance Concrete-A Review." International journal of Advanced Structures and Geotechnical Engineering, ISSN: 2319-5347, 2012

Alkire, Richard, and Antonio Cangellari. "Effect of benzotriazole on the anodic dissolution of iron in the sence of fluid flow." Journal of The Electrochemical Society 135.10 (1988): 2441-2446.

Arzola, S., M. E. Palomar-Pardave, and J. Genesca. "Effect of resistivity on the corrosion mechanism of mild steel in sodium sulfate solutions." Journal of applied electrochemistry 33.12 (2003): 1233-1237.

ASTM, C 642," Standard test method for density, absorption, and voids in hardened concrete," Annual Book of ASTM Standards, vol. 04.02, American Society for Testing and Materials ,West Conshohocken, PA 2002. 
ASTM, C1580-05, "Standard test method for water -soluble sulfate in soil," American Society for Testing and Materials ,West Conshohocken, PA(2007)

ASTM, C566-13,"Standard Test Method for Total Evaporable Moisture Content of Aggregate by Drying," American Society for Testing and Materials ,West Conshohocken, PA

ASTM, D4972-13," Standard Test Method for pH of Soils ," American Society for Testing and Materials, West Conshohocken, PA

ASTM,C25-11," Standard Test Methods for

Quicklime, and Hydrated Lime," American Society for Testing and Materials ,West Conshohocken, PA

B. Hansen, "Forensic Engineering: Tendon Failure Raises Questions about Grout in Post- Tensioned B ridges," C i il Eng neering N ew s, 2007. Vo L 77, No. 11. p.17-18.

Behnood, Ali, Kim Van Tittelboom, and Nele De Belie. "Methods for measuring pH in concrete: A review." Construction and Building Materials 105 (2016): 176-188.

Bertolini, Luca, and Maddalena Carsana. "High pH corrosion of prestressing steel in segregated grout." Modelling of corroding concrete structures. Springer Netherlands, 2011. 147-158.

Broomfield, John P. "Carbonation and its effects in reinforced concrete." Materials performance 39.1 (2000).

Carsana, M., and Bertolini, L. "Corrosion Failure of Post-Tensioning Tendons in Alkaline and Chloride-Free Segregated Grout: A Case Study." Structure and Infrastructure Engineering: 2015

Corven, John, and Alan Moreton. Post-tensioning tendon installation and grouting manual. No. FHWA-NHI-13-026. 2013.

Cyler F. Hayes "Test Methods for water-Soluble Sulfate in Soils" Portland cement association, PCA R\&D serial No. $3016 \quad$,2007

D. et al.Trejo, "Effect of Voids in Grouted, Post-Tensioned Concrete Bridge Construction: Vol.1- E lectrochem ica IT esting and R e liab ility A sse ssm ent" TTI, College Station, TX, 2009. 
Das, Parag C., Dan M. Frangopol, and Andrzej S. Nowak, eds. Current and Future Trends in Bridge Design, Construction and Maintenance 2: Safety, Economy, Sustainability and Aesthetics: Proceedings of the International Conference Organized by the Institution of Civil Engineers, and Held in Hong Kong on 25-26 April 2001. Vol. 2. Thomas Telford, 2001.

Dehwah, H. A. F., M. Maslehuddin, and S. A. Austin. "Effect of sulfate ions and associated cation type on the pore solution chemistry in chloridecontaminated plain and blended cements." Cement and Concrete Composites 25.4 (2003): 513-525.

Dehwah, H. A. F., M. Maslehuddin, and Simon A. Austin. "Long-term effect of sulfate ions and associated cation type on chloride-induced reinforcement corrosion in Portland cement concretes." Cement and Concrete Composites 24.1 (2002): 17-25.

Durability of post-tensioning tendons: technical report: proceedings of a workshop held at Ghent University on 15-16 November 2001. Vol. 15. fib Fédération internationale du béton, 2001

Elahi, AHM Fazle, Zia Uddin Md Chowdhury, and Mohammed Enamul Hoque. "Characterization of Coastal Water Deposits and its Subsequent Effect on Piping Materials."2014

FDOT (Florida Department of Transportation), "Sunshine Skyway Bridge Post-Tensioned Tendons Investigation,"Ta

FM 5-516 "Florida Method of Test For Determining Low-Levels of Chloride in Concrete and Raw Materials " May 7,2013

Frankel, G. S. "Pitting corrosion of metals a review of the critical factors." Journal of the Electrochemical Society 145.6 (1998): 2186-2198.

G.T. Burstein, P.C. Pistorius, S.P. Mattin, The nucleation and growth of corrosion pits on stainless steel, Corros. Sci. 35 (1993) 57-62.

Gui, Jing, and T. M. Devine. "The influence of sulfate ions on the surface enhanced Raman spectra of passive films formed on iron." Corrosion science 36.3 (1994): 441-462..

H. R. Hamilton ,Final report "Simulation of Prepackaged Grout Bleed under Field Conditions," FDOT ,Gainesville, Florida , (2014) 
H.-H. Strehblow, Mechanisms of Pitting Corrosion, in: P. Marcus (Ed.) Corrosion Mechanisms in Theory and Practice, 2nd ed., Marcel Dekker Inc., New York, 2002, pp. 243-285.

Hekal, E. Eo, E. Kishar, and H. Mostafa. "Magnesium sulfate attack on hardened blended cement pastes under different circumstances." Cement and Concrete Research 32.9 (2002): 1421-1427.

Hewson, Nigel R. Prestressed concrete bridges: design and construction. Thomas Telford, 2003.

Holden, W. R., C. L. Page, and N. R. Short. "Corrosion of reinforcement in concrete construction." Chichester: Ellis Horwood Ltd (1983): 143-50.

Hurst, Melvin Keith. Prestressed concrete design. CRC Press, 2002.

J. Corven, "Mid Bay Bridge Post Tensioning Evaluation," FDOT, Tallahassee, FL, 2001.

Jones, Denny A. Principles and prevention of corrosion. Macmillan, 1992

K. Lau, I , Lasa, and M. Paredes," Update on Corrosion of Post-Tensioned Tendons with Deficient Grout in Florida." NACE International Corrosion Conference 2014.

K. Lau, M, Paredes, and R, Powers "Corrosion Evaluation of Repair-Grouted Post-Tensioned Tendons in Presence of Bleed Water." NACE Int. Paper No. 2604. Houston., 2013.

K. Lau,I. Lasa, and M. Paredes, "Corrosion Failure of Post-Tensioned Tendons in Presence of Houston, 2013

K.K.Krishna Vinheshwaran, K.Lau, S.Permeh, and I.Lasa. "Anodic Behavior of Steels in Enhanced Sulfate Solution "71 ${ }^{\text {st }}$,NACE International Corrosion Conference, Vancouver,BC,Canada.March 2016

Kishar, Essam A., et al. "Effect of calcium chloride on the hydration characteristics of ground clay bricks cement pastes." Beni-Suef university journal of basic and applied sciences 2.1(2013): 20-30

Kwan, Albert KH, and Henry HC Wong. "Durability of Reinforced Concrete Structures, Theory vs Practice." Department of Civil Engineering, The University of Hong Kong (2005). 
L.L. Shreir, R.A. Jarman, G.T. Burstein (Eds.), Corrosion, 3rd Ed., Vol. 1, 1994, Butterworth Heinemann, Oxford.

Lagerblad, Björn. Leaching performance of concrete based on studies of samples from old concrete constructions. SKB, 2001.

Lamond, Joseph F. Significance of tests and properties of concrete and concrete-making materials. Vol. 169. P(256-258),ASTM International, 2006.

Leckie, H. P., and H. H. Uhlig. "Environmental factors affecting the critical potential for pitting in 18-8 stainless steel." Journal of the Electrochemical Society 113.12 (1966): 1262-1267

Lee, Seung-Kyoung, and James Zielske. An FHWA Special Study: Posttensioning Tendon Grout Chloride Thresholds. No. FHWA-HRT-14-039. 2014.

M. Acha, C. Alonso, and C. Andrade, "Corrosión bajo tension de alambres de acero de pretensado en $\mathrm{m} e$

Revista/Libro: 1990

MacDougall, B., and Jennifer A. Bardwell. "Passivation of iron in sulfate, perchlorate, and borate solutions: role of borate in the passivation process." Journal of the Electrochemical Society 135.10 (1988): 2437-2441.

Man, H. C., and D. R. Gabe. "The determination of pitting potentials." Corrosion Science 21.4 (1981a): 323-326.

Man, H. C., and D. R. Gabe. "The study of pitting potentials for some austenitic stainless steels using a potentiodynamic technique." Corrosion Science 21.9 (1981b): 713-721.

Mandhyan, A. K. "Corrosion of metals and its prevention." (2007): 19-47.

Marchand, Jacques, Ivan Odler, and Jan P. Skalny. Sulfate attack on concrete. CRC Press, 2003.

Maslehuddin, M., and C. L. Paget. "Temperature effect on the pore solution chemistry in contaminated cements." Magazine of Concrete Research 49.178 (1997): 5-14.

Mindess, Sidney, J. Francis Young, and David Darwin. Concrete. 2003.

Mrowczynski, G., and Z. Szklarska-Smialowska. "Electrochemical and eclipsometric study of iron corrosion inhibition in sodium sulphate solutions 
containing aliphatic acids." Journal of Applied Electrochemistry 9.2 (1979): 201-207.

Nürnberger, U. "Korrosion der Baumetalle im Kontakt mit mineralischen Baustoffen.",IBAUSIL,Tagung,2000

O'Reilly, Matthew, David Darwin, and JoAnn Browning. Corrosion Performance of Prestressing Strands in Contact with Dissimilar Grouts. No. KS-12-4. Kansas Department of Transportation, 2013

PCA , Americas cement manufacture association (http://www.cement.org/forconcrete-books-learning/concrete-technology/durability/corrosion-ofembedded-materials)

Pistorius, P. C., and G. T. Burstein. "Growth of corrosion pits on stainless steel in chloride solution containing dilute sulphate." Corrosion science 33.12 (1992): 1885-1897.

Powell, L. C., John Edward Breen, and Michael Eugene Kreger. State of the Art Externally Post-tensioned Bridges with Deviators. The Center, 1988.

Pradhan, Bulu. "Corrosion behavior of steel reinforcement in concrete exposed to composite chloride-sulfate environment." Construction and Building Materials 72 (2014): 398-410.

Prasad, J., D. K. Jain, and A. K. Ahuja. "Factors influencing the sulphate resistance of cement concrete and mortar." Asian Journal of civil engineering (Building and housing) 7.8 (2006).

$\mathrm{Pu}$, Qi, et al. "Evolution of $\mathrm{pH}$ and chemical composition of pore solution in carbonated concrete." Construction and Building Materials 28.1 (2012): 519524.

R. P. Spragg, J. Castro, T. Nantung, M. Paredes, W. J. Weiss ,"Variability analysis of the bulk resistivity measured using concrete CYLINDERS", Joint transportation research program . Indiana department of Transportation and purdue University.(2011)

R.G. Powers, "Corrosion Evaluation of Post-Tensioned Tendons on the Niles Channel Bridge," FDOT, Gainesville, FL, 1999

Räsänen, $\mathrm{V}$., and V. Penttala. "The pH measurement of concrete and smoothing mortar using a concrete powder suspension." Cement and Concrete Research 34.5 (2004): 813-820. 
Raupach, Michael, et al., eds. Corrosion of reinforcement in concrete: Monitoring, prevention and rehabilitation techniques. Woodhead Publishing, 2014.

Rosenfeld, I. L., and I. S. Danilov. "Electrochemical aspects of pitting corrosion." Corrosion science 7.3 (1967): 129-142

S. K. Lee, "Literature Review of Chloride Threshold Values of Grouted PostTensioned Tendons," Federal Highway Administration, FHWA-HRT-12-067, McLean, 2012.

S.M. Abd El Haleem, S. Abd El Wanees, E.E. Abd El Aal, A. Diab" Environmental factors affecting the corrosion behavior of reinforcing steel II. Role of some anions in the initiation and inhibition of pitting corrosion of steel in $\mathrm{Ca}(\mathrm{OH}) 2$ solutions", Corrosion science, Volume 52, Issue 2, February 2010, Pages 292-302.

Saleem, M., et al. "Effect of moisture, chloride and sulphate contamination on the electrical resistivity of Portland cement concrete." Construction and Building Materials 10.3 (1996): 209-214.

Soil in the Urban Environment, SOIL SCINCE AUSTERALIA

Szklarska-Smialowska, Z. "The pitting corrosion of iron in sodium sulphate." Corrosion Science 18.1 (1978): 97-101.

Taylor, Harry FW. Cement chemistry. Thomas Telford, 1997

Tex-620-J "Determining chloride and sulfate contents in soil ", Construction Division, August 2005

The Portland Cement Association (PCA). Corrosion of Embedded Materials.[Online] [Cited: March 30, 2016.] http://www.cement.org/forconcrete-books-learning/concrete- technology/durability/corrosion-ofembedded-materials.

Thomas Telford- "Ponts en Béton Précontrait Par Post-tension, post tensioned concrete bridges" Jan 1, 1999 , 164 pages

Thomas, M. D. A., et al. Alkali-Silica Reactivity Field Identification Handbook. No. FHWA-HIF-12-022. 2011. 
Traubenberg, S. E., and R. T. Foley. "The influence of chloride and sulfate ions on the corrosion of iron in sulfuric acid." Journal of The Electrochemical Society 118.7 (1971): 1066-1070.

V.K. Gouda, "Corrosion and corrosion inhibition of reinforcing steel: I. Immersed in alkaline -3034tion." B ritish C o 1970.

V.K. Gouda, and W.Y. Halaka, "Corrosion and corrosion inhibition of reinforcing steel: II. Em bedded in cc pp.204-8, 1970.

Vatankhah, Gh, et al. "Electrodissolution of iron in sodium sulfate and sodium bicarbonate solutions at pH8." Journal of applied electrochemistry 28.2 (1998): 173-183

Yonezawa T, Ashworth V. Procter RPM. The Mechanism of fixing $\mathrm{Cl} \square$ by Cement Hydrates resulting in the transformation of $\mathrm{NaCl}$ to $\mathrm{NaOH}$. Proceedings of the 8th International Conference on Alkali-Aggregate Reaction. Kyoto. 1989:153-160.

Zuquan, Jin, et al. "Interaction between sulfate and chloride solution attack of concretes with and without fly ash." Cement and Concrete Research 37.8 (2007): 1223-1232. 


\section{APPENDICES}


Appendix A: Photos of pH Results for MIT and INT Test (By applying the $\mathrm{pH}$ indicator)

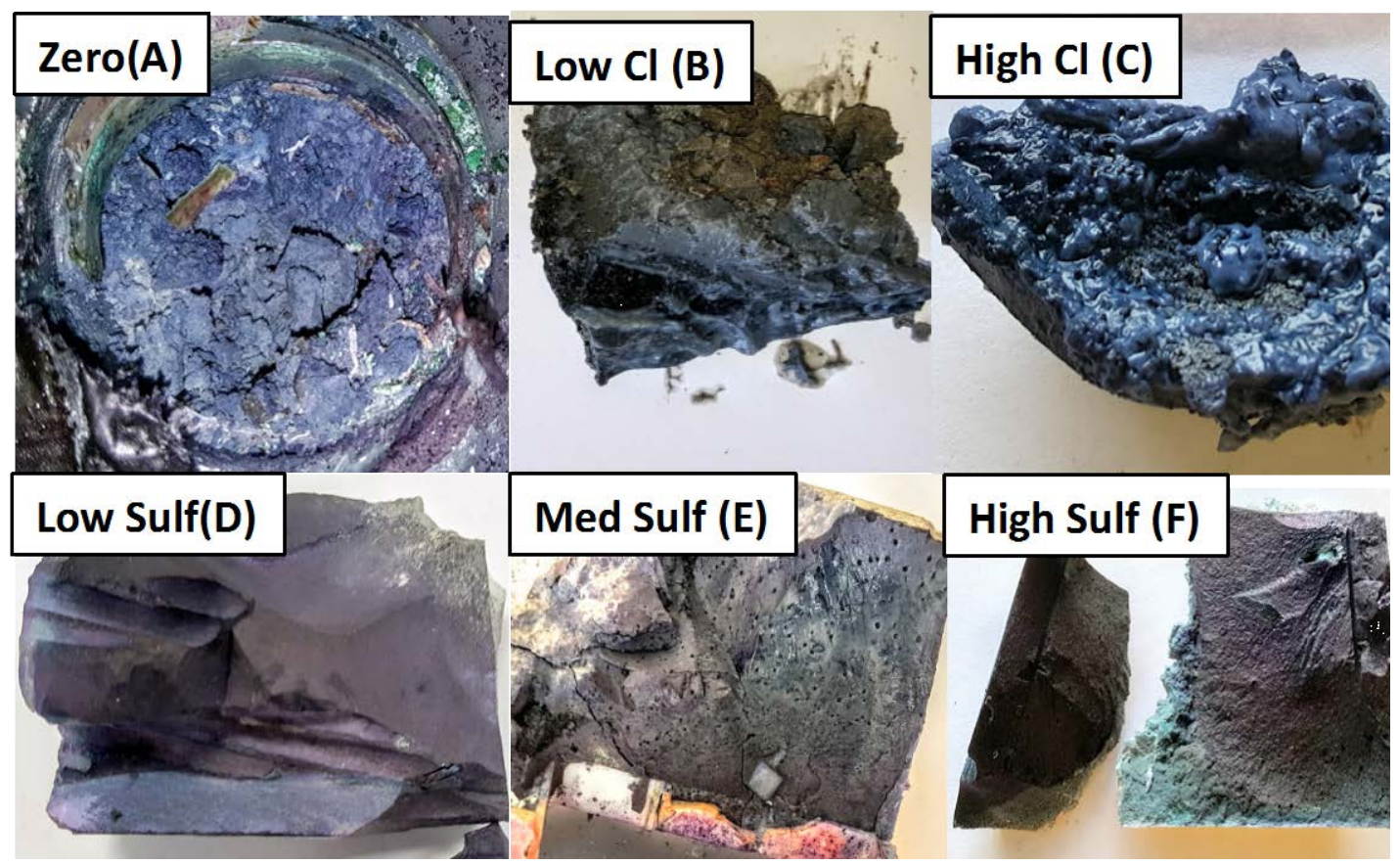

Figure A.1: Photos of pH Results for MIT Test (Case A,B,C, D,E,F)

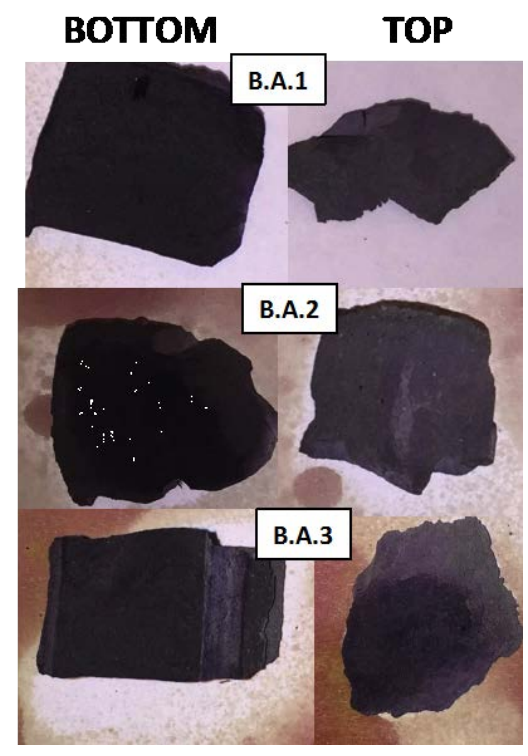

Figure A.2: Photos of pH Results for INT Test (Case B.A.1-3) 


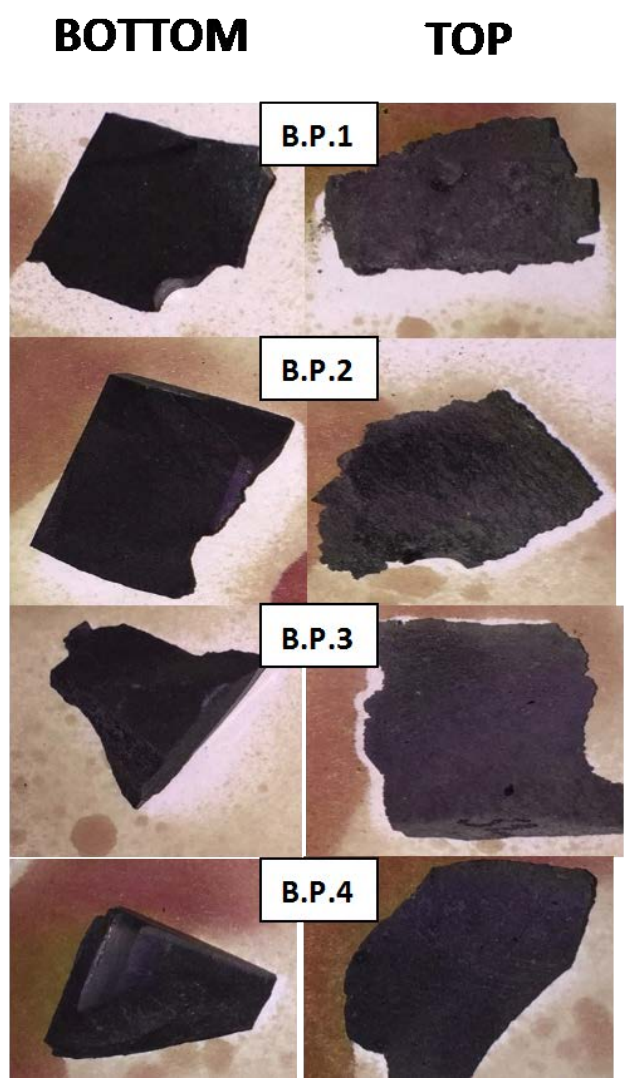

Figure A.3: Photos of pH Results for INT Test (Case B.P.1-4)

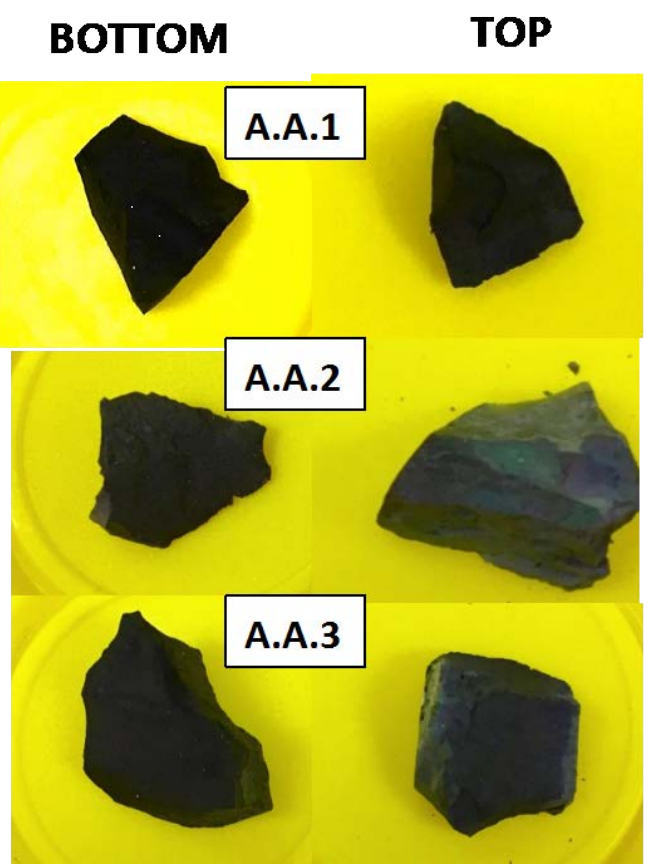

Figure A.4: Photos of pH Results for INT Test (Case A.A.1-3) 


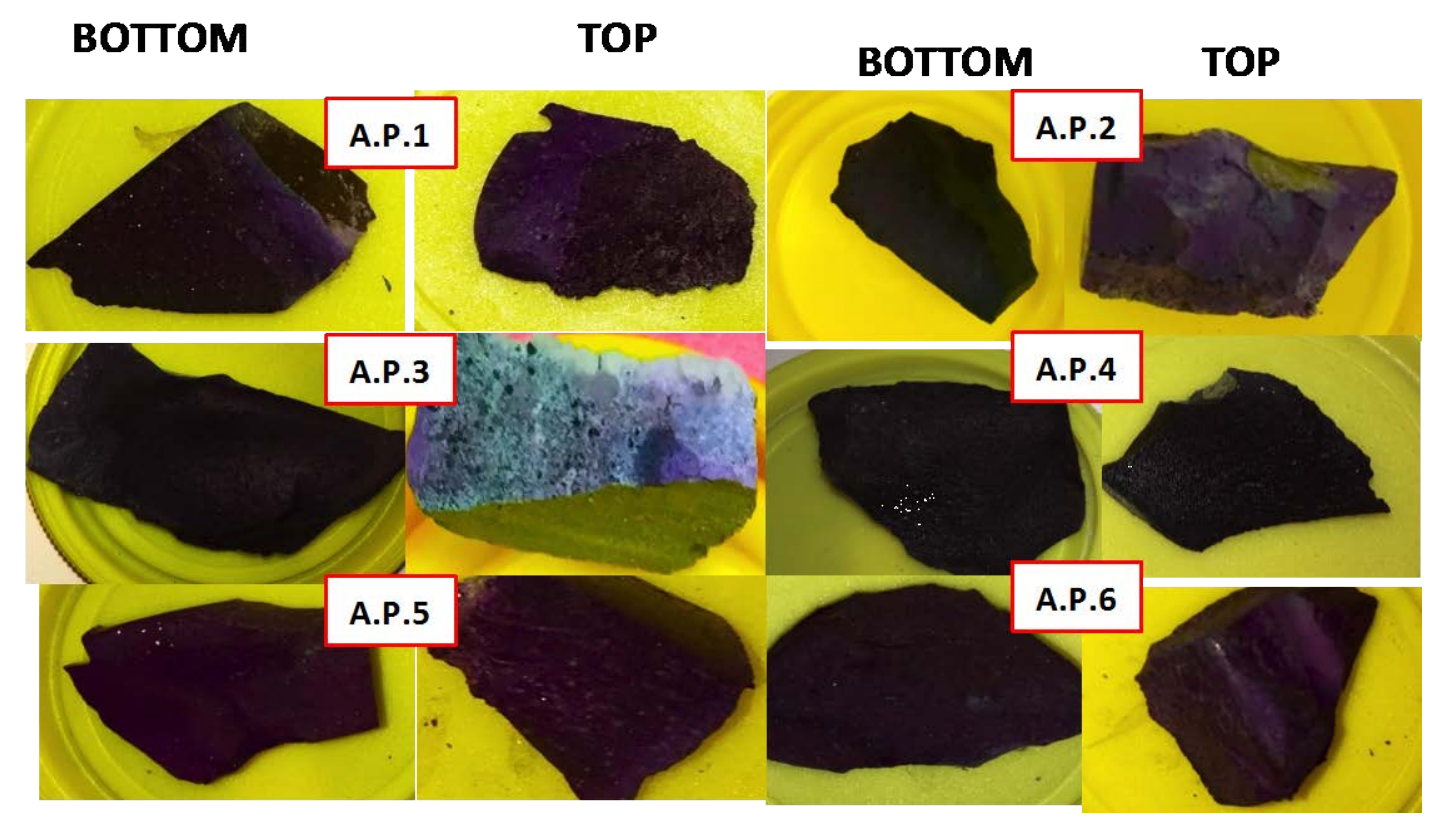

Figure A.5: Photos of pH Results for INT Test (Case A.P.1-6)

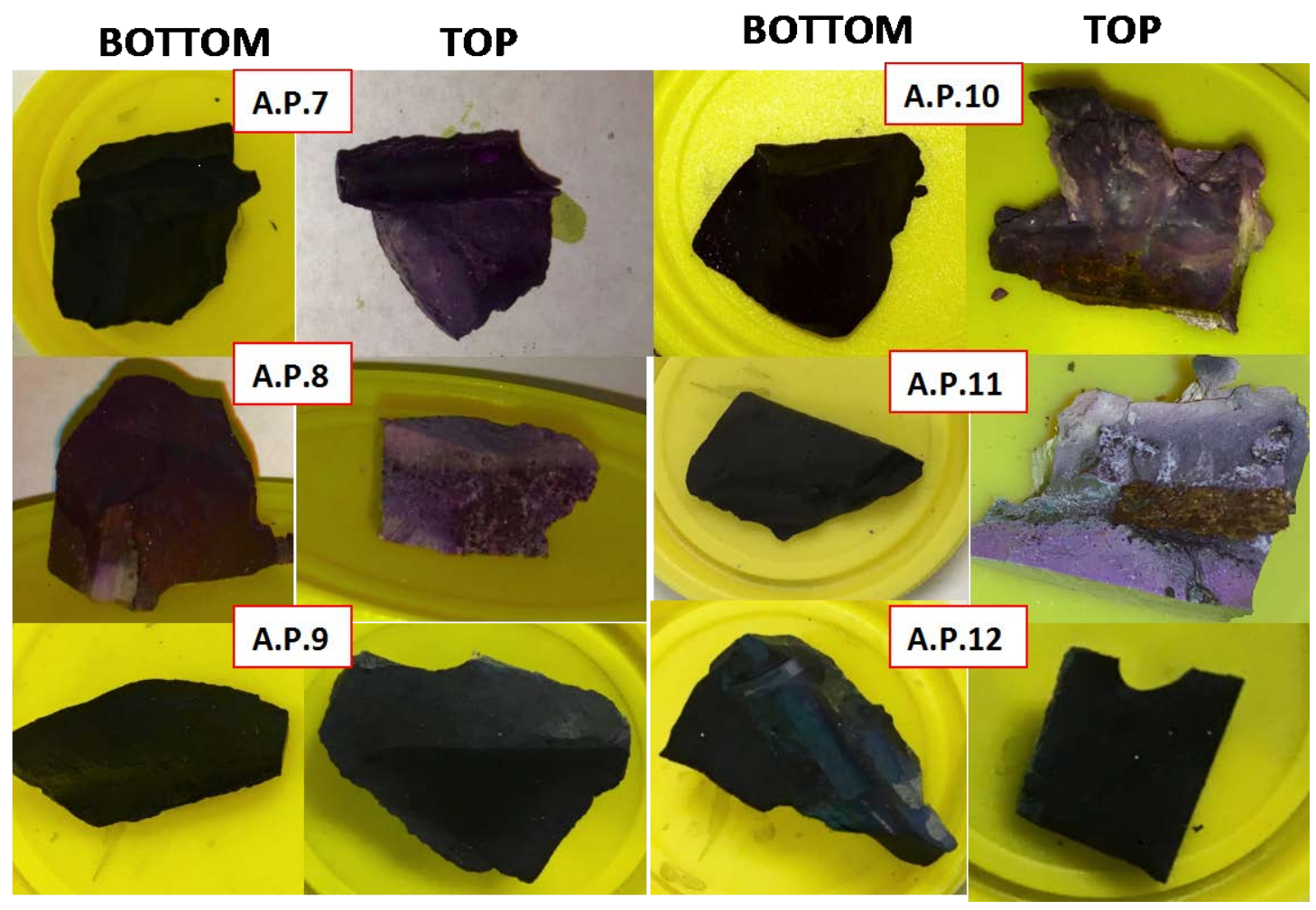

Figure A.6: Photos of pH Results for INT Test (Case A.P.7-12) 
Appendix B: Photos of Steel Wire at Tee Header in INT Test

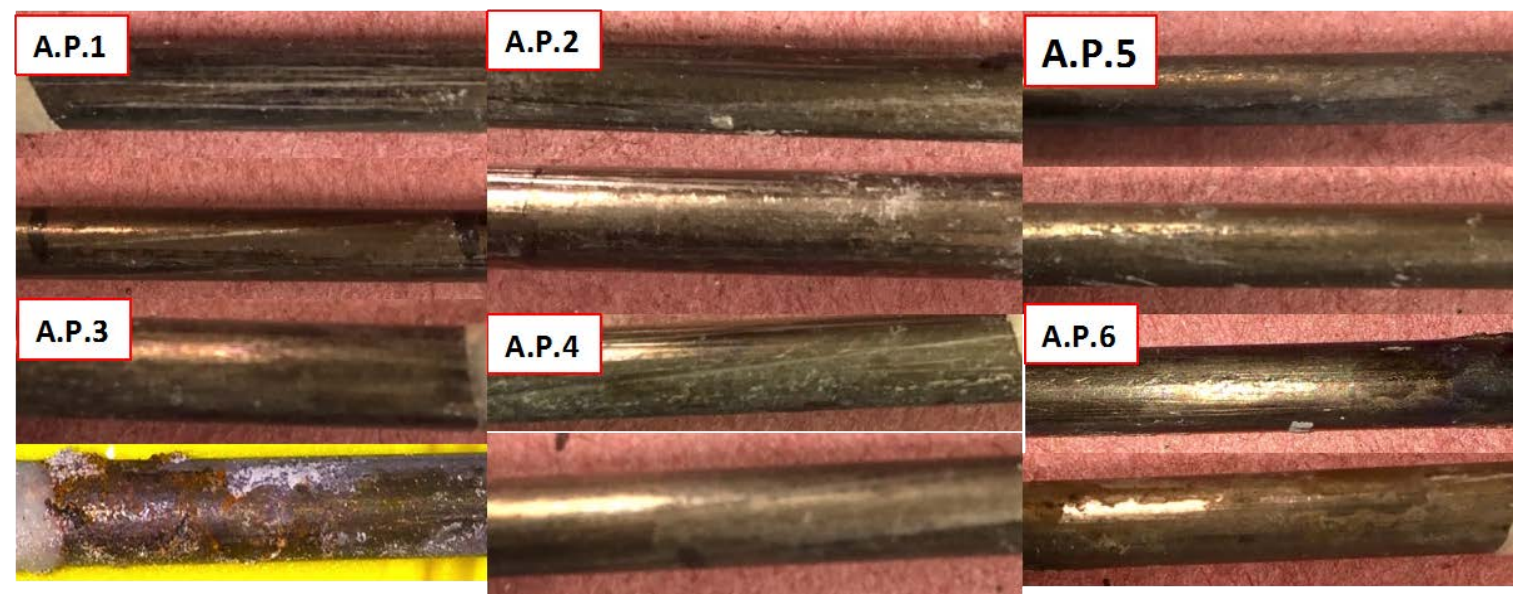

Figure B.1: Photos of Steel wire in Tee Header in INT Test (Case A.P.1-6)

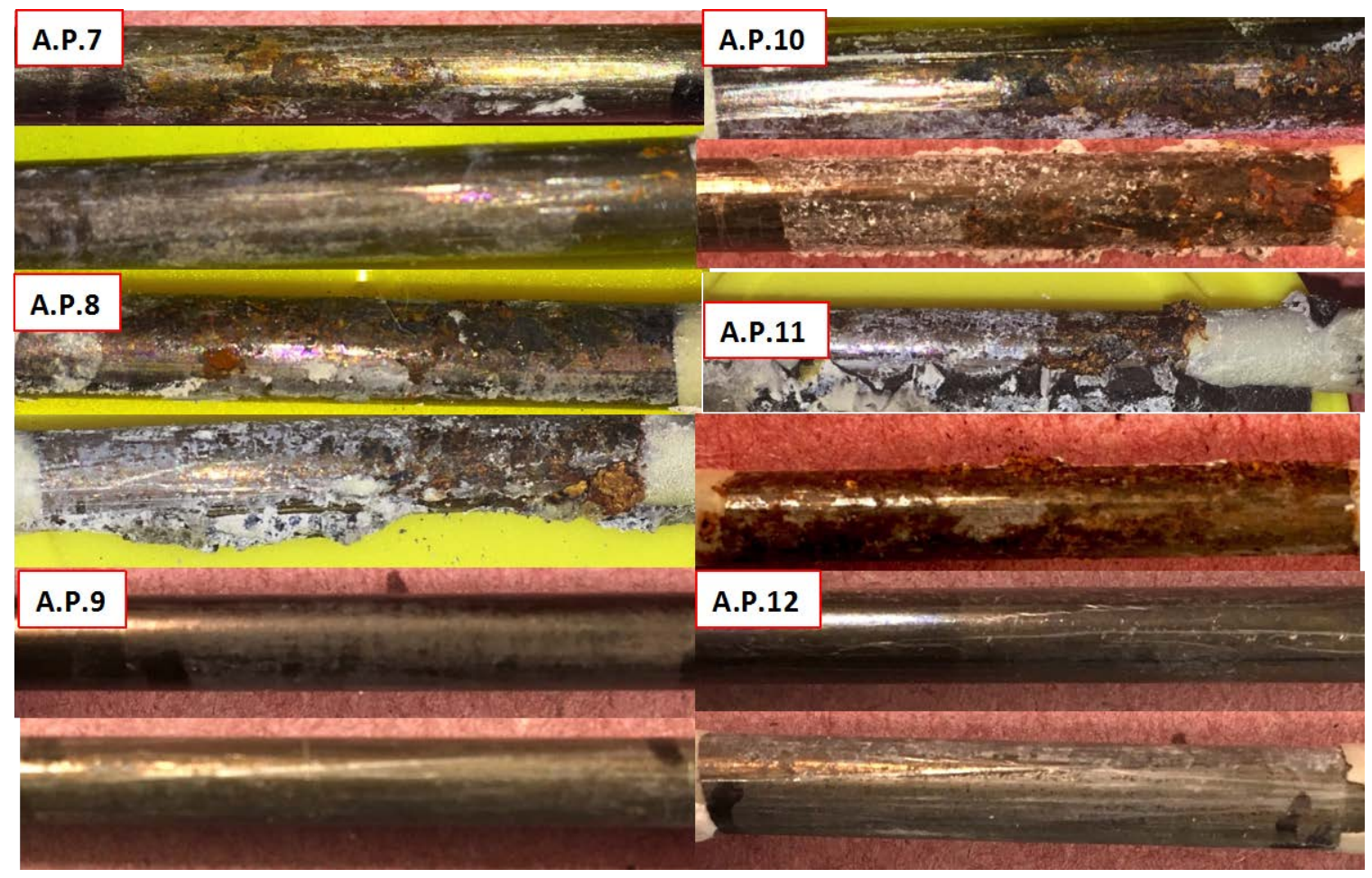

Figure B.1: Photos of Steel wire in Tee Header in INT Test (Case A.P.7-12) 